\title{
Hospital-at-home for COPD exacerbations : evaluation of a community-based early assisted discharge scheme
}

Citation for published version (APA):

Utens, C. M. A. (2012). Hospital-at-home for COPD exacerbations : evaluation of a community-based early assisted discharge scheme. [Doctoral Thesis, Maastricht University]. Datawyse / Universitaire Pers Maastricht. https://doi.org/10.26481/dis.20121031cu

Document status and date:

Published: 01/01/2012

DOI:

10.26481/dis.20121031cu

Document Version:

Publisher's PDF, also known as Version of record

\section{Please check the document version of this publication:}

- A submitted manuscript is the version of the article upon submission and before peer-review. There can be important differences between the submitted version and the official published version of record.

People interested in the research are advised to contact the author for the final version of the publication, or visit the DOI to the publisher's website.

- The final author version and the galley proof are versions of the publication after peer review.

- The final published version features the final layout of the paper including the volume, issue and page numbers.

Link to publication

\footnotetext{
General rights rights.

- You may freely distribute the URL identifying the publication in the public portal. please follow below link for the End User Agreement:

www.umlib.nl/taverne-license

Take down policy

If you believe that this document breaches copyright please contact us at:

repository@maastrichtuniversity.nl

providing details and we will investigate your claim.
}

Copyright and moral rights for the publications made accessible in the public portal are retained by the authors and/or other copyright owners and it is a condition of accessing publications that users recognise and abide by the legal requirements associated with these

- Users may download and print one copy of any publication from the public portal for the purpose of private study or research.

- You may not further distribute the material or use it for any profit-making activity or commercial gain

If the publication is distributed under the terms of Article $25 \mathrm{fa}$ of the Dutch Copyright Act, indicated by the "Taverne" license above, 


\section{HOSPITAL-AT-HOME FOR COPD EXACERBATIONS}

evaluation of a community-based early assisted discharge scheme

Cecile Utens 
The research in this thesis was financially supported by the Pulmonology Research Education and Development Foundation and health insurance companies CZ and VGZ.

This study was funded by the Netherlands Organisation for Health Research and Development (ZonMw) grant number 945-50-7730).

A pilot study in the Orbis Medical Centre was funded by Picasso for COPD

'The research presented in this thesis was conducted at the Department of Pulmonary Diseases of the Catharina Hospital in collaboration with the School for Public Health and Primary Care: CAPHRI, Department of General Practice of Maastricht University. CAPHRI participates in the Netherlands School of Primary Care Research CaRe. CAPHRI was classified as 'excellent' by the external evaluation committee of leading international experts that reviewed CAPHRI in December 2010.

ISBN: 9789461591678

Cover design: Marieke Steegh

Printed by Datawyse/ Universitaire Pers Maastricht

(C) C.M.A. Utens, Eindhoven 2012 


\title{
HOSPITAL-AT-HOME FOR COPD EXACERBATIONS
}

\author{
evaluation of a community-based \\ early assisted discharge scheme
}

\author{
Proefschrift
}

Ter verkrijging van de graad van doctor aan de Universiteit Maastricht, op gezag van de Rector Magnificus prof. dr. L.L.G. Soete volgens het besluit van het College van Decanen, in het openbaar te verdedigen op woensdag 31 oktober 2012 om 16:00 uur

$$
\text { door }
$$

Cecile Maria Antonius Utens

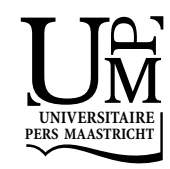




\section{Promotores}

Prof. dr. C.P. van Schayck

Prof. dr. M.P.M.H. Rutten-van Mölken, IMTA, Erasmus University Rotterdam

\section{Copromotor}

Dr. F.W.J.M. Smeenk, Catharina Hospital Eindhoven

\section{Beoordelingscommissie}

Prof. dr. G. Wesseling (voorzitter)

Prof. dr. C.D. Dirksen

Prof. dr. T. van der Molen, University Medical Center Groningen 
Soms is iets

gewoon voor jezelf. 



\section{Table of content}

Chapter $1 \quad$ General Introduction

Chapter 2 Care delivery pathways for chronic obstructive

Pulmonary disease in England and the Netherlands:

a comparative study

Chapter $3 \quad$ Effectiveness and cost-effectiveness of early assisted discharge for chronic obstructive pulmonary disease exacerbations: the design of a randomised controlled trial

Chapter $4 \quad$ Early assisted discharge with community nursing for chronic obstructive pulmonary disease exacerbations: results of a randomised controlled trial

Chapter $5 \quad$ Cost-effectiveness of early assisted discharge for COPD exacerbations in the Netherlands

Chapter $6 \quad$ Early assisted discharge for chronic obstructive pulmonary disease exacerbations: patient satisfaction and preference for treatment place

Chapter $7 \quad$ Informal caregiver evaluation of an early discharge hospital-at-home scheme for chronic obstructive pulmonary disease exacerbations

Chapter $8 \quad$ Evaluation of health care providers' role transition and satisfaction in hospital-at-home for COPD exacerbations: a survey study

Chapter 9 General Discussion

Chapter 10

Summary

Samenvatting

Co-authors and affiliations

Dankwoord

171

About the author 



\section{Chapter 1}

\section{GENERAL INTRODUCTION}


10 Chapter 1

\section{General introduction}

Chronic Obstructive Pulmonary Disease (COPD) is a chronic condition of which the pulmonary component is characterised by airflow limitation that is not fully reversible [1]. The airflow limitation is usually progressive and associated with abnormal inflammatory responses of the lung to noxious particles or gases [1]. Most important symptoms of the disease are dyspnoea, cough and sputum production. The symptoms are progressive over time and with the deterioration of lung function, the impact increases. Main cause of the disease is smoking [1], but occupational dust and pollution are also related to the cause of COPD [1,2]. Prevalence of the disease is high and varies between $2.1 \%$ and $26.1 \%$ across Europe [3]. However, many people have not been diagnosed yet. Gold standard for diagnosis is currently lung function testing, allowing to make a distinction in 4 'severity' stages, GOLD I to IV, as displayed in table 1 [1]. Within and across the GOLD stages wide variation is observed in symptoms, exercise tolerance and comorbidities, making COPD patients a heterogeneous group that is difficult to classify [4]. This heterogeneity is increasingly being recognised and diagnosis, categorisation and management of the disease is no longer purely based on GOLD staging. The in 2011 updated GOLD report recommends an assessment of COPD on the following 4 aspects: 1) symptoms, assessed with the Modified British Medical Research Council questionnaire (mMRC) or COPD assessment test (CAT); 2) Severity of spirometric abnormality (former classic GOLD stages as displayed in table 1 ); 3) the exacerbations risk, based on the exacerbation rate in the previous year and 4) comorbidities [5]. The first 3 aspects are included in a new classification as displayed in figure 1. In the Netherlands, staging in the Care Standard COPD [in Dutch: Zorgstandaard COPD] is based on burden of the disease, which incorporates $\mathrm{FEV}_{1}$ values with symptoms, disabilities and level of adaptation, among others [6].

\section{Treatment of COPD}

COPD cannot be cured yet and treatment aims at stabilising the disease and relieving symptoms, minimising the impact of the disease on daily functioning and treating complications and exacerbations [1]. COPD treatment consists of a pharmacological part and a non-pharmacological part. Cornerstone in the pharmacological treatment is inhaled bronchodilator medication and, in severe stages, inhaled glucocorticosteroids to prevent or reduce symptoms [1].

Non-pharmacological treatments are those therapies or interventions that aim to reduce symptoms or improve health status and exercise capacity. Smoking cessation, nutritional counselling, exercise training (often supported by physiotherapists), education, self-management support and psychological counselling are examples of non-pharmacological treatments, which can be integrated in a pulmonary 
rehabilitation program or disease management program [1]. Finally, long-term oxygen treatment is available to patients who meet the criteria for this treatment [1].

Table 1. Classification of COPD severity based on post-bronchodilator Forced Expiratory Volume in 1 second ( $\mathrm{FEV}_{1}$ ).

\begin{tabular}{|c|c|}
\hline Stage & Values \\
\hline \multirow[t]{2}{*}{ GOLD I: mild } & $\mathrm{FEV}_{1} / \mathrm{FVC} \leq 0.70$ \\
\hline & $\mathrm{FEV}_{1} \geq 80 \%$ of predicted \\
\hline \multirow[t]{2}{*}{ GOLD II: moderate } & $\mathrm{FEV}_{1} / \mathrm{FVC} \leq 0.70$ \\
\hline & $50 \% \leq \mathrm{FEV}_{1}<80 \%$ of predicted \\
\hline \multirow[t]{2}{*}{ GOLD III: severe } & $\mathrm{FEV}_{1} / \mathrm{FVC} \leq 0.70$ \\
\hline & $30 \% \leq \mathrm{FEV}_{1}<50 \%$ of predicted \\
\hline \multirow[t]{2}{*}{ GOLD IV: very severe } & $\mathrm{FEV}_{1} / \mathrm{FVC} \leq 0.70$ \\
\hline & $\mathrm{FEV}_{1}<30 \%$ of predicted OR FEV $\mathrm{F}_{1}<50 \%$ with respiratory failure* \\
\hline
\end{tabular}

*respiratory failure: arterial pressure of oxygen $<60 \mathrm{mmHg}$ with or without arterial partial pressure of $\mathrm{CO}_{2}>$ $50 \mathrm{mmHg}$ while breathing air at sea level.

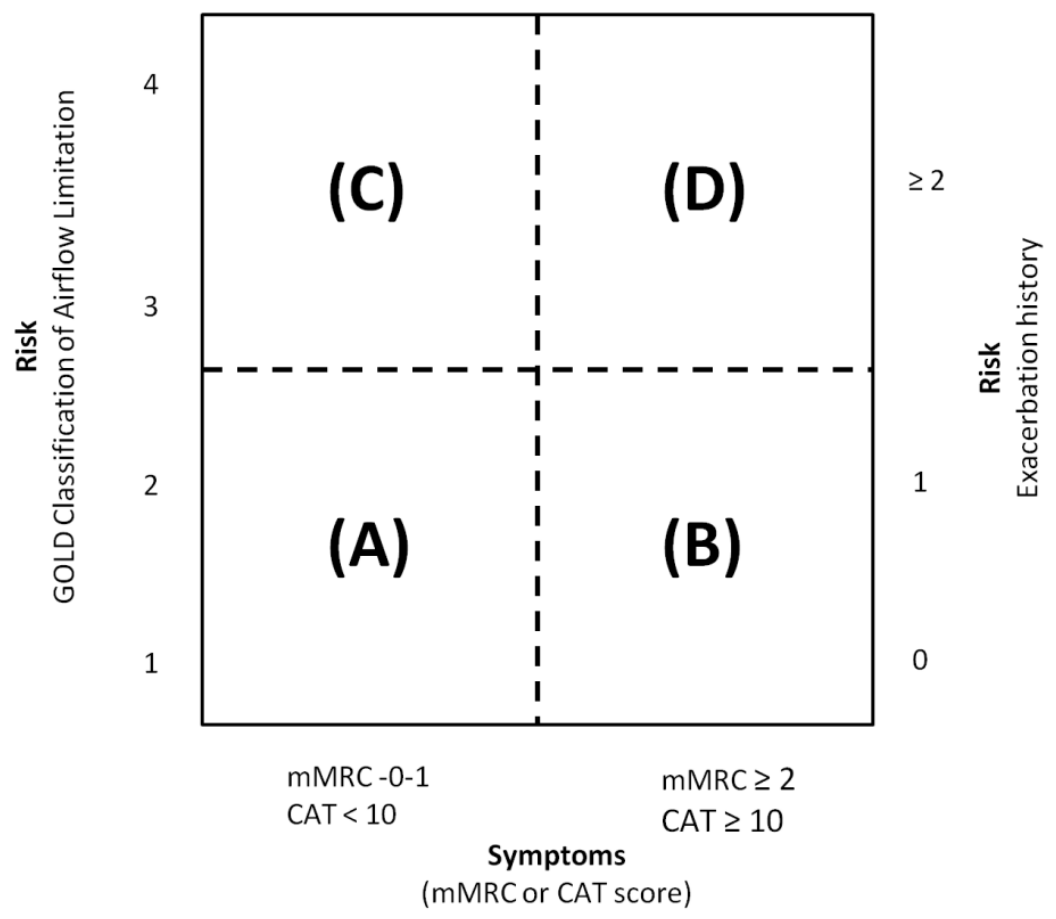

Source: GOLD report 2011 [5]

Figure 1. Model of symptom/risk evaluation COPD.

\section{Exacerbations}

COPD is characterised by exacerbations, especially in more severe stages of the disease [7]. Exacerbations are defined as "an event in the natural course of the disease characterised by a change in the patient's baseline dyspnoea, cough, and/or sputum 
that is beyond normal day-to-day variations, is acute in onset and may warrant a change in regular medication in a patient with underlying COPD" [8,9]. Most common cause for exacerbations are viral or bacterial respiratory tract infections [5]. However, in one-third of severe exacerbations the cause cannot be identified [5].

Exacerbations are treated by increasing the regular bronchodilator medication (sometimes combined with a changed way of administration), a course of systemic glucocorticosteroids and a course of antibiotics for patients with increased dyspnoea, increased sputum volume and increased sputum purulence or patients with increased sputum purulence and 1 of the previously mentioned symptoms as being indicators for bacterial infection [1]. In hospitals oxygen therapy and/or non-invasive mechanical ventilation (NIV) or invasive mechanical ventilation can be added to the treatment.

Exacerbation frequency, the severity of the exacerbation and the risk for hospitalisation for exacerbation increase with disease severity $[10,11]$. Average exacerbation rate per patient, per year for patients with moderate disease (GOLD II) is 0.85 , for patients with severe disease (GOLD III) 1.34 and for patients with very severe disease (GOLD IV) 2.0 [10]. However, 80\%, 70\% and 50\% of patients with COPD GOLD stage II, III, and IV respectively, experience no exacerbation [10]. Conversely, many exacerbations are unreported to health care staff $[12,13]$. Previous exacerbations are a strong predictor for exacerbation in the near future and 'frequent exacerbators' is considered to be a separate phenotype in COPD [5].

There is no agreed classification for the severity of exacerbations. Table 2 shows an overview of different classifications reported in literature. The classifications are based on symptoms of the exacerbation [14], the treatment patients receive or need [8], the place of treatment [15], or a combined classification based on use of health care resources and place of treatment [9] or a combination of symptoms and place of treatment [16]. There is variety in the classifications of what is considered as a mild or severe exacerbation. For example, all exacerbations treated with systemic glucocorticosteroids are severe exacerbations, according to the classification used by Burge et al. [8], whereas exacerbations requiring hospitalisation are severe exacerbations, according to the classification of Rodriguez-Roisi et al. [9] and Fabbri et al. [16].

\section{Hospitalisations}

Exacerbations are the main cause for hospitalisations in COPD patients. Approximately $20 \%$ of exacerbations results in hospital admission [17]. Several risk factors can be identified for being hospitalised for a COPD exacerbation. These factors include admission and/or exacerbation in the previous year $[18,19]$, low $\mathrm{FEV}_{1}$ as $\%$ of predicted 
$[18,20]$, increased age [20], presence of coexisting morbidities [20], course of oral corticosteroids in the previous 3 months [18,21], Body Mass Index of < 18.5 [22], high dyspnoea scores [22], social circumstances [23] and depression [24].

Table 2. COPD exacerbation classifications.

\begin{tabular}{|c|c|c|c|}
\hline Author & $\begin{array}{l}\text { Classification } \\
\text { method }\end{array}$ & Classification & Class definition \\
\hline Burge [8] & Treatment & $\begin{array}{l}\text { Mild/moderate } \\
\text { Severe }\end{array}$ & $\begin{array}{l}\text { Other treatment than systemic glucocorticosteroids } \\
\text { Treatment with systemic glucocorticosteroids }\end{array}$ \\
\hline $\begin{array}{l}\text { Rodriguez- } \\
\text { Roisi [9] }\end{array}$ & $\begin{array}{l}\text { Care } \\
\text { utilisation } \\
\text { and place of } \\
\text { treatment }\end{array}$ & $\begin{array}{l}\text { Mild } \\
\text { Moderate } \\
\text { Severe }\end{array}$ & $\begin{array}{l}\text { Increased need for medication which can be managed in } \\
\text { own normal environment } \\
\text { Increased need for medication and patient feels need to } \\
\text { seek additional medical assistance } \\
\text { Patient or caregiver recognises obvious and/or rapid } \\
\text { deterioration in condition requiring hospitalisation }\end{array}$ \\
\hline $\begin{array}{l}\text { Anthonisen } \\
{[14]}\end{array}$ & Symptoms & $\begin{array}{l}\text { Level I } \\
\text { Level II } \\
\text { Level III }\end{array}$ & $\begin{array}{l}\text { Increased dyspnoea, increase sputum volume and } \\
\text { increased sputum purulence } \\
2 \text { of symptoms mentioned in level I } \\
\text { Increased sputum purulence and one other symptom like } \\
\text { cough, increased wheeze etc. }\end{array}$ \\
\hline Celli [15] & $\begin{array}{l}\text { Place of } \\
\text { treatment }\end{array}$ & $\begin{array}{l}\text { Level I } \\
\text { Level II } \\
\text { Level III }\end{array}$ & $\begin{array}{l}\text { Treated at home } \\
\text { Requires hospitalisation } \\
\text { Leads to respiratory failure }\end{array}$ \\
\hline Fabbri [16] & $\begin{array}{l}\text { Symptoms } \\
\text { and place of } \\
\text { treatment }\end{array}$ & Severe & $\begin{array}{l}\text { Increased breathlessness, possibly associated with } \\
\text { increased cough and increased sputum colour that force } \\
\text { patient to seek medical attention outside the hospital (at } \\
\text { least outpatient) } \\
\text { Acute respiratory failure, frequently requiring hospital } \\
\text { admission }\end{array}$ \\
\hline
\end{tabular}

Internationally guidelines are available that describe when patients with exacerbations should be treated in the hospital, or at home $[1,15,25]$. Table 3 shows an overview of these guidelines. Conversely, in the Netherlands such detailed guidelines are not available. Current practice is that, generally, general practitioners treat patients with exacerbations, but refer patients to the hospital when a) within 30 minutes of increased inhaled therapy no improvement occurs; b) previous exacerbations required hospital admission; c) there are insufficient care options at home and d) the patient is exhausted [26]. Comparison of the national and international guidelines shows that different aspects, physical and non-physical, are taken into account and that some criteria are open for subjective interpretations. As a result, in practice, it is the decision of the assessing physician whether a patient is admitted to the hospital or not.

In the Netherlands the annual number of admissions for COPD in 2007 was 18,462, which was 11.6 per 10,000 population [27]. Average length of hospital stay was 11.1 days [27]. Figure 2 shows the trend in the number of hospitalisations for COPD per 10,000 population and the average length of hospital stay. Between 1998 and 2004 the number of hospital admissions decreased. Since 2004 the number has slightly 
increased and fluctuates around 11 days. Despite the overall decrease over the last years in the Netherlands, the average length of stay in acute hospitals is still among the highest in Europe [28,29].

Table 3. Indications and criteria for hospital admission and treatment

Celli et al. [15]

Presence of high-risk comorbid conditions including pneumonia, cardiac arrhythmia, congestive heart failure, diabetes mellitus, renal or liver failure

Inadequate response of symptoms to outpatient management

Marked increase of dyspnoea

Inability to eat or sleep due to symptoms

Worsening hypoxaemia

Worsening hypercapnia

Changes in mental status

Inability of the patient to care for himself (lack of home support)

Uncertain diagnosis

Inadequate home care

Rabe et al. [1]

Marked increase in intensity of symptoms such as sudden development of resting dyspnoea, change in vital signs

Severe underlying COPD

Onset of new physical signs (e.g. cyanosis, peripherical oedema)

Failure of exacerbation to respond to initial medical management

Significant comorbidities

Frequent exacerbations

Newly occurring arrhythmias

Diagnostic uncertainty

Older age

Insufficient home support

NICE guideline [25]

Not able to cope at home

Severe breathlessness

Poor or deteriorating general health

Poor level of activity or confined to bed

Presence of cyanosis

Worsening peripheric oedema

Impaired level of consciousness

Living alone and not coping

Acute confusion

Rapid rate of onset

Significant comorbidity

$\mathrm{SaO}_{2}<90 \%$

Changes on chest radiograph

Arterial $\mathrm{pH}$ level $<7.35$

Arterial $\mathrm{PaO}_{2}<52 \mathrm{mmHg}$

\section{Burden}

Exacerbations and hospitalisation have severe impact on patients. Patients who have had an exacerbation have an increased risk of new exacerbations [10], have accelerated decline of lung function [30], high mortality [31,32] and decline in quality of life [33-36] among others. In addition, COPD exacerbations and hospitalisations are responsible for the high use of health care resources and accompanying health care 
costs. Hospitalisations are responsible for up to $85 \%$ of the costs for the treatment of exacerbations, depending on which country, health care system, study population and the definition of exacerbation is used [37]. In 2000, in the Netherlands, the total costs for COPD were $€ 280$ million (€915 per COPD patient) of which $27 \%$ was spent on hospital admissions [38]. Furthermore, hospital admissions place a high burden on hospital beds, especially during winters when the incidence of exacerbations increases [17].

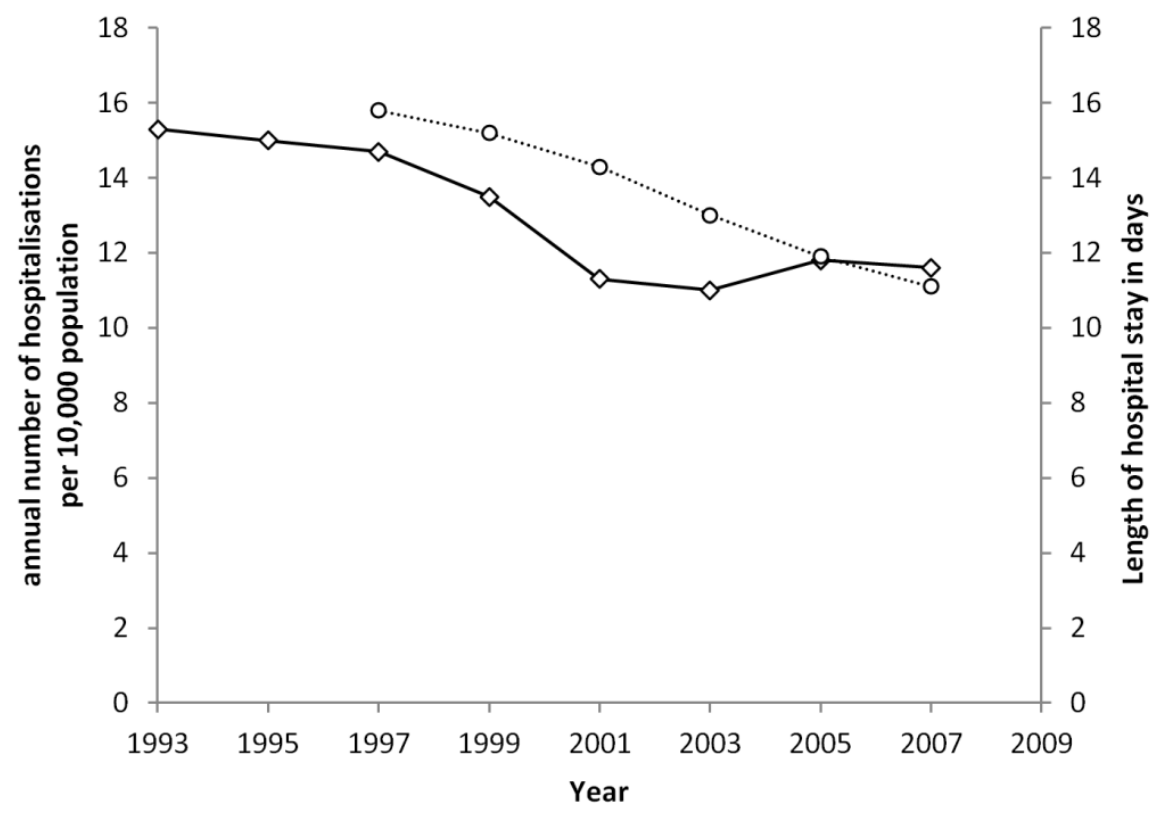

Source: Centraal Bureau voor de Statistiek [statistics Netherlands] [27]

Figure 2. Hospitalisations and length of hospital stay for COPD in the Netherlands.

\section{Managing hospitalisations}

Policy aims to manage the number of hospitalisations and the average length of hospital stay. On the 1 side there are interventions that aim to avoid or prevent admission and on the other hand there are interventions that aim to reduce length of hospital stay.

Avoiding hospital admissions starts with the prevention of exacerbations. Several interventions and treatments have proved to reduce the number of exacerbations and hospitalisations. Among these are the optimisation of pharmacological therapies $[39,40]$, self-management and education plans [41], pulmonary rehabilitation [42], flu vaccination $[39,40]$, timely treatment of exacerbation symptoms (reduce treatment delay) [43] and long-term oxygen supply [39,40]. Which intervention is most appropriate in which patient is not always clear and combinations of interventions are 
possible. Although these interventions are effective in some patients, their overall effect is insufficient, reflected in the high number of exacerbations and hospitalisations. Alternative for the prevention of exacerbations that lead to hospital admission is to provide an immediate alternative for hospital admission (admission avoidance) or reduce length of hospital stay. The use of clinical pathways is a method to structure the hospital admission and enhance efficiency by which length of stay can be reduced [44-46]. In recent years Dutch hospitals have been implementing clinical pathways for COPD exacerbations, but it is unknown whether this indeed did reduce length of hospital stay. Other, mainly in the United Kingdom, popular methods to avoid admission or reduce length of stay, is are hospital-at-home schemes, which are the focus of this thesis.

\section{Hospital-at-home}

Hospital-at-home is defined as "a service that provides active treatment by health care professionals in the patient's home of a condition that otherwise would require acute hospital in-patient care, always for a limited period of time" [47]. The fact that hospital-at-home schemes are substitutive for hospital treatment and care is offered for a limited period of time distinguishes it from long term community care. In hospital-at-home schemes patients are treated and supervised by nurses at home, instead of the hospital. There are 2 types of hospital-at-home schemes: admission avoidance schemes that substitute the entire hospital admission and early assisted or support discharge schemes in which patients are further treated and supervised at home after a short hospital admission (usually up to 72 hours). Another distinction that can be made is that the scheme can be operated as a community-based service or as a hospital-based outreach service. The former refers to schemes that built on existing community services while the latter involves hospital staff working in the community. Several studies have proved the safety and effectiveness of hospital-at-home schemes for COPD exacerbations [48-55].

In the United Kingdom, 44\% of hospitals have a hospital-at-home service for COPD exacerbations and more than half of these schemes are early discharge schemes [56]. In addition, the majority of the schemes involve hospital-based, specialised respiratory nurses that perform visits at the patients' home [56]. However, whether this is the most effective and/or most cost-effective form of hospital-at-home is not known. It is suggested that the use of community nurses for supervision at home is just as effective and possibly more cost-effective, as community nurses are less expensive compared to specialised respiratory nurses $[57,58]$. Patient and informal caregiver satisfaction with hospital-at-home schemes is high and some studies report that the majority of patients prefers home treatment rather than hospital treatment [51,59-64]. 
In the Netherlands the development of hospital-at-home did not come into existence. Extrapolation of results to other countries should be done with some caution as the effectiveness of interventions may be different in different health care systems. However, the average length of hospital stay for COPD is high in the Netherlands. Furthermore, the Netherlands has an extensive and well organised system of home care organisations providing nursing at home. From this perspective, early assisted discharge would be a good possibility to reduce length of hospital stay for COPD exacerbations. Therefore we designed the GO AHEAD study. GO AHEAD is the acronym for "Assessment of Going Home under Early Assisted Discharge". In the GO AHEAD study, early assisted discharge with supervision at home performed by community nurses is compared to usual hospital care.

\section{Aim and research questions}

Hospital-at-home for COPD exacerbations is new in the Netherlands, and, communitybased hospital-at-home schemes have not been studied thoroughly. Furthermore, little is known about the effects on patient, informal caregivers and care providers in general. Therefore we incorporated different perspectives in our evaluation of the community-based, early assisted discharge, hospital-at-home scheme.

The main research questions are:

1) What is the effectiveness of early assisted discharge for COPD exacerbations compared to usual hospital care?

2) What is the cost-effectiveness of early assisted discharge compared to usual hospital care?

3) How do patients and their informal caregivers value early assisted discharge involving community nurses and what is the impact on informal caregivers strain?

4) What is the impact of early assisted discharge on professional care providers involved in the scheme and how do they value early assisted discharge.

\section{Outline of this thesis}

Chapter 2 describes a comparison of care delivery pathways in England and the Netherlands and tries to find an explanation for the presence of hospital-at-home schemes for COPD exacerbations in England and the absence in the Netherlands. In chapter 3 the study design and rationale of the GO AHEAD study is described. Chapter 4 describes the effectiveness of early assisted discharge, as executed in the GO AHEAD trial. The effects of early discharge on health status, readmissions, mortality and generic quality of life are addressed in this chapter. In chapter 5 the cost-effectiveness of early discharge is assessed. Chapters 6 and 7 describe the satisfaction of patients and informal caregivers with early assisted discharge, and their preferences for 
18 Chapter 1

treatment place. In addition, chapter 7 describes the impact of early assisted discharge on informal caregivers' strain. To complete, in chapter 8 the evaluation of early discharge among the care providers is described. Finally, a summary and discussion of the main findings are described in chapter 9. This chapter concludes with the implications of the results for practice and policy and recommendations for future research. 


\section{References}

1. Rabe KF, Hurd S, Anzueto A et al. Global strategy for the diagnosis, management, and prevention of chronic obstructive pulmonary disease: GOLD executive summary. Am J Respir Crit Care Med 2007;176:532-555.

2. Coggon D, Newman TA. Coal mining and chronic obstructive pulmonary disease: a review of the evidence. Thorax 1998;53:398-407.

3. Atsou K, Chouaid C, Hejblum G. Variability of the chronic obstructive pulmonary disease key epidemiological data in Europe: systematic review. BMC Med 2011;9:7.

4. Agusti A, Calverley PM, Celli B et al. Characterisation of COPD heterogeneity in the ECLIPSE cohort. Respir Res 2010;11:122.

5. Global Initiative for Chronic Obstructive Lung Disease: Global strategy for the diagnosis, management and prevention of Chronic Obstructive Pulmonary Disease. 2011.

6. Long Alliantie Nederland (LAN). Zorgstandaard COPD [Care Standard COPD]. Amersfoort: Long Alliantie Nederland 2010.

7. Donaldson GC, Wedzicha JA. COPD exacerbations .1: Epidemiology. Thorax 2006;61:164-168.

8. Burge S, Wedzicha JA. COPD exacerbations: definitions and classifications. Eur Respir J Suppl 2003;41:46s-53s.

9. Rodriguez-Roisin R. Toward a consensus definition for COPD exacerbations. Chest 2000;117:398S-401S.

10. Hurst JR, Vestbo J, Anzueto A et al. Susceptibility to exacerbation in chronic obstructive pulmonary disease. N Engl J Med 2010;363:1128-1138.

11. Hoogendoorn M, Feenstra TL, Hoogenveen RT et al. Association between lung function and exacerbation frequency in patients with COPD. Int J Chron Obstruct Pulmon Dis 2010;5:435-444.

12. Donaldson GC, Seemungal TA, Patel IS et al. Longitudinal changes in the nature, severity and frequency of COPD exacerbations. Eur Respir J 2003;22:931-936.

13. Wedzicha JA, Donaldson GC. Exacerbations of chronic obstructive pulmonary disease. Respir Care 2003;48:1204-1213.

14. Anthonisen NR, Manfreda J, Warren CP et al. Antibiotic therapy in exacerbations of chronic obstructive pulmonary disease. Ann Intern Med 1987;106:196-204.

15. Celli BR, MacNee W. Standards for the diagnosis and treatment of patients with COPD: a summary of the ATS/ERS position paper. Eur Respir J 2004;23:932-946.

16. Fabbri L, Beghe B, Caramori G et al. Similarities and discrepancies between exacerbations of asthma and chronic obstructive pulmonary disease. Thorax 1998;53:803-808.

17. Jenkins CR, Celli B, Anderson JA et al. Seasonality and determinants of moderate and severe COPD exacerbations in the TORCH study. Eur Respir J 2011.

18. Garcia-Aymerich J, Monso E, Marrades RM et al. Risk factors for hospitalization for a chronic obstructive pulmonary disease exacerbation. EFRAM study. Am J Respir Crit Care Med 2001;164:1002-1007.

19. Bahadori K, FitzGerald JM. Risk factors of hospitalization and readmission of patients with COPD exacerbation--systematic review. Int J Chron Obstruct Pulmon Dis 2007;2:241-251.

20. Miravitlles M, Guerrero T, Mayordomo $C$ et al. Factors associated with increased risk of exacerbation and hospital admission in a cohort of ambulatory COPD patients: a multiple logistic regression analysis. The EOLO Study Group. Respiration 2000;67:495-501.

21. Jordan RE, Hawker JI, Ayres JG et al. Effect of social factors on winter hospital admission for respiratory disease: a case-control study of older people in the UK. Br J Gen Pract 2008;58:400402.

22. Oostenbrink JB, Rutten-van Molken MP. Resource use and risk factors in high-cost exacerbations of COPD. Respir Med 2004;98:883-891. 
23. Prescott $E$, Lange $P$, Vestbo J. Socioeconomic status, lung function and admission to hospital for COPD: results from the Copenhagen City Heart Study. Eur Respir J 1999;13:1109-1114.

24. $\quad \mathrm{Xu} \mathrm{W}$, Collet JP, Shapiro $S$ et al. Independent effect of depression and anxiety on chronic obstructive pulmonary disease exacerbations and hospitalizations. Am J Respir Crit Care Med 2008;178:913-920.

25. Chronic obstructive pulmonary disease. National clinical guideline on management of chronic obstructive pulmonary disease in adults in primary and secondary care. Thorax 2004;59 Suppl 1:1-232.

26. Smeele IJM, Schayck CP, van der Molen T et al. NHG-Standaard COPD (Tweede herziening). Huisarts Wet 2007; 50:362-379.

27. Centraal Bureau voor de Statistiek (CBS) [Statistics Netherlands]. http://statline.cbs.nl/StatWeb/publication/?DM=SLNL\&PA=71859NED\&D1=6,8\&D2= $0 \& D 3=0, \mid \& D 4=106 \& D 5=9-26 \& H D R=T \& S T B=G 1, G 2, G 3, G 4 \& V W=T$ last accessed: 15-1- 2010.

28. World Health Organization Europe: WHO European Health for All Database: update January 2010. http://data.euro.who.int/hfadb/ last accessed: 19-1-2011.

29. Borghans I, Heijink R, Kool T et al. Benchmarking and reducing length of stay in Dutch hospitals. BMC Health Serv Res 2008;8:220.

30. Donaldson GC, Seemungal TA, Bhowmik A et al. Relationship between exacerbation frequency and lung function decline in chronic obstructive pulmonary disease. Thorax 2002;57:847-852.

31. Soler-Cataluna JJ, Martinez-Garcia MA, Roman SP et al. Severe acute exacerbations and mortality in patients with chronic obstructive pulmonary disease. Thorax 2005;60:925-931.

32. Hoogendoorn M, Hoogenveen RT, Rutten-van Molken MP et al. Case fatality of COPD exacerbations: a meta-analysis and statistical modelling approach. Eur Respir J 2011;37:508515.

33. Seemungal TA, Donaldson GC, Paul EA et al. Effect of exacerbation on quality of life in patients with chronic obstructive pulmonary disease. Am J Respir Crit Care Med 1998;157:1418-1422.

34. Esteban C, Quintana JM, Moraza J et al. Impact of hospitalisations for exacerbations of COPD on health-related quality of life. Respir Med 2009;103:1201-1208.

35. O'Reilly JF, Williams AE, Rice L. Health status impairment and costs associated with COPD exacerbation managed in hospital. Int J Clin Pract 2007;61:1112-1120.

36. Miravitlles $M$, Ferrer $M$, Pont $A$ et al. Effect of exacerbations on quality of life in patients with chronic obstructive pulmonary disease: a 2 year follow up study. Thorax 2004;59:387-395.

37. Toy EL, Gallagher KF, Stanley EL et al. The economic impact of exacerbations of chronic obstructive pulmonary disease and exacerbation definition: a review. COPD 2010;7:214-228.

38. Hoogendoorn, EJI, Feenstra, TL, and Rutten-van Mölken, MPHM: Inventarisatie van het gebruik en de kosten van zorg voor astma en COPD in Nederland [Resource use and costs of care for treating asthma and COPD in the Netherlands]. Bilthoven: Rijksinstituut voor Volksgezondheid en Milieu (RIVM); 2004.

39. Bourbeau J. Preventing hospitalization for COPD exacerbations. Semin Respir Crit Care Med 2010;31:313-320.

40. Hurst JR, Wedzicha JA. Management and prevention of chronic obstructive pulmonary disease exacerbations: a state of the art review. BMC Med 2009;7:40.

41. Effing T, Monninkhof EM, van der Valk PD et al. Self-management education for patients with chronic obstructive pulmonary disease. Cochrane Database Syst Rev 2007;CD002990.

42. Casaburi R, ZuWallack R. Pulmonary rehabilitation for management of chronic obstructive pulmonary disease. N Engl J Med 2009;360:1329-1335.

43. Wilkinson TM, Donaldson GC, Hurst JR et al. Early therapy improves outcomes of exacerbations of chronic obstructive pulmonary disease. Am J Respir Crit Care Med 2004;169:1298-1303. 
44. Santamaria N, Connors A, Osteraas J et al. A prospective cohort study of the effectiveness of clinical pathways for the in-patient management of acute exacerbation of chronic obstructive pulmonary disease (COPD). Collegian 2004;11:12-16.

45. Rotter T, Kinsman L, James $E$ et al. Clinical pathways: effects on professional practice, patient outcomes, length of stay and hospital costs. Cochrane Database Syst Rev 2010;CD006632

46. McManus TE, Marley A., Kidney JC. The Mater Hospital multiprofessional care pathway for acute exacerbations of chronic obstructive pulmonary disease. Journal of Integrated Care Pathways 2005;9:32-36.

47. British Thoracic Society. Intermediate care--Hospital-at-Home in chronic obstructive pulmonary disease: British Thoracic Society guideline. Thorax 2007;62:200-210.

48. Davies L, Wilkinson M, Bonner S et al. "Hospital at home" versus hospital care in patients with exacerbations of chronic obstructive pulmonary disease: prospective randomised controlled trial. BMJ 2000;321:1265-1268.

49. Cotton MM, Bucknall CE, Dagg KD et al. Early discharge for patients with exacerbations of chronic obstructive pulmonary disease: a randomized controlled trial. Thorax 2000;55:902-906.

50. Skwarska E, Cohen G, Skwarski KM et al. Randomized controlled trial of supported discharge in patients with exacerbations of chronic obstructive pulmonary disease. Thorax 2000;55:907-912.

51. Ojoo JC, Moon T, McGlone S et al. Patients' and carers' preferences in two models of care for acute exacerbations of COPD: results of a randomised controlled trial. Thorax 2002;57:167-169.

52. Diaz LS, Gonzalez LF, Gomez Mendieta MA et al. [Evaluation of a home hospitalization program in patients with exacerbations of chronic obstructive pulmonary disease]. Arch Bronconeumol 2005;41:5-10.

53. Gravil JH, Al-Rawas OA, Cotton MM et al. Home treatment of exacerbations of chronic obstructive pulmonary disease by an acute respiratory assessment service. Lancet 1998;351:1853-1855.

54. Murphy NM, Byrne CC, O'Neill SJ et al. An outreach programme for patients with an exacerbation of chronic obstructive pulmonary disease. Ir Med J 2003;96:137-140.

55. Hernandez C, Casas A, Escarrabill J et al. Home hospitalisation of exacerbated chronic obstructive pulmonary disease patients. Eur Respir J 2003;21:58-67.

56. Quantrill SJ, Lowe D, Hosker HS et al. Survey of early discharge schemes from the 2003 UK National COPD Audit. Respir Med 2007;101:1026-1031.

57. Davison AG, Monaghan M, Brown D et al. Hospital at home for chronic obstructive pulmonary disease: an integrated hospital and community based generic intermediate care service for prevention and early discharge. Chron Respir Dis 2006;3:181-185.

58. Nicholson C, Bowler S, Jackson C et al. Cost comparison of hospital- and home-based treatment models for acute chronic obstructive pulmonary disease. Aust Health Rev 2001;24:181-187.

59. Clarke A, Sohanpal R, Wilson $G$ et al. Patients' perceptions of early supported discharge for chronic obstructive pulmonary disease: a qualitative study. Qual Saf Health Care 2010;19:95-98.

60. Leff B, Burton L, Mader S et al. Satisfaction with hospital at home care. J Am Geriatr Soc 2006;54:1355-1363.

61. Leff B, Burton L, Mader SL et al. Comparison of stress experienced by family members of patients treated in hospital at home with that of those receiving traditional acute hospital care. J Am Geriatr Soc 2008;56:117-123.

62. Montalto M. Patients' and carers' satisfaction with hospital-in-the-home care. Int J Qual Health Care 1996;8:243-251.

63. Schofield I, Knussen C, Tolson D. A mixed method study to compare use and experience of hospital care and a nurse-led acute respiratory assessment service offering home care to people with an acute exacerbation of chronic obstructive pulmonary disease. Int J Nurs Stud 2006;43:465-476. 
22 Chapter 1

64. Wilson A, Wynn A, Parker H. Patient and carer satisfaction with 'hospital at home': quantitative and qualitative results from a randomised controlled trial. Br J Gen Pract 2002;52:9-13. 


\section{CARE DELIVERY PATHWAYS FOR CHRONIC OBSTRUCTIVE PULMONARY DISEASE IN ENGLAND AND THE NETHERLANDS: A COMPARATIVE STUDY}

Cecile MA Utens, Hans JAM Maarse, Onno CP van Schayck, Boudewijn LP Maesen, Maureen PMH Rutten-van Mölken and Frank WJM Smeenk

Published in: International Journal of Integrated Care, 12, 18 May 2012 
24 Chapter 2

\begin{abstract}
Introduction: A remarkable difference in care delivery pathways for Chronic Obstructive Pulmonary Disease (COPD) is the presence of hospital-at-home for COPD exacerbations in England and its absence in the Netherlands. The objective of this paper is to explain this difference.

Methods: Descriptive COPD statistics and care delivery pathways on all care levels within the institutional context, followed by a comparison of care delivery pathways and an explanation of the difference with regard to hospital-at-home.

Results: The Netherlands and England show broad similarities in their care delivery pathways for COPD patients. A major difference is the presence of hospital-at-home for COPD exacerbations in England and its absence in the Netherlands. Three possible explanations for this difference are presented: differences in the urgency for alternatives (higher urgency for alternative treatment models in England), the differences in funding (funding in England facilitated the development of hospital-athome) and the differences in the substitution of tasks to nurses (substitution to nurses has taken place to a larger extent in England).

Discussion and Conclusion: The difference between the Netherlands and England regarding hospital-at-home for COPD exacerbations can be explained in 3 ways. Hospital-at-home has proved to be a safe alternative for hospital care for selected patients, and should be considered as a treatment option for COPD exacerbations in the Netherlands.
\end{abstract}




\section{Introduction}

Chronic Obstructive Pulmonary Disease (COPD) is a chronic illness with pulmonary symptoms of dyspnoea, cough and sputum production [1]. The disease is progressive over time and, as yet, not curable [1]. In Western countries the main risk factor for COPD is smoking [1]. The prevalence of COPD is increasing, mainly because of aging and the late effects of smoking [2]. Although high prevalence is a global phenomenon, national and even regional differences can be observed $[3,4]$. The burden of the disease is high for patients and society. Health care costs for COPD are rising while available resources are under increasing pressure. Hospital treatment of acute exacerbations of COPD is the main contributor to the high health care costs of COPD [5]. These developments have focused global attention on the disease and have led to new organisational interventions to manage the impact of the disease on patients and society.

Countries often respond in different ways to similar problems. International comparative research can yield insight into these similarities and differences, which in turn can serve to improve health and the functioning of health services [6]. Both the Netherlands and England are facing an increasing prevalence of COPD. Reported prevalence in England varies from $2.5 \%$ to $13.3 \%$, depending on the study population and the definitions used [4,7]. Prevalence is higher in socially deprived areas like the north of England [4]. It is estimated that $31 \%$ of patients are undiagnosed [8]. COPD prevalence in the Netherlands varies from $1.9 \%$ to $11.6 \%[3,7]$. The percentage undiagnosed patients is estimated at $19 \%$ [9].

A remarkable difference between England and the Netherlands in the organisation of care delivery to COPD patients concerns the development of a new form of care for COPD exacerbations in England - termed 'hospital-at-home'. Hospital-at-home refers to treatment schemes that substitute (parts of) hospital admission with treatment at home. This arrangement is only available for patients for whom admission is considered necessary. Treatment at home is always for a limited time. In the Netherlands a similar development for patients who need to be admitted has not occurred.

The purpose of this article is to explain why hospital-at-home is present in England and absent in the Netherlands. To do so we will first briefly compare COPD care in England and the Netherlands. Next, we present 3 complementary explanations for the presence of hospital-at-home in England and its absence (so far) in the Netherlands. Lastly, we address the question of what the Netherlands can learn from England with regard to COPD care. 


\section{Methods}

Our study is a descriptive comparison between COPD care in England and the Netherlands based on previous findings published in literature and databases. Statistics on COPD, health care use (i.e. number of hospitalisations and length of stay) and health care resources (i.e. number of respiratory physicians, number of general practitioners, number of available hospital beds and financial resources) were obtained from both national and international databases to guarantee comparability. Furthermore, publications in national and international journals, communications from national professional associations and the results of the Confronting COPD surveys in the Netherlands and the United Kingdom performed in 2003 [8,9] were used. Hospital admissions include admissions with principal International Classifications of Disease codes (ICD-10) J40-J44 ((chronic) bronchitis, emphysema, chronic obstructive pulmonary diseases) and $J 47$ (bronchiectasis) [10]. These generally pertain to admissions for exacerbations. Statistics are presented as figure per 1,000,10,000 or 100,000 population. For the description and comparison of care delivery pathways for COPD patients we studied national and international guidelines on COPD care as well as policy reports and documents from professional associations and organisations involved in COPD care in both countries.

In the United Kingdom the responsibility for health (care) is devolved to England, Scotland, Wales and Northern Ireland. This article focuses on England. However, if no other data available, we used statistics representing the entire United Kingdom.

\section{Results}

\section{Statistical overview of COPD in England}

In 1998, the number of annual hospital episodes for COPD was 22 per 10,000 population, which increased to 25 per 10,000 population in 2008 [11]. The number of hospital admissions, standardised for the age distribution of the population, was 360 per 10,000 population in 2007 [11]. In 2003, approximately $14 \%$ of COPD patients was hospitalised [8]. The average length of hospital stay for COPD decreased between 1998 and 2008 from 10.2 days to 8.0 days [11]. The Confronting COPD survey showed that the average annual direct health care costs of COPD in 2003 were $€ 819$ (€1270) per patient, half of which was spent on hospital admissions [8]. About 53\% of COPD patients have at least 1 comorbidity besides their COPD [8] and 55\% of patients use some (inhaled) medication for their COPD [8]. 


\section{Statistical overview of COPD in the Netherlands}

Between 1998 and 2002, the number of annual hospital episodes for COPD dropped from 14.9 to 10.9 admissions per 10,000 population. Since then the number has remained stable [12]. In 2007, the number of hospital admissions, standardised for the age distribution of the population, was 128 per 10,000 population [13]. In 2003, 9\% of COPD patients was hospitalised [9]. The average length of hospital stay for COPD decreased from 15.2 days in 1998 to 10.4 days in 2007 [12]. The Confronting COPD survey indicated that in 2003, the average total direct costs per patient were $€ 614$ annually, of which $20 \%$ was spent on hospital admissions [9]. One-third of COPD patients report to have at least 1 comorbidity and $73 \%$ of patients use some (inhaled) medications for COPD [9].

\section{The organisation and funding of COPD care in England}

In England, patients' pathway in COPD care usually starts in primary care. General practitioners and practice nurses (although not always only dedicated to COPD) provide preventive care, diagnostics and treatment and follow-up care in stable and acute phases (exacerbations) of the disease. The number of FTE (Full Time Equivalent) general practitioners in 2005 was 55.7 per 100,000 population in the United Kingdom [16]. Eighty-six percent of patients stated that the general practitioner was the health professional they went to for the management of their COPD [8]. Only 14\% received care from a respiratory physician [8]. COPD patients are offered several community services, for which most referrals are made by hospitals [18]. The community services are often led by specialist nurses [18]. In addition to general nursing services (medication support), practice nurses, community matrons or nurse specialists offer chronic disease management services (e.g. smoking cessation, education or long-term oxygen services) or acute management services (e.g. home visits or outpatient clinics) [18-20]. Services provided in the community are based in secondary care (42\%) or have bases in both secondary and primary care (41\%) [18]. Patients can be referred to secondary care (hospitals) for specialist examination according to the NICE guideline [21]. This guideline also includes instructions on which patients should be treated in primary and secondary care (outpatient care) and when hospital admission should be considered. In addition to the inpatient treatment management of patients with acute exacerbations, hospitals also provide outpatient treatment and follow-up, diagnostic services and rehabilitation programmes. The available number of acute hospital beds in 2008 was 2.6 per 1,000 population and 2.2 in 1995 [14]. The main professionals involved in hospital care for COPD are respiratory physicians and (specialised) nurses. The number of respiratory physicians per 100,000 population was 1.7 in 2007 [15]. Physiotherapists are also involved in COPD care, mainly in hospitals and community or hospital-based rehabilitation programmes. 
28 Chapter 2

Table 1. Statistics of COPD, related health care resources and health care costs with [reference].

\begin{tabular}{|c|c|c|}
\hline COPD specific & England & $\begin{array}{l}\text { The } \\
\text { Netherlands }\end{array}$ \\
\hline COPD prevalence (per 100 population) & $2.5-13.3[4,7]$ & $1.9-11.6[3,7]$ \\
\hline Percentage of patients undiagnosed (2003) & $31[8]$ & 19 [9] \\
\hline Percentage of patients reporting comorbidities (2003) & $53[8]$ & 30 [9] \\
\hline $\begin{array}{l}\text { Percentage of patients with COPD medication prescription } \\
\text { (2003) }\end{array}$ & $55[8]$ & 73 [9] \\
\hline $\begin{array}{l}\text { Percentage of patients mainly treated by } \\
\text { general practitioner ( } 2003 \text { ) }\end{array}$ & $86[8]$ & 55 [9] \\
\hline Annual hospital episodes (per 10,000 population) (2008) & $22[11]$ & $11.6[12]$ \\
\hline $\begin{array}{l}\text { Standardised number of hospital admissions (per } 10,000 \\
\text { population)* (2007) }\end{array}$ & 360 & 127 \\
\hline $\begin{array}{l}\text { Percentage of COPD patients annually admitted to the hospital } \\
\text { (2003) }\end{array}$ & $14[8]$ & $8[9]$ \\
\hline Average length of hospital stay (days) & $8^{\dagger}[11]$ & $10.4^{\ddagger}[12]$ \\
\hline Direct health care costs per patient (2003) & $\begin{array}{c}€ 1270 \\
(£ 819)[8]\end{array}$ & $€ 614$ [9] \\
\hline $\begin{array}{l}\text { Percentage of COPD expenditure spent on hospital admissions } \\
\text { (2003) }\end{array}$ & $50[8]$ & 20 [9] \\
\hline \multicolumn{3}{|l|}{ Non COPD specific } \\
\hline Number of hospital beds (per 1000 population) (2008) & $2.6[14]$ & $3[14]$ \\
\hline $\begin{array}{l}\text { Number of hospital respiratory physicians } \\
\text { (per } 100,000 \text { population) }\end{array}$ & $1.7^{\Delta}[15]$ & $\begin{array}{l}2.6^{ \pm} \text {[personal } \\
\text { communication] }\end{array}$ \\
\hline Number of FTE general practitioners (per 100,000 population) & $55.67^{\ddagger}[16]$ & $42.53^{\beta}[17]$ \\
\hline
\end{tabular}

*correction for countries' age distribution [11,13]. FTE: Full Time Equivalent

${ }^{\dagger}: 2008 ;^{\ddagger}: 2007 ;^{\wedge}: 2005 ;^{\ddagger}: 2009 ;^{\beta}: 2011$

A special service available in $44 \%$ of British hospitals is hospital-at-home for patients with a COPD exacerbation who require hospital admission [22]. This type of care was developed in the United Kingdom in the mid-1990s. It differs in various respects from other types of care. As said, hospital-at-home is intended for patients who would otherwise be or remain hospitalised. This means that the patient's condition requires hospital admission. Care at home is similar to the care provided in hospital. Hospitalat-home is a nurse-led facility. Care is delivered by specialised respiratory nurses, mostly based (but not necessarily employed) in secondary care, under clinical responsibility of the respiratory physician in secondary care. Nurses visit the patient for several days (mean is 11 days) to monitor recovery and initiate the patient's own disease management [23]. Approximately 30\% of hospital admissions for exacerbations is considered eligible for hospital-at-home [22]. Costs of hospital-athome are estimated to be lower than usual hospital care. Skwarska et al. [24] found the mean total health care costs of hospital-at-home to be $£ 877$ per patient, whereas usual hospital care costs $£ 1753$. In a Spanish hospital-at-home scheme, a difference in mean costs was found of $€ 810$ per patient [25]. These results should be interpreted 
with some caution, however, as outcomes of the cost-analyses are influenced by the decision as to which costs are incorporated and the design of the scheme. A schematic overview of the English care delivery pathway is displayed in Figure 1a.

Care is funded by Primary Care Trusts (PCTs) which control $80 \%$ of the (tax-financed) budget for health care [26]. PCTs are responsible for the assessment of the health care needs of local communities and the commissioning of services from providers in primary care, secondary care, private providers and from community services[26]. In addition, PCTs employ staff to deliver care directly. This staff may be stationed in primary care practices, secondary care (hospitals), or other care facilities. This arrangement makes it possible for PCTs to base (respiratory) nurses in secondary care to provide hospital-at-home care for COPD exacerbations, but also to commission this service from hospitals or primary care facilities. In practice, most hospital-at-home schemes are hospital-based services with nurses working on an outreach basis.

\section{The organisation and funding of COPD care in the Netherlands}

Care pathways of COPD patients in the Netherlands usually start in primary care. General practitioners are involved in the prevention, diagnosis and treatment of the disease in chronic and acute phases, and follow-up care. In 2009, the Netherlands had 42.5 FTE general practitioners per 100,000 population [17]. Some aspects of the care (e.g. education, inhalation instruction) are delegated to practice nurses. In 2007, approximately $62 \%$ of GP practices had practice nurses [27]; however, these nurses are often not dedicated to COPD only but also tend to patients with other chronic illnesses. Practice nurses mainly work in the general practice, but sometimes perform home visits as well (outreach). Patients can be referred to secondary care facilities (hospitals) and professionals, according to guidelines [28,29]. These guidelines describe which patients should be treated in primary or secondary care (outpatient care) and when hospital admission is indicated. The Confronting COPD survey revealed that, in $55 \%$ of patients, the general practitioner is the primary physician that treats the COPD patient, whereas for $42 \%$ this was the respiratory physician at the hospital [9]. Apart from inpatient treatment in acute phases of the disease, hospitals provide diagnostic facilities, specialist examination, prevention, treatment and follow-up (outpatient management) and outpatient rehabilitation programmes. Respiratory nurses are involved in some of these activities. The number of acute hospital beds was 3.5 beds per 1,000 population in 1995 and 3 beds per 1,000 population in 2008 [14]. The number of respiratory physicians in hospitals in 2011 was 2.7 per 100,000 population [personal communication]. Seventy-five percent of medical specialists are organised in partnerships and are paid fee-for-service [30]. The remaining $25 \%$ of respiratory physicians and all other hospital staff are salary-paid [30]. Physiotherapists involved in the treatment of COPD patients work in hospitals, in rehabilitation programmes 
30 Chapter 2

(secondary care), and in community (maintenance) reactivation programmes. Community nursing is a facility available for patients in their home setting. Community nurses are employed by home care organisations [31] and are involved in general services such as nursing, medication supervision, washing and dressing. Community nurses with a focus on COPD/lung diseases also provide chronic management services like smoking cessation programmes and disease management [31]. Figure $1 \mathrm{~b}$ shows an overview of the care delivery pathway for COPD patients in the Netherlands.

There are 2 separate insurance programmes for the funding of COPD care. Care provided by general practitioners, hospitals and physiotherapists is covered by the mandatory basic health insurance scheme and by voluntary, complementary insurance schemes [31]. Health insurers are responsible for the purchasing and funding of this care [31]. Community nursing is covered by the exceptional medical expenses scheme [31].

\section{Comparison of care delivery and explanation for hospital-at-home development in England}

We find several common elements in the delivery of COPD care in England and the Netherlands. A first common element concerns the involvement of general practitioners, practice nurses or COPD nurse specialists in primary care. A second common element is the availability of inpatient and outpatient facilities in secondary care for diagnostics, prevention, treatment and follow-up care.

However, England has a stronger focus on primary care, as illustrated by the higher number of FTE general practitioners per 100,000 population in England (55.7 vs. 42.5) and the higher percentage of patients that is mainly treated by general practitioners.

Furthermore, the percentage of patients annually admitted to hospital and the standardised hospitalisation figure is higher in England than in the Netherlands $[8,9]$. Further research is required to explore these and other differences, as this is beyond the scope of this article. Nonetheless, it seems that the demand for hospital beds for COPD exacerbations is higher in England. A third common element is that both countries use guidelines to describe when patients should be treated in primary or secondary care, when referral is necessary and when admission to the hospital is indicated. A fourth common element is the presence of chronic management services in the community, mainly delivered by nurses. However, in England more diverse services are available at the community level. A final common element is that in both countries tasks and responsibilities have been delegated to nurses to relieve some of the pressure on general practitioners and hospital doctors. 
Study Design

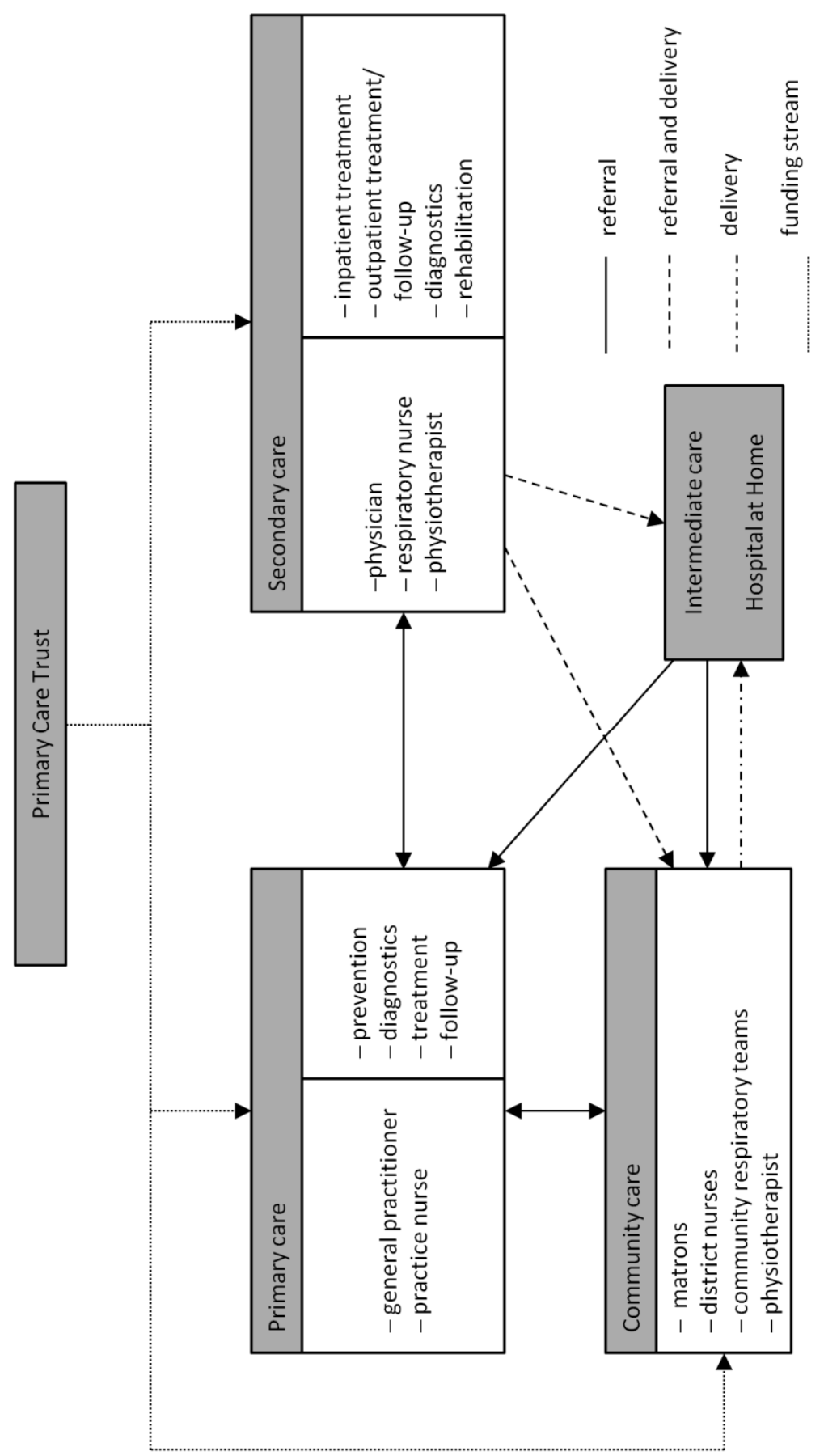

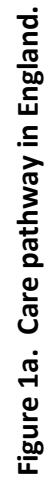


32 Chapter 2

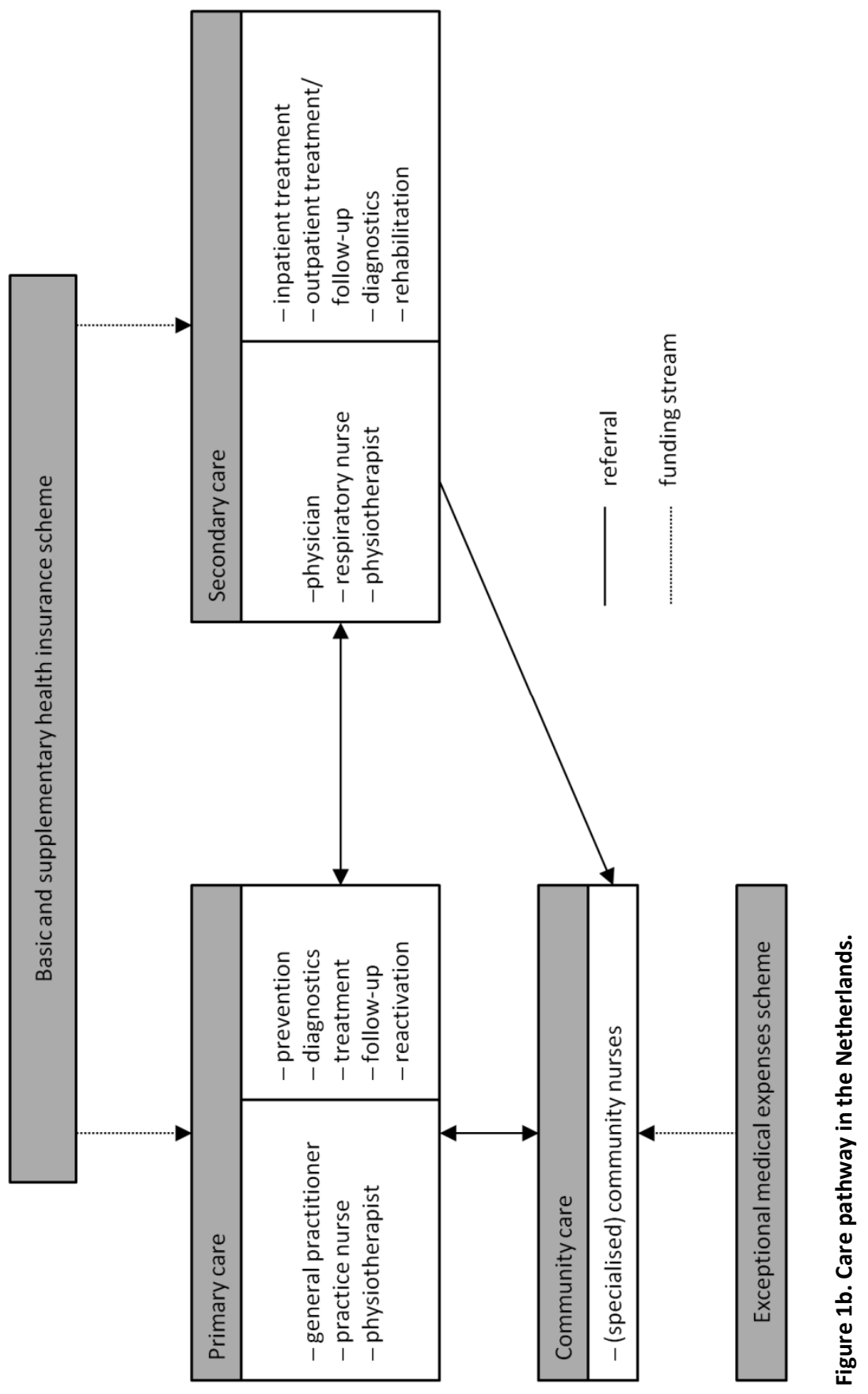


A significant difference in the care delivery pathways between England and the Netherlands concerns the acute management of exacerbations that require hospital admission. In England a service for COPD exacerbations named hospital-at-home is available, whereas a comparable type of acute service to substitute hospital care when admission is indicated does not exist in the Netherlands. Why has any equivalent of hospital-at-home schemes for selected patients with a COPD exacerbation not been developed in the Netherlands so far? We suggest 3 explanations: the differences in urgency for alternatives, differences in funding, and differences in the substitution of tasks to nurses. These 3 explanations do not exclude but complement each other.

\section{Differences in funding}

The first explanation concerns differences in the funding of COPD care. Whereas England has single-source funding, the Netherlands has a multiple-payer system with 2 separate insurance schemes. The single-source funding in England has much facilitated the development of integrated care, like hospital-at-home and staff working across institutional boundaries and across different levels of care. In the Netherlands, the institutional split between the basic health insurance scheme on the one hand and the exceptional medical expenses scheme on the other is hampering the coordinated delivery of COPD care and the development of intermediary services, such as hospitalat-home for acute COPD exacerbations. Hospital-at-home in England takes place under clinical responsibility of respiratory physicians in secondary care and works on an outreach basis from hospitals in the community, or it requires the involvement of community nurses. In the Netherlands, outreach activities in the community by hospitals, under responsibility of the hospital, are not reimbursed by the health insurance scheme. At the same time, however, the exceptional medical expenses scheme forbids community care providers to pay for care that takes place under responsibility of the hospital and that is covered by the hospital budget [31]. The example of hospital-at-home demonstrates how the co-existence of distinct financial flows in the Netherlands obstructs the integration of care. It is also important to note that, despite guidelines on who should be treated in primary and/or secondary care, there has always been some competition between hospitals, medical specialists and other providers (general practitioners, home care organisations) regarding the treatment of COPD patients. Physicians receive reimbursement for every patient they treat. Almost all patients are listed in a general practice but it is financially rewarding for respiratory physicians and hospitals to treat patients as well. Furthermore, the rivalry has been intensified by the fact that the payment of all providers has become more performance-related. Introduction of hospital-at-home in the Netherlands would have financial consequences for each provider. Fewer hospital admissions imply that hospitals would receive less funding as reimbursement is based on the number of 
registered admissions. This makes hospitals less willing to participate in outreach treatment for COPD-patients.

A related difference between England and the Netherlands is that the role of PCTs as funding organisation in England is stronger than the purchasing role of the health insurers in the Netherlands. PCTs have more leverage to initiate changes because they control almost the entire budget for health in their service area. In the Netherlands, health insurers have to compete with each other under the new Health Insurance Act, which may complicate the development of new forms of care (such as hospital-athome). Furthermore, nearly all respiratory physicians in England are employed and paid by the NHS hospitals, whereas $75 \%$ of Dutch respiratory physicians are independent entrepreneurs. This results in a difference in power balance, interests and incentives for change. In hospitals where physicians are salaried employees, the hospital has more power than when physicians operate in entrepreneurial ventures.

\section{Differences in urgency}

The prevalence of COPD and the number of hospitalisations in England is higher than in the Netherlands, whereas England has fewer hospital beds than the Netherlands. Consequently, the pressure on the available beds is higher in England than in the Netherlands, especially during winters when the incidence of COPD exacerbations increases. These circumstances highlight that the urgency to develop alternatives for hospital admission and free hospital beds has been much higher in England than in the Netherlands.

\section{Differences in the substitution of tasks to nurses}

The third explanation concerns the role of nurses in health care provision. In hospitalat-home schemes, nurses supervise the treatment at home, which is a form of substitution. Both England and the Netherlands have delegated tasks from physicians to nurses, but in England the delegation started earlier than in the Netherlands, and also on a larger scale [32,33]. In England the incentive to delegate was strong because of the low number of hospital doctors per 100,000 population and the government's strategy to shift, as far as possible, health services from hospitals into the community (primary care and community care services) [34]. PCTs quickly recognised the costeffectiveness of task substitution to nurses, and set up a large network of (specialised) nurses to perform tasks, often in the community [33]. The delegation of tasks (or task substitution) began later in the Netherlands [32] on the argument that expanding the medical role of nurses could impact the specific relationship between patients and nurses and the clearly defined caring function of nursing [33]. Furthermore, in the Netherlands physician scarcity - which is the main driver for substitution - was less urgent than in England. 


\section{Lessons}

In our comparison of the care delivery pathways of COPD patients in the Netherlands and England, we found not only common elements but also a significant difference: the presence of hospital-at-home for COPD exacerbations in England and its absence in the Netherlands. We suggested 3 complementary explanations for this remarkable difference. Table 1 shows that length of hospital stay is higher in the Netherlands than in England, while the Netherlands scores better with respect to the other variables. The next step in our analysis is to address the question whether the Netherlands could learn from England in order to reduce the length of stay, in particular with regard to hospital-at-home. In England hospital-at-home has been shown to reduce the length of hospital stay: the average length of stay (which includes patients not eligible for hospital-at-home) in hospitals with hospital-at-home is 8 days versus 9 days in hospitals without hospital-at-home [22]. In the Netherlands the average length of stay for COPD patients is still high with an average of 10.4 days. Although the reduction in length of stay reached by hospital-at-home in England is small, our suggestion is that the Netherlands can learn from this type of care. In England hospital-at-home for COPD exacerbations has been studied and described extensively. It has proved to be a safe alternative for traditional inpatient stay for selected patients, without negatively affecting patient outcomes [35]. In addition, patients accept this type of care and show great satisfaction [35].

In the Netherlands, the introduction of hospital-at-home for COPD exacerbations would perfectly fit the government's strategy to delegate more tasks from hospital specialists and general practitioners to nurses. However, the introduction of hospitalat-home in the Netherlands has implications for the professionals involved. In order to realise a hospital-based outreach service, the available number of specialised nurses in hospitals must be increased. However, considering how the funding system prohibits hospitals from funding outreach care, the option of using more readily available (nonspecialised) community nurses for the home visits should be considered, as has already been suggested by Davison at al. [36]. This development would expand nurses' activities with the supervision of patients that would otherwise be hospitalised. Another alternative could be to use practice nurses employed by general practitioners. This would bypass some of the barriers of the funding system since the funding of hospital care and primary care are part of the same segment. Furthermore, clinical responsibility for hospital patients that are being treated at home needs to be dealt with in the current funding system. It should be further explored whether general practitioners are willing to take responsibility and whether this would be feasible, or whether it would be possible, within the current system, to retain clinical responsibility at the hospital. The prospects of realising the introduction of hospital-at-home in the 
Netherlands have improved with the government's strategy of shifting some forms of community nursing from the exceptional medical expenses scheme to the basic health insurance scheme. This may help bring about a better integrated system of health services for COPD patients. Another promising development concerns the introduction of a bundled payment system for chronic care [37]. The essence of this model is to pay an annual budget for the treatment of patients with a chronic disease such as COPD. The bundle-payment covers a wide range of services for COPD patient contracted and delivered by care groups (which are often general practitioners) in primary care, as well as 1 consultation of a respiratory physician in secondary care. The care group can deliver the services directly, or can contract other providers, e.g. physiotherapists, to do so. Unfortunately, the funding of inpatient care and outpatient care provided by the hospital is not (yet) included in this budget. Community nursing is not included in this budget either. Ideally, the chain funding would cover all types of care in primary care, secondary care and community care.

\section{Conclusions}

This comparative study has demonstrated the differences and similarities in COPD care delivery pathways in the Netherlands and England. An important difference between both countries concerns the presence of hospital-at-home for COPD exacerbations in England. We have suggested 3 explanations for this difference. In England hospital-athome for COPD exacerbations has proved to be a safe alternative for inpatient treatment, without adverse patient outcomes and with great patient satisfaction. We argue that the development of hospital-at-home COPD exacerbations should be seriously considered in the Netherlands to reduce length of hospital stay, which is significantly longer in the Netherlands than in England. Given some current changes in the funding of health care, the prospects for the introduction of hospital-at-home are improving. 


\section{References}

1. Rabe KF, Hurd S, Anzueto A et al. Global strategy for the diagnosis, management, and prevention of chronic obstructive pulmonary disease: GOLD executive summary. Am J Respir Crit Care Med 2007;176:532-555.

2. Mannino DM, Buist AS. Global burden of COPD: risk factors, prevalence, and future trends. Lancet 2007;370:765-773.

3. Hoogendoorn, EJI, Feenstra, TL, and Rutten-van Mölken, MPHM: Inventarisatie van het gebruik en de kosten van zorg voor astma en COPD in Nederland [Resource use and costs of care for treating asthma and COPD in the Netherlands]. Bilthoven: Rijksinstituut voor Volksgezondheid en Milieu (RIVM); 2004.

4. Smith CJ, Gribbin J, Challen KB et al. The impact of the 2004 NICE guideline and 2003 General Medical Services contract on COPD in primary care in the UK. QJM 2008;101:145-153.

5. Chapman KR, Mannino DM, Soriano JB et al. Epidemiology and costs of chronic obstructive pulmonary disease. Eur Respir J 2006;27:188-207.

6. John Ovretveit. Comparative and Cross-cultural Health Research. A practical guide. Abingdon: Radcliffe Medical Press Ltd 1998.

7. Atsou K, Chouaid C, Hejblum G. Variability of the chronic obstructive pulmonary disease key epidemiological data in Europe: systematic review. BMC Med 2011;9:7.

8. Britton M. The burden of COPD in the U.K.: results from the Confronting COPD survey. Respir Med 2003;97 Suppl C:S71-S79.

9. Wouters EF. The burden of COPD in The Netherlands: results from the Confronting COPD survey. Respir Med 2003;97 Suppl C:S51-S59.

10. World Health Organisation: International Classification of Diseases (ICD). http://apps.who.int/classifications/apps/icd/icd10online/ last accessed: 13-10-2011.

11. NHS Information Centre: Hospital Episode Statistics - inpatient statistics. http://www.hesonline.nhs.uk/Ease/servlet/ContentServer?siteID=1937\&categorylD=192 last accessed: 19-1-2011.

12. Centraal Bureau voor de Statistiek. Statistisch Jaarboek 2004 [Statistical Yearbook 2004]. Heerlen: Centraal Bureau voor de Statistiek 2004.

13. Centraal Bureau voor de Statistiek (CBS) [Statistics Netherlands]. http://statline.cbs.nl/ StatWeb/publication/?DM=SLNL\&PA=71859NED\&D1=6,8\&D2=0\&D3=0,I\& D4=106\&D5=926\&HDR=T\&STB=G1,G2,G3,G4\&VW=T last accessed: 15-1-2010.

14. World Health Organization Europe: WHO European Health for All Database: update January 2010. http://data.euro.who.int/hfadb/ last accessed: 19-1-2011.

15. Royal College of Physicians: Consultant physicians working with patients: the duties, responsibilities and practice of physicians in medicine (4th edition). London: Royal College of Physicians; 2008.

16. Royal College of General Practitioners: Profile of UK General Practitioners: RCGP information sheet. 2006.

17. Hingstman, L. and Kenens, R. J.: Cijfers uit de registratie van huisartsen [statistics from general practitioners recordings]. Utrecht: NIVEL; 2009.

18. Candy B, Taylor SJ, Ramsay J et al. Service implications from a comparison of the evidence on the effectiveness and a survey of provision in England and Wales of COPD specialist nurse services in the community. Int J Nurs Stud 2007;44:601-610.

19. Upton J, Madoc-Sutton $\mathrm{H}$, Sheikh A et al. National survey on the roles and training of primary care respiratory nurses in the UK in 2006: are we making progress? Prim Care Respir J 2007;16:284-290.

20. O'Kelly N, Ghosh S, Smith J. Specialist practice in the community: chest medicine. Postgrad Med J 2009;85:649-654. 
21. Chronic obstructive pulmonary disease. National clinical guideline on management of chronic obstructive pulmonary disease in adults in primary and secondary care. Thorax 2004;59 Suppl 1:1-232.

22. Quantrill SJ, Lowe D, Hosker HS et al. Survey of early discharge schemes from the 2003 UK National COPD Audit. Respir Med 2007;101:1026-1031.

23. British Thoracic Society. Intermediate care--Hospital-at-Home in chronic obstructive pulmonary disease: British Thoracic Society guideline. Thorax 2007;62:200-210.

24. Skwarska E, Cohen G, Skwarski KM et al. Randomized controlled trial of supported discharge in patients with exacerbations of chronic obstructive pulmonary disease. Thorax 2000;55:907-912.

25. Puig-Junoy J, Casas A, Font-Planells J et al. The impact of home hospitalization on healthcare costs of exacerbations in COPD patients. Eur J Health Econ 2007;8:325-332.

26. van Kemenade YW: United Kingdom. In Healthcare in Europe 2007. The finance and reimbursement systems of 11 European Countries. Second edition. Maarssen: Elsevier/de Tijdstroom; 2007:159-173.

27. Noordman, J., Verheij, R., and Verhaak, P.: De inzet van doktersassistenten en praktijkondersteuners in de huisartspraktijk. [The employment of practice assistents and practice nurses in general practices]. Utrecht: NIVEL; 2008.

28. Folmer H, Smeenk FWJM, Geijer RMM et al. Landelijke Transmurale Afspraak COPD [national transmural agreement COPD]. Huisarts en Wetenschap 2001;220-225.

29. Long Alliantie Nederland (LAN). Zorgstandaard COPD [Care Standard COPD]. Amersfoort: Long Alliantie Nederland 2010.

30. van Kemenade YW: The Netherlands. In Healthcare in Europe 2007. The finance and reimbursement systems of 11 European countries. Second edition. Maarssen: Elsevier/de Tijdstroom; 2007:105-120.

31. Schäfer, W., Kroneman, M., Boerma, W., van den Berg, M., Westert, G., Devillé, W., and van Ginneken, E.: Netherlands: health system review. Copenhagen: European Observatory on Health Care Systems; 2010.

32. Raad voor de Volksgezondheid en Zorg: Taakherschikking in de gezondheidszorg [task reforms in health care] . Zoetermeer: Raad voor de Volksgezondheid en Zorg; 2002.

33. Salvage J, Heijnen S. Nursing in Europe: a resource for better health. Copenhagen: WHO, Regional Office for Europe 1997.

34. Department of Health: Our health, our care, our say: a new direction for community services. London: The Stationary Office; 2006.

35. Ram FS, Wedzicha JA, Wright J et al. Hospital at home for acute exacerbations of chronic obstructive pulmonary disease. Cochrane Database Syst Rev 2003;CD003573.

36. Davison AG, Monaghan M, Brown D et al. Hospital at home for chronic obstructive pulmonary disease: an integrated hospital and community based generic intermediate care service for prevention and early discharge. Chron Respir Dis 2006;3:181-185.

37. Struijs JN, Baan CA. Integrating care through bundled payments--lessons from The Netherlands. N Engl J Med 2011;364:990-991. 


\section{EFFECTIVENESS AND COST-EFFECTIVENESS OF EARLY ASSISTED DISCHARGE FOR CHRONIC OBSTRUCTIVE PULMONARY DISEASE EXACERBATIONS: THE DESIGN OF A RANDOMISED CONTROLLED TRIAL}

Cecile MA Utens, Lucas MA Goossens, Frank WJM Smeenk, Onno CP van Schayck, Walter van Litsenburg, Annet Janssen, Monique van Vliet, Wiel Seezink, Dirk RAJ Demunck, Brigitte van de Pas, Peter J de Bruijn, Anouschka van der Pouw, Jeroen MAM Retera, Petra de Laat-Bierings, Loes van Eijsden, Maria Braken, Riet Eijsermans and Maureen PMH Rutten-van Mölken 


\begin{abstract}
Background: Exacerbations of Chronic Obstructive Pulmonary Disease (COPD) are the main cause for hospitalisation. These hospitalisations result in a high pressure on hospital beds and high health care costs. Because of the increasing prevalence of COPD this will only become worse. Hospital-at-home is 1 of the alternatives that has been proved to be a safe alternative for hospitalisation in COPD. Most schemes are early assisted discharge schemes with specialised respiratory nurses providing care at home. Whether this type of service is cost-effective depends on the setting in which it is delivered and the way in which it is organised.
\end{abstract}

Methods/Design: GO AHEAD (Assessment Of Going Home under Early Assisted Discharge) is a 3-month, randomised controlled, multi-centre clinical trial. Patients admitted to hospital for a COPD exacerbation are either discharged on the fourth day of admission and further treated at home, or receive usual inpatient hospital care. Home treatment is supervised by general nurses. Primary outcome is the effectiveness and cost effectiveness of an early assisted discharge intervention in comparison with usual inpatient hospital care for patients hospitalised with a COPD exacerbation. Secondary outcomes include effects on quality of life, primary informal caregiver burden and patient and primary caregiver satisfaction. Additionally, a discrete choice experiment is performed to provide insight in patient and informal caregiver preferences for different treatment characteristics. Measurements are performed on the first day of admission and 3 days, 7 days, 1 month and 3 months thereafter. Ethical approval has been obtained and the study has been registered.

Discussion: This article describes the study protocol of the GO AHEAD study. Early assisted discharge could be an effective and cost-effective method to reduce length of hospital stay in the Netherlands which is beneficial for patients and society. If effectiveness and cost-effectiveness can be proven, implementation in the Dutch health care system should be considered.

Trial registration: Netherlands Trial Register NTR1129. 


\section{Background}

Chronic Obstructive Pulmonary Disease (COPD) is a chronic disease that is currently ranked as fourth major cause of death globally [1]. Due to an aging population and late effects of smoking, the prevalence of COPD will increase in the following 20 years [2]. Projections for the year 2030 indicate that COPD will be third major cause of death, as a result of the projected increase of tobacco use, especially among women and lowand middle income countries [1]. COPD is characterised by an airflow limitation which is not fully reversible. Symptoms include sputum production, cough and dyspnoea. These symptoms are chronic and progressive over time [3].

Acute exacerbations of COPD can be defined as 'an event in the natural course of the disease characterized by a change in a patients' baseline dyspnoea, cough and/or sputum production that is beyond the day-to-day variations, is acute in onset, and may warrant a change in regular medication in a patient with underlying COPD' [3]. The exacerbation frequency is dependent on several factors including disease severity and number of exacerbations in the previous year [4,5]. Although most exacerbations are treated in the community [5], exacerbations are the main cause for hospitalisations in COPD patients $[5,6]$. Studies have shown that exacerbations and hospital admissions negatively influence patient outcomes, by increasing lung function decline $[5,6]$, decreasing quality of life $[7,8]$, increasing mortality [9] and increasing readmission risk $[8,10]$.

With a mean length of stay in the hospital of 9 days $[6,11]$ the large number of hospital admissions for exacerbations among COPD patients result in a high pressure on scarce hospital beds and high health care costs, accounting for up to $70 \%$ of total expenses for COPD [12,13]. Even without intervention, hospital costs will rise as a result of the increasing prevalence of COPD, especially among women. To reduce health care costs, alternatives for hospital treatment have been developed. One alternative that has gained popularity in the last 15 years are hospital-at-home schemes [14,15]. These schemes aim at reducing the pressure on hospital beds and overall health care costs without negatively influencing the patient outcomes and increase patient satisfaction [16].

\section{Hospital-at-home and early assisted discharge}

Hospital-at-home is defined as "a service that provides active treatment by health care professionals in the patient's home for a condition that otherwise would require acute in-patient care, and always for a limited time period" [17]. Hospital-at-home is also known as 'home hospitalisation' or 'hospital in the home'. Depending on the target population of the scheme and the type of care provided, schemes vary in 
organisational structure and may involve different professionals [17]. Hospital-at-home schemes can be divided in admission avoidance schemes, (early) assisted or supported discharge schemes and combined schemes. Depending on who bears the financial and management responsibilities, the schemes can further be divided in community based or hospital based. Community based schemes commonly built on the existing infrastructure for care provision in the community, whereas hospital based schemes work on an outreach basis and home care is provided by hospital staff.

\section{Hospital-at-home for COPD exacerbations}

Hospital-at-home schemes for the treatment of COPD exacerbations specifically, have been studied in several randomised controlled trials [18-25] and various nonrandomised studies including observational studies [26-31] and studies with retrospective analysis [32]. Studies were performed in the United Kingdom [19,20,2429,32], Ireland [30], Australia [23], Italy [18] and Spain [21,22,31]. These studies showed that approximately $25 \%$ of all patients with an acute exacerbation of COPD can be treated at home safely with no negative effects on their health outcomes and with great patient satisfaction [16]. These results triggered the wide implementation of hospital-at-home schemes for COPD exacerbations in the United Kingdom over the last 10 years [14,15]. In 2007, the British Thoracic Society developed the Hospital-at-Home in Chronic Obstructive Pulmonary Disease guideline providing a framework for the development and adjustment of hospital-at-home schemes [33]. Most hospital-athome schemes active in the United Kingdom are assisted discharge schemes, with specialised respiratory nurses providing home care on an outpatient basis [14,15]. However, it remains unknown whether this is the most effective model for hospital-athome care. The use of generic community district or nurses or telephone monitoring might be an option that increases the capacity of the hospital-at-home schemes for COPD exacerbation. Supported by their positive results, Davison et al. [28] suggest that the use of generic community nurses in hospital-at-home schemes should be studied more intensively.

Hospital-at-home for COPD exacerbations initially requiring hospital admission has also been the subject of several cost or cost-effectiveness studies [18,22,23,25,34-36]. Significant and substantial cost savings were found in Australia (€1200 per episode) [23], Spain (€800) [22,35] and the United States (€1700) [37]. No significant cost savings were found for England and Italy [36]]. (Amounts were converted to Euros, using exchange rates of March 2010). All studies were performed from a health care or payer perspective, meaning that they recorded only costs in the health care sector and not included costs of informal care. Although treating COPD exacerbations at home has the potential to reduce costs, whether and the extent to which it does so in the Netherlands is unknown. Apart from the exact organisation of the hospital-at-home 
scheme, its health economic impact depends heavily on national and local treatment patterns, health care delivery structures, funding and reimbursement systems, absolute and relative differences in unit costs of resource use and drug prices. The limited transferability of cost-effectiveness results to other settings stresses the need for setting-specific cost-effectiveness studies.

This contribution presents the design of the GO AHEAD trial (GO AHEAD is an acronym for Assessment Of Going Home under Early Assisted Discharge). In this randomised controlled trial (RCT) patients admitted to the hospital for an exacerbation of their COPD are discharged early and monitored at home by nurses.

\section{Research questions}

Our primary research question is: "What is the effectiveness and cost-effectiveness of an early assisted discharge intervention compared to hospital care as usual for patients hospitalised with an exacerbation of their COPD." The primary measure of effectiveness will expressed by the change in health status, measured by the change in Clinical COPD Questionnaire (CCQ) [38] scores between randomisation and day 7, while costs include COPD-related health care costs, patients' and informal caregivers' out-of-pocket costs and patients' and informal caregivers' costs of production loss.

The following secondary research questions will be addressed:

1) What is the long-term effectiveness of early assisted discharge compared to hospital care as usual?

2) What is the difference in treatment failures between the early assisted discharge scheme and usual care in hospital? Treatment failure in the intervention group is defined as readmission before day 7 or death before day 7. In the control group treatment failure is defined as death before day 7 or clinical deterioration leading to prolongation of hospital stay after day 7 .

3) What is the effect of early assisted discharge on readmission rates after discharge from hospital or the early assisted discharge scheme, in comparison with usual care in hospital?

4) What is the effect of early assisted discharge on mortality after discharge from hospital or early assisted discharge scheme, in comparison with usual care in hospital?

5) What is the effect of early assisted discharge on patients quality of life in comparison with usual care in hospital?

6) What is the effect of early assisted discharge on primary informal caregiver burden in comparison with usual care in hospital?

7) How is patient and primary informal caregiver satisfaction with the early assisted discharge scheme compared with usual care in hospital? 
Additionally a discrete choice experiment (DCE) is performed in order to provide more insight in patient and primary informal caregiver preferences for different treatment characteristics.

\section{Methods/Design}

\section{Study design}

The GO AHEAD study is a randomised controlled, multi-centre trial comparing 2 management strategies for patients admitted to the hospital for a COPD exacerbation. The intervention strategy is early assisted discharge, which implies that patients are discharged early from hospital with a package of home care. Recovery is monitored while patients are further treated at home. This management strategy is compared to usual hospital care, where patients remain hospitalised and are monitored in hospital. The total length of the active, supervised treatment phase for both groups is planned to be 7 days. The follow up period of the trial is 3 months. Figure 1 gives a complete overview of the study design. Main focus of the study is not only to perform an effect evaluation, but also a cost evaluation and a discrete choice experiment. This trial was approved by the Medical Ethics Committee of the Catharina-hospital Eindhoven, the Netherlands and this approval was reconfirmed by the Medical Ethics Committees of the other participating hospitals.

\section{Setting and recruitment}

Patients admitted to 1 of the participating hospitals because of an exacerbation of their COPD, through either the emergency and accident department or after an unscheduled outpatient visit to the pulmonologist, are screened for eligibility. Patients are assessed for eligibility at 2 time points. On day 1, the pulmonologist and research nurse screen the patient for eligibility according to the inclusion and exclusion criteria listed in table 1 . On day 1 , patients are considered eligible for potential early discharge if they meet the following inclusion criteria: aged 40 or over, competent, diagnosed with at least COPD GOLD stage 1 (post- bronchodilator $\mathrm{FEV}_{1} / \mathrm{FVC}<70 \%$ [3]) and a smoking history of minimally 10 pack years (PY), hospitalised with a moderate to severe exacerbation and finally, completed informed consent on day 3 of admission. Patients are excluded if they meet any of the following exclusion criteria: major uncontrolled comorbidity, mental disability, active alcohol- or drug abuse, inability to understand the program, living outside the region of the participating home care organisation, indication for admission to the intensive care unit or non-invasive ventilation and insufficient availability of informal care at home. 


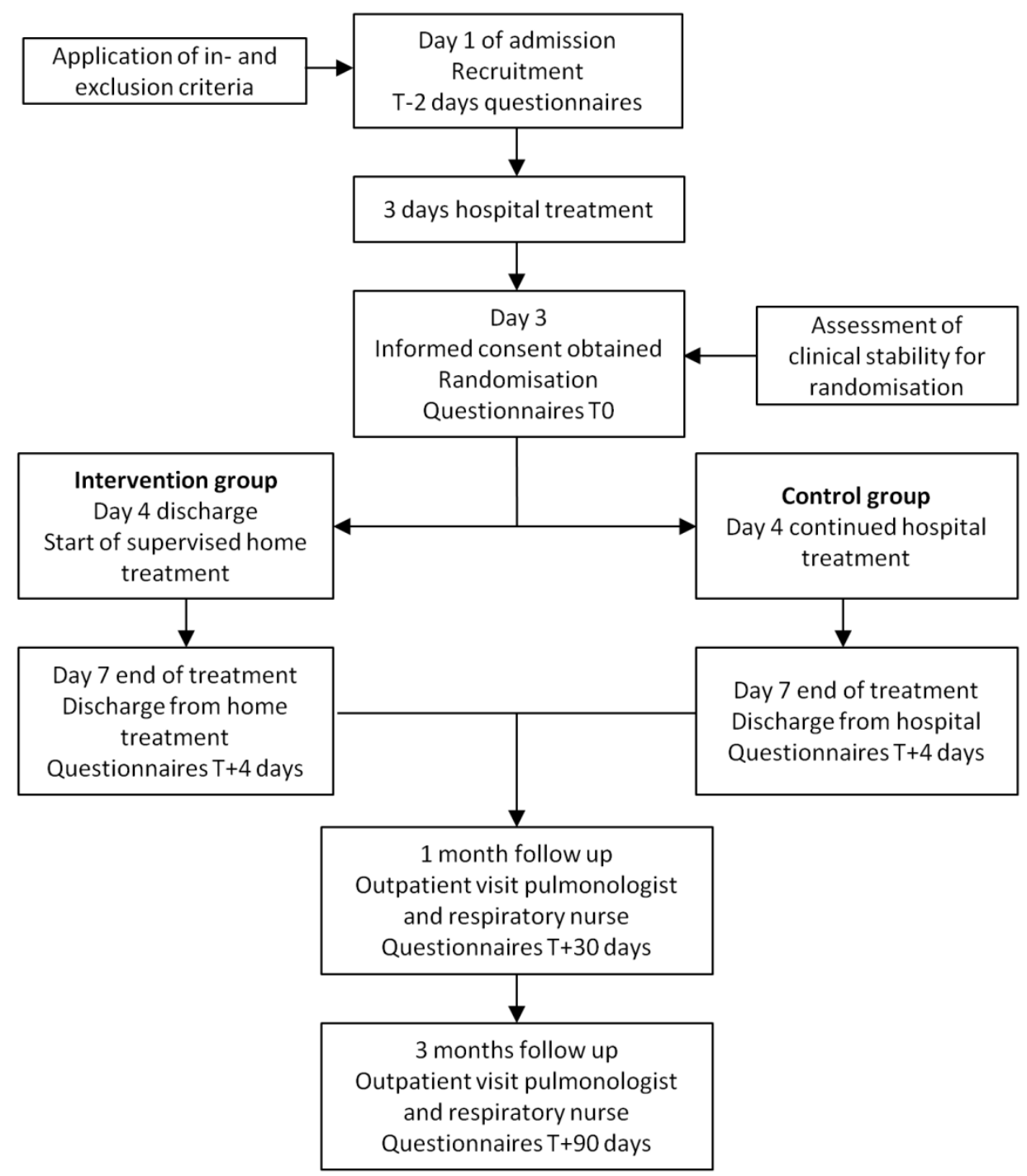

Figure 1. Study design.

On day 1, all patients considered eligible for potential early discharge are invited to participate in the controlled clinical trial in which they either continue their hospital admission or are discharged early to home care. These patients are informed that, if they fulfil the in- and exclusion criteria and are still willing to participate on day 3 , they will be randomised on day 3 and discharged on day 4 . For patients admitted before 12:00 PM, the day of admission is considered as day 1 , otherwise, the following day is considered as day 1 . 
Patients must have signed the informed consent form before randomisation on day 3 , which means they have 3 days to decide whether they want to participate in the trial or not. This procedure is possible because the treatment in the first 3 days is not different from that of patients not participating in the trial. Data collected before the third day of admission will be destroyed if the patient does not give informed consent on that day. This procedure has been approved by the ethics committee.

Patients who refuse to participate in the trial are invited to participate only in the discrete choice experiment study without participating in the RCT. These patients are contacted by telephone one month after admission and asked to give informed consent for this part of the study. This informed consent form is different from the form that is used in the RCT.

Table 1: Inclusion and exclusion criteria

Inclusion criteria
Age 40 years and over
Competent
Diagnosed with at least COPD GOLD I and 10 Pack Years of smoking or grounded susceptibility for COPD
Hospitalised with COPD exacerbation
Completed informed consent on day 3 of admission
Exclusion criteria
Major uncontrolled comorbidity
Mental disability
Active alcohol abuse and/or drug abuse
Inability to understand the program
Living outside care region of the home care organisation
Indication for admission to intensive care unit or non invasive ventilation
Insufficient availability of informal care at home

\section{Randomisation procedure}

On the third day of admission clinical stability is assessed in order to determine whether patients can be randomised. This design for randomisation is copied from the Spanish study performed by Diaz et al. [21] although the criteria for clinical stability were adapted to represent the current practice in the participating hospitals and because of the difference in treatment package patients receive at home. Patients need to meet the following criteria to be randomised: 1) acceptable general health defined as decrease of physical complaints, non dependency of therapies that cannot be given at home and being able to visit the toilet independently; 2) normal or moderately increased blood sugar levels, defined as $\leq 15 \mathrm{mmol} / \mathrm{L}$ or $\geq 15 \mathrm{mmol} / \mathrm{L}$ while the patient is capable to regulate blood sugars independently at home; and 3) respiratory complaints of dyspnoea, wheezing and rhonchi must have decreased in comparison with day 1 of admission. A special symptoms scoring list adapted from the one used by Ojoo et al [24] is used for this (see appendix 1). This scoring chart scores the major exacerbation symptoms such as dyspnoea, coughing, mucus production and 
colour, and oedema. By scoring these symptoms daily, improvement or deterioration in comparison with the previous days becomes more visual and supports the pulmonologist when applying the randomisation criteria to the patient.

Randomisation is performed on a 1:1 scale using a computer-generated randomisation list that is placed in sealed envelopes containing the allocation sequence of the 2 treatment groups. Randomisation is performed per participating location of the hospitals. We chose this procedure to ensure all participating hospitals have a similar proportion of patients in the intervention group and patients in the control group, and that the burden for each participating home care organisations is similar. Furthermore, a block size of 6 is applied to create equal numbers in both groups.

The treatment protocol for the following 4 days is started after randomisation and for the intervention group the process of discharge planning is started.

\section{Treatment protocol day 1-3 and day 4-7}

The treatment protocol during the 7 days of supervised treatment can be divided in the treatment before randomisation and the treatment after randomisation. During the first 3 days of the treatment all patients receive usual care. The pharmacological part of this treatment consists of systemic corticosteroids ( 10 days in total, first 3 days $50 \mathrm{mg}$ of oral or intravenous prednisolone or other corticosteroid with an equivalent dose, following 7 days of $30 \mathrm{mg}$ oral prednisolone or other corticosteroid with an equivalent dose), nebulised bronchodilators (ipratropium $500 \mu \mathrm{g} / \mathrm{salbutamol} 2.5 \mathrm{mg}$, 4-6 times per day), sub cutaneous thrombosis prophylaxis, stomach protection because of the high dosage of corticosteroids - and, if necessary, oxygen therapy. Antibiotics are prescribed if patients meet any of the following criteria: increase of the amount of mucus, mucus purulence or CRP > 50 for which no other cause can be determined. First choice of antibiotics is co-amoxiclav. However, if previous mucus cultures show sensitivity for different antibiotics, or patients are allergic, different antibiotics can be prescribed. Antibiotics are prescribed for at least 7 days. Nonpharmacologic usual care consists of physiotherapy for all patients and dietary advice upon indication [39]. The physiotherapist instructs the patient in breathing and coughing techniques and reactivation. A standardised (additional) written instruction was developed ensuring identical instruction in the participating hospitals. Dietary advice is indicated in case of a Body Mass Index $\leq 21$ or $10 \%$ unintended weight loss in the 6 months prior to admission [39]. After randomisation systemic corticosteroids are continued and patients start with pressure metered dose inhaled medication via spacer (at least an $\beta_{2}$-agonist or anticholinergic with inhaled glucocorticosteroid). Patients receive inhalation instruction on the day before starting with these inhalations. Patients already using nebulised inhalation medication prior to admission, 
may continue this after randomisation. The physiotherapist instructs patients to follow the written instructions at home and dietary consultation is continued as in usual care and at the dietician's judgement. On the fourth day of admission the intervention group is transferred home and undergoes the early assisted discharge intervention. The control group remains hospitalised and receives usual care in hospital. In both groups, patient recovery progress is monitored daily using the translated and adapted exacerbation symptom scoring chart.

\section{Early assisted discharge intervention}

Patients randomised into the early assisted discharge group are transferred home on day 4 of admission. The previously described treatment is continued at home and supervised by nurses. These nurses have daily contact with the patient for 4 consecutive days. Main objective of the supervision of the home treatment is the observation of the patient's recovery and providing counselling and reassurance to the patient and the primary informal caregiver. The nurses also address medication compliance and inhalation techniques, provide support in applying breathing- and coughing techniques and, if applicable, provide support in adhering to dietary advices. If necessary patients, can be supported in their daily life activities (e.g. washing and dressing) by the home care organisation. During the 4 days of home treatment, the emphasis lies on the recovery of the exacerbation. Secondary objectives like disease management and smoking cessation are addressed during the first follow-up moment 1 month after randomisation.

General practitioners are informed about patients' participation in the trial, but are not directly involved in these patients' home care. In cases of deterioration of the patient, the patient is discussed with the treating hospital pulmonologist and, if necessary, the patient is readmitted to the hospital. Patients can contact the hospital 24 hours a day, 7 days a week with questions or in cases of emergency.

\section{Follow-up visits}

For both treatment groups 2 follow-up visits at the outpatient clinic are scheduled at 1 month and 3 months after randomisation. During these visits patients are seen by their own pulmonologist and a respiratory nurse. The visits to the pulmonologist are as in usual care, the visits to the respiratory nurse have a two-fold purpose. Firstly, these visits focus on the different aspects of disease management. It is at the discretion of the respiratory nurse which aspects need to be addressed for each specific patient. Secondly, these visits are used to collect, dispense and administer the questionnaires and cost diaries. Additional visits can be planned at the discretion of the pulmonologist (e.g. for additional testing), but do not fall under the study protocol. At the 3-month 
follow-up visit lung function testing and a 6 minute walking distance test are performed as well.

\section{Data collection}

Data are collected on 5 time points: on the first day of admission (T-2 days), on the third day of admission (randomisation, $T$ ), at the end of the supervised treatment (day $7, T+4$ days) and 1 month ( $T+30$ days) and 3 months after randomisation ( $T+90$ days). We use self-administered questionnaires and cost diaries to obtain data. The questionnaires are administered when supervision is available. Cost diaries are supplied at 2 time points ( $T+4$ days and $T+30$ days) for the upcoming period, collected at the end of each follow up period and if necessary completed under supervision.

\section{Effect evaluation}

Table 2 provides an overview of the measures of the effect evaluation and the economic evaluation, and at which time point the measurements are performed.

\section{Primary outcome measurements}

Primary outcome measure in this study is the effectiveness of early assisted discharge compared to usual care expressed by the change on the Clinical COPD Questionnaire (CCQ) [38] between the third day of admission (TO) and the last day of supervised treatment $(T+4$ days $=$ day 7$)$. The $C C Q$ is a disease specific, 10-item questionnaire that calculates an overall score and 3 domain scores: symptoms, functional state and emotional state. All items are scored on a 7 point scale with 0 representing the best possible score and 6 representing the worst possible score [38]. In this study the version with a 24-hour recall period is used, reflecting the health status of the past 24 hours. The CCQ is responsive to change [38] and a study in patients admitted to the hospital with an acute exacerbation of COPD, indicated that the minimal clinical important difference (MCID) of the CCQ is 0.4 [40].

\section{Secondary outcome measurements}

Main secondary outcome measurement of the study is the cost-effectiveness. This will be discussed in the economic evaluation section. The following other secondary measurements will be performed. These correspond with the secondary research questions from the last paragraph of the introduction:

1. Long-term effectiveness, measured with the CCQ change over the time points from day 1 to the end of the follow-up period ( $T+90$ days).

2. Number of treatment failures.

3. Number of readmissions to hospital and time to readmission during the 3months follow-up period.

4. Mortality and time to death during the 3-months follow-up. 
5. Generic health related quality of life, measured with the EuroQol (EQ-5D) 5D [41]. The EQ-5D will also be used to calculate quality adjusted life year (QALYs), discussed in the economic evaluation section.

6. Effects on primary informal caregiver burden measured by the Caregiver Strain Index [42].

7. Patient and primary informal caregiver satisfaction with the program. We use a translated version of the satisfaction questionnaire used by Ojoo et al. [24] and extended it with additional questions.

Table 2: Overview of measurements per time point.

\begin{tabular}{|c|c|c|c|c|c|}
\hline Measurement & $\begin{array}{l}\mathrm{T}-2 \\
\text { days }\end{array}$ & TO & $\begin{array}{l}\mathrm{T}+30 \\
\text { days }\end{array}$ & $\begin{array}{l}\mathrm{T}+4 \\
\text { days }\end{array}$ & $\begin{array}{l}\mathrm{T}+90 \\
\text { days }\end{array}$ \\
\hline Demographic characteristics & $x$ & & & & \\
\hline Smoking & $x$ & & & & \\
\hline Body Mass Index & $x$ & & & & \\
\hline Living situation & $x$ & & & & \\
\hline Comorbidity & $x$ & & & & \\
\hline Coping style (UCL) & & $x$ & & & \\
\hline Medical treatment prior to admission & $x$ & & & & \\
\hline Exacerbation severity & $x$ & & & & \\
\hline Indication for admission & $x$ & & & & \\
\hline Clinical COPD Questionnaire (CCQ) & $x$ & $x$ & $\mathrm{x}$ & & $x$ \\
\hline EuroQol 5D (EQ-5D) & & $x$ & $x$ & & $x$ \\
\hline \multicolumn{6}{|l|}{ Satisfaction } \\
\hline Patient satisfaction & & & $\mathrm{x}$ & & $x$ \\
\hline Informal caregiver satisfaction & & & $x$ & & $x$ \\
\hline Caregiver Strain Index & & & $x$ & & $x$ \\
\hline Treatment Failures & & & $x$ & & \\
\hline Readmissions & & & & & $x$ \\
\hline Mortality & & & & & $x$ \\
\hline Cost diary & & & $x(I G)$ & $x$ & $x$ \\
\hline Discrete Choice Experiment & & & & $\mathrm{x}$ & \\
\hline Lung function testing & & & & & $x$ \\
\hline 6 Minute Walking Distance & & & & & $x$ \\
\hline
\end{tabular}

$\mathrm{T} 0$ = baseline; $\mathrm{T} 1$ = randomisation; $\mathrm{T} 2$ = end of supervised treatment; $\mathrm{T} 3$ = follow up $1 ; \mathrm{T} 4$ =

follow up 2; IG = intervention group only.

\section{Patient characteristics}

Patients are characterised using the following variables: demographic factors (age, gender, socioeconomic status measured through level of education and income), smoking, Body Mass Index, living situation, comorbidity measured with the Charlson Comorbidity Index (CCI) [43], Coping Style measured with the Utrecht Coping List [44], medical treatment at home prior to the admission, severity of the exacerbation, indication for admission and finally severity of the disease are measured as well. In addition, severity of COPD is measured 3 months after admission at the end of the follow up period by performing lung function testing and a 6 minute walking test. 


\section{Economic evaluation}

In accordance with the broad international consensus that economic evaluations should be conducted from a societal perspective [45] this cost-effectiveness analysis will include all costs, irrespective of who actually bears them. All direct health care and non-health care costs as well as the costs of productivity losses of patient and caregiver within the 3 months after randomisation will be taken into account. The following types of resource use will be recorded to calculate direct health care costs: number and length of hospital admissions and readmissions, total amount of time of community nursing care (distinguished by nurse grade), number of visits to the emergency department, number of contacts with pulmonologist, other specialist physicians, general practitioner, respiratory nurse, dietician, physiotherapist, and social worker, number of ambulance rides and medication use. These will be recorded in cost diaries and obtained from hospital records. Costs of organisational arrangements of the early discharge scheme will also be included. Direct non-health care costs primarily include paid and unpaid household help, including the time spent by the primary informal caregiver.

Indirect costs are costs of productivity losses. We record the days a patient is absent from paid work. We also ask informal caregivers to record the number of days off work due to caring for the patient. Costs are calculated by multiplying the volume of resource use (such as hospital days, physician visits, time spent by formal and informal caregivers) by a price per unit that includes total, not marginal costs. In addition to the societal perspective, we will calculate the costs from the financial hospital perspective, the financial perspective of the organisation providing the home care and the perspective of the health care sector. This includes costs covered by the hospital budget, the budget of the home care organisation and the health care sectors budget, respectively.

The principal health outcome measures in the economic evaluation are the number of patients with a clinically relevant improvement in CCQ between day of randomisation and day 7, and between day of randomisation and month 3, the change in CCQ score between day of randomisation and day 7 and day of randomisation and month 3 , the number of QALYs at randomisation and the end of the 3-month follow-up period. The latter is calculated using the Dutch EQ-5D tariff [46]. Health outcomes will be related to cost outcomes. If 1 of the treatment options is more effective but also more costly, results will be presented as an incremental cost-effectiveness analysis: the additional cost per additional unit of health gain, which is calculated as the difference in mean costs between early discharge and usual inpatient hospital care divided by the mean health effects. 


\section{Data analysis}

Data analysis will be performed according to the intention to treat principle. Data from patients who die, quit participation or are otherwise lost to follow up will be included in the analysis up until the point of drop out. Missing observations will be imputed or weighted appropriately.

All primary and secondary outcome measurements will be analysed using analysis of covariance. In order to control for dependency between the repeated measurements within 1 patient, and for the dependency between patients from the same hospital, multilevel analyses will be performed as well. We set the significance level at $\alpha=0.05$.

\section{Primary outcome measure}

The changes on the primary outcome measurement, the $C C Q$, will be analysed with the repeated measurements ANOVA technique. The dependent variable is the change in CCQ score from baseline (TO) to the end of the supervised treatment ( $T+4$ days). Treatment group is considered as independent variable and baseline CCQ score (TO) and centre of treatment are considered as covariates. Age, gender and severity of the disease will also be included in the model as covariates. If necessary, other covariates will be included in the model.

\section{Secondary outcomes measurements}

All time-to-event outcomes (i.e. time to readmission and time to death) will be analysed using Kaplan-Meier curves and Cox Proportional Hazards regression model. Event rates (i.e. treatment failures, readmission rates and mortality rates) will be analysed using an appropriate model for count data (e.g. poisson regression or binomial regression)

Differences in outcomes defined as the mean change from baseline (e.g. long-term effectiveness, primary informal caregiver burden, patient- and primary informal caregiver satisfaction and quality of life) will be analysed using repeated measurements ANOVA. Patient- and caregiver preference for place of treatment will be analysed using a logistic regression model.

\section{Cost-effectiveness}

In order to derive the total utility experienced over the course of the investigation, the number of QALYs per patient will be calculated as the area under the utility curve. Uncertainty around the estimates of costs and health outcomes will be addressed by bootstrapping the data with bias correction and acceleration (BCa) $[47,48]$. The $95 \%$ confidence interval around the difference in mean costs and health outcomes will be determined by taking the $2.5^{\text {th }}$ percentile and the $97.5^{\text {th }}$ percentile of these bootstrap replications. The bootstrap replicates will be plotted in cost-effectiveness planes (CE- 
planes). A CE-plane is an $x$-y-diagram with the $x$-axis representing the difference in health outcome between the treatment and usual care group and the $y$-axis representing the difference in costs. By plotting all bootstrap replicates in this diagram the uncertainty around the point estimates of the ICERs will be displayed [47]. The information from the CE-planes will be summarised into cost-effectiveness acceptability curves, which represent the likelihood that early assisted discharge is the most cost-effective option at different values of the maximum acceptable willingness to pay (WTP) for a health outcome [48].

\section{Sample Size calculation}

Primary outcome is the change in the CCQ score between baseline (day 3 of admission) and the end of the supervised treatment (day 7). Before the start of the study, a preliminary sample size calculation for an independent samples t-test was performed based on the results of a pilot study, where the average CCQ decreased from 3.8 on the day of admission to 2.6 by the end of the supervised treatment The standard deviation of that change was 1.04. With a MCID of 0.4, the required Cohen's effect size $d$ would be 0.385 [99]. For a risk of a type-I error of $5 \%(\alpha=0.05)$ and a risk of a type-II error $20 \%(1-\beta=0.80)$, the required sample size was 214 . However, primary outcome measure in this study is the change in the CCQ score from the third day of admission and the end of the supervised treatment (day 7), which is likely to have a stronger correlation with the baseline score. Therefore, a new sample size calculation for ANCOVA was performed after 85 patients had been treated, without breaking the randomisation code. Taking into account the correlation between the baseline score and the change $(r=0.288)$, as well as the standard deviations measured in the trial ( 0.988 for the intervention group and 0.922 for the control group), the required effect size $f$ is 0.22 and the sample size is 165 .

\section{Discrete Choice Experiment}

\section{Background}

As part of the GO AHEAD trial we perform a discrete choice experiment (DCE) to explore the preferences of patients and their informal caregivers for different treatment arrangements. The DCE provides quantitative information on the relative importance of the characteristics of the hospital treatment and the early assisted discharge scheme and the rate at which patients are willing to trade between them. A DCE is a type of conjoint analysis used to determine individual preferences. In this study it involves presenting respondents with a series of choices between an early assisted discharge scenario and a usual hospital care scenario. Each scenario is described in terms of several characteristics, which are called attributes. DCEs originate from mathematical psychology and have been most widely applied in market 
research to determine consumer preferences for goods and services and investigate the relative importance of the characteristics of these goods and services $[49,50]$.

\section{Design}

A review of literature and conversations with patients and pulmonologists have lead to the selection of 7 attributes with 2 or 3 levels each for the home treatment options, while the hospital option is kept constant and is not described by attributes. The attributes for the home treatments are: type of nurse (generic or respiratory), number of home visits ( 1,2 or 3 per day), copayment ( $€ 0, € 50$ or $€ 100$ ), risk of readmission to hospital within treatment period $(1 \%, 5 \%$ or $10 \%)$, whom to contact in case of emergency (general practitioner or pulmonary ward in the hospital), number of hours of informal care (1, 3 or 5 hours per day), number of different nurses visiting the patient (1-2 or more than 2). The questionnaire consists of 14 choice scenarios, 2 of which have a 'right answer' and aimed at testing if the respondent understands the task. There are 3 versions of the questionnaire, which add up to a D-optimal design of 36 different scenarios. Each respondent is asked to complete 1 version of the questionnaire. In each scenario respondents indicate a preference for 1 of 2 home treatment options or the complete hospital treatment. Respondents who initially choose the hospital option are subsequently asked to make a choice between the 2 home treatments. By using this forced choice question, we ascertain that all respondents provide information about their preferences for attributes of the home treatment.

\section{Data analysis}

Depending on the choice pattern of the respondents, the data will be analysed using conditional logit model with alternative-specific constants, a random parameter multinomial logit model (i.e. a mixed logit model) or a multilevel latent class conditional logit model, all with and without interaction effects. This analysis results in a regression coefficient for each level of the attributes. The estimated coefficients allow conclusions to be made about the relative importance of the attributes and possible trade-offs between them. Furthermore, we will test whether the patients who were assigned to the early assisted discharge scheme have different preferences for various characteristics of the care delivery than patients who were assigned to the conventional inpatient hospital care.

Finally, we will test for differences in preferences between patients, their informal and formal caregivers.

\section{Discussion}

We presented the protocol of the GO AHEAD study, which assesses the effectiveness and cost-effectiveness of an early assisted discharge intervention for patients admitted 
to the hospital for a COPD exacerbation. It is a multi-centre randomised controlled trial comparing the early assisted discharge intervention with usual care in the hospital. Despite research on the effectiveness of early assisted discharge for COPD exacerbations, several aspects of these hospital-at-home schemes remain unclear. This study will provide not only information on the effectiveness and cost-effectiveness, but also on which aspects of the intervention are important for patients to make a certain choice (DCE) and secondary outcome measurements, namely effects on quality of life, effects on informal caregiver burden and patient and informal caregiver satisfaction.

There are several critical success factors to be mentioned. In the past 2 decades average length of hospital stay, for acute care of all conditions, has already decreased internationally from approximately 9 days to 6 days [51]. Average length of stay for COPD exacerbations follows these trends, with changes from approximately 8.5 days to 6.5 days $[11,37,52]$. Although this trend has occurred in the Netherlands as well, average length of hospital stay for COPD patients is still 10.5 days [53]. With the projected increasing prevalence of COPD, especially for women, in the following years, this leaves room for interventions that reduce length of stay.

Prolonged hospital stay is associated with the presence of comorbidities [54], continuation of conservative therapy (e.g. therapies that can only be given in hospital or pulmonologists wish to observe stable patients) [37] and complex discharge planning that requires additional home care arrangements [37,52] among others. Moreover, comorbidities are more present in patients with more severe COPD [55], and most patients hospitalised have COPD stages III or more [52,56]. This might suggest that the Dutch hospitalised population is different from that in the United Kingdom. However, the national UK audit from 2008 [56] showed that severity of the disease of patients admitted to the hospital has not changed between 2003 and 2008 (median $\mathrm{FEV}_{1}=38 \%$ of predicted value, GOLD stage III) and $77 \%$ of all patients admitted to hospital have 1 or more comorbidities.

Early assisted discharge also anticipates for the need for social work involvement during hospitalisation. In the early assisted discharge scheme care at home is arranged for a certain number of days and patients are closely monitored at home. Because of the presence of nurses at home, the possible need for prolonged or extended home care is quickly identified. Arrangements can be made more easily because patients are already in the system of the home care organisation.

In the United Kingdom, early assisted discharge for COPD exacerbations is more common in hospitals that are characterised by greater number of hospital beds, higher numbers of hospital admissions and the presence of respiratory nurses [15]. The Dutch hospitals are of similar size or larger than those in the United Kingdom [51]. The 
number of admissions is high (11,6 per 10.000 population in 2007 [67]) and respiratory nurses have an important role in patient care. The Dutch health care systems also has a large network of primary care organisations that deliver home care that is easily accessible for the population. Therefore the use of generic community nurses in the early assisted discharge scheme is possible. Despite similarities between the British and Dutch health care system, organisational and financial differences between these countries exist and results from studies performed in 1 country, with its own characteristics, cannot simply be translated to and implemented in other countries. Similarities and differences should be studied more intensively and taken into account before implementing early assisted discharge in the Dutch health care system. Possible boundary for implementation in the Netherlands are the different reimbursement systems and budgets of hospital care and home care. An integrated financing structure may facilitate the implementation in the health care system.

In this trial supervision of the treatment at home is either performed by community based, generic nurses or hospital based specialised respiratory nurses (nurse practitioners). The use of hospital based specialised respiratory nurses is the most frequently described and studied form of supervision at home. Using generic community nurses, who are more available and less costly, could enable the development of more hospital-at-home services. In this study both strategies for early assisted discharge (hospital resources or community based) and the different professionals involved in home care (generic nurses or specialised respiratory nurses) are being used. When sample sizes of both groups allow it, this study may provide more insight in which model for early assisted discharge is more preferable.

Compared to commonly applied measures of satisfaction, a DCE quantifies the relative importance of the characteristics and levels. It assesses the trade-offs that respondents make and provides an estimate of the overall value of early assisted discharge treatments and the usual inpatient hospital care option.

Because common satisfaction questionnaires do not quantify the relative importance of attributes and levels, it is likely that patient preferences are not represented correctly in organising the process of care delivery. This may lead to suboptimal decision-making and may impair the acceptance of early assisted discharge.

To summarise, in this contribution we presented the research protocol of a multicentre RCT studying the effectiveness and cost-effectiveness of an early assisted discharge scheme for COPD exacerbations in the Netherlands 
Study Design | 57

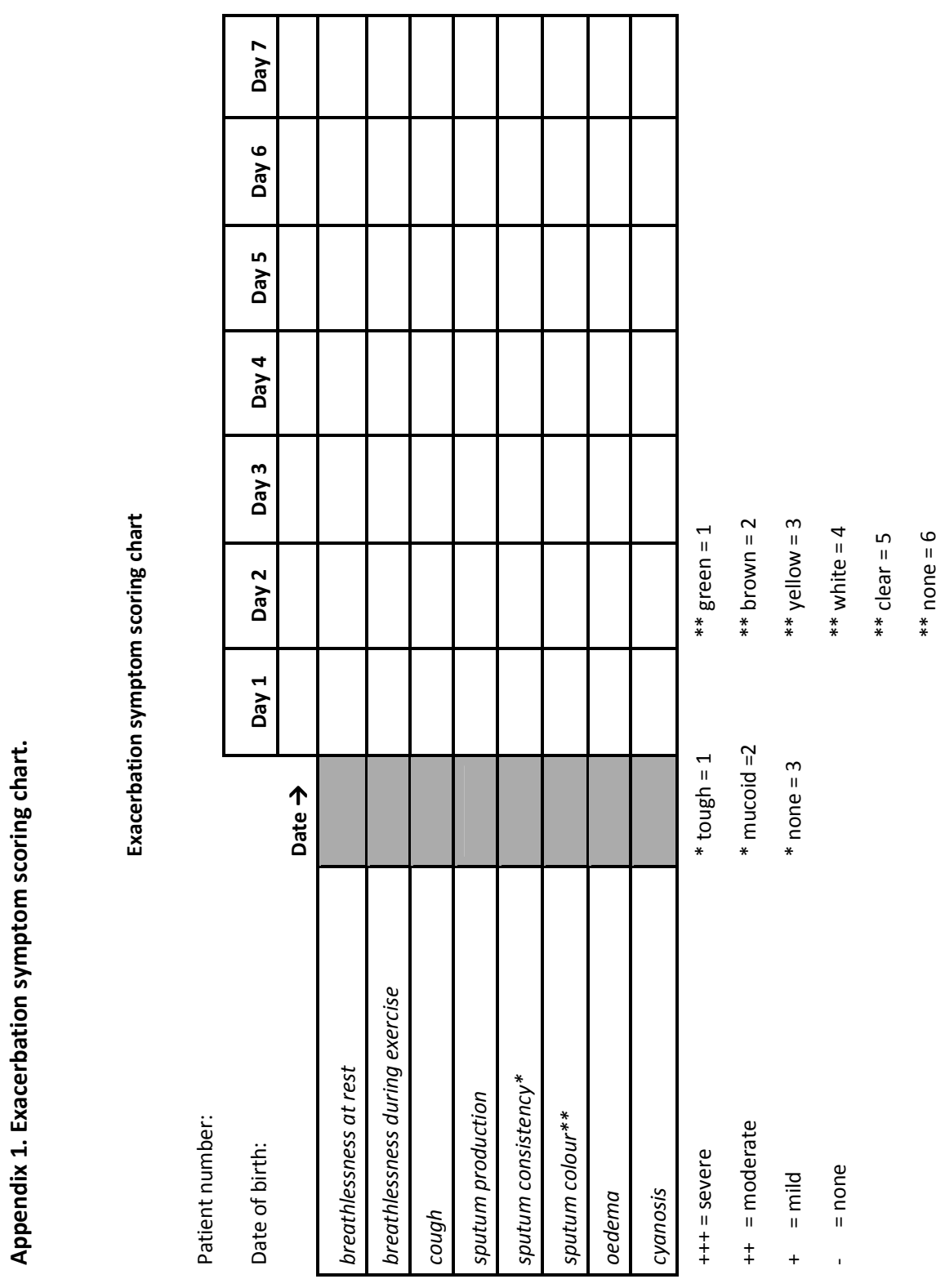




\section{References}

1. World Health Organization. World Health Statistics 2008.

Geneva: World Health Organization 2008.

2. Mannino DM, Buist AS. Global burden of COPD: risk factors, prevalence, and future trends. Lancet 2007;370:765-773.

3. Rabe KF, Hurd S, Anzueto A et al. Global strategy for the diagnosis, management, and prevention of chronic obstructive pulmonary disease: GOLD executive summary. Am J Respir Crit Care Med 2007;176:532-555.

4. Burge S, Wedzicha JA. COPD exacerbations: definitions and classifications. Eur Respir J Suppl 2003;41:46s-53s.

5. Wedzicha JA, Donaldson GC. Exacerbations of chronic obstructive pulmonary disease. Respir Care 2003;48:1204-1213.

6. Donaldson GC, Wedzicha JA. COPD exacerbations .1: Epidemiology. Thorax 2006;61:164-168.

7. Seemungal TA, Donaldson GC, Paul EA et al. Effect of exacerbation on quality of life in patients with chronic obstructive pulmonary disease. Am J Respir Crit Care Med 1998;157:1418-1422.

8. Wang $\mathrm{Q}$, Bourbeau J. Outcomes and health-related quality of life following hospitalization for an acute exacerbation of COPD. Respirology 2005;10:334-340.

9. Hoogendoorn M, Hoogenveen RT, Rutten-van Molken MP et al. Case-fatality of COPD exacerbations: a meta-analysis and statistical modeling approach. Eur Respir J 2010.

10. Almagro $P$, Barreiro B, Ochoa de EA et al. Risk factors for hospital readmission in patients with chronic obstructive pulmonary disease. Respiration 2006;73:311-317.

11. Saynajakangas $\mathrm{O}$, Kinnunen $\mathrm{T}$, Tuuponen $\mathrm{T}$ et al. Length of stay and interval to readmission in emergency hospital treatment of COPD. Age Ageing 2004;33:567-570.

12. Sullivan SD, Ramsey SD, Lee TA. The economic burden of COPD. Chest 2000;117:5S-9S.

13. Strassels SA, Smith DH, Sullivan SD et al. The costs of treating COPD in the United States. Chest 2001;119:344-352.

14. Johnson MK, Flanigan U, Fuld J et al. Hospital at home services for acute exacerbation of chronic obstructive pulmonary disease: a survey of British practice. Health Bull (Edinb ) 2001;59:163-170.

15. Quantrill SJ, Lowe D, Hosker HS et al. Survey of early discharge schemes from the 2003 UK National COPD Audit. Respir Med 2007;101:1026-1031.

16. Ram FS, Wedzicha JA, Wright $J$ et al. Hospital at home for acute exacerbations of chronic obstructive pulmonary disease. Cochrane Database Syst Rev 2003;CD003573.

17. Shepperd S, Doll H, Broad J et al. Early discharge hospital at home. Cochrane Database Syst Rev 2009;CD000356.

18. Aimonino RN, Tibaldi V, Leff B et al. Substitutive "hospital at home" versus inpatient care for elderly patients with exacerbations of chronic obstructive pulmonary disease: a prospective randomized, controlled trial. J Am Geriatr Soc 2008;56:493-500.

19. Cotton MM, Bucknall CE, Dagg KD et al. Early discharge for patients with exacerbations of chronic obstructive pulmonary disease: a randomized controlled trial. Thorax 2000;55:902-906.

20. Davies L, Wilkinson M, Bonner S et al. "Hospital at home" versus hospital care in patients with exacerbations of chronic obstructive pulmonary disease: prospective randomised controlled trial. BMJ 2000;321:1265-1268.

21. Diaz LS, Gonzalez LF, Gomez Mendieta MA et al. [Evaluation of a home hospitalization program in patients with exacerbations of chronic obstructive pulmonary disease]. Arch Bronconeumol 2005;41:5-10.

22. Hernandez C, Casas A, Escarrabill J et al. Home hospitalisation of exacerbated chronic obstructive pulmonary disease patients. Eur Respir J 2003;21:58-67.

23. Nicholson C, Bowler S, Jackson C et al. Cost comparison of hospital- and home-based treatment models for acute chronic obstructive pulmonary disease. Aust Health Rev 2001;24:181-187. 
24. Ojoo JC, Moon T, McGlone S et al. Patients' and carers' preferences in two models of care for acute exacerbations of COPD: results of a randomised controlled trial. Thorax 2002;57:167-169.

25. Skwarska E, Cohen G, Skwarski KM et al. Randomized controlled trial of supported discharge in patients with exacerbations of chronic obstructive pulmonary disease. Thorax 2000;55:907-912.

26. Callaghan S. ACTRITE: Acute Chest Triage Rapid Intervention Team. Accid Emerg Nurs 1999;7:4246.

27. Chetty $M$, MacKenzie $M$, Douglas $G$ et al. Immediate and early discharge for patients with exacerbations of chronic obstructive pulmonary disease: is there a role in "real life"? Int J Chron Obstruct Pulmon Dis 2006;1:401-407.

28. Davison AG, Monaghan M, Brown D et al. Hospital at home for chronic obstructive pulmonary disease: an integrated hospital and community based generic intermediate care service for prevention and early discharge. Chron Respir Dis 2006;3:181-185.

29. Gravil JH, Al-Rawas OA, Cotton MM et al. Home treatment of exacerbations of chronic obstructive pulmonary disease by an acute respiratory assessment service. Lancet 1998;351:1853-1855.

30. Murphy NM, Byrne CC, O'Neill SJ et al. An outreach programme for patients with an exacerbation of chronic obstructive pulmonary disease. Ir Med J 2003;96:137-140.

31. Sala E, Alegre L, Carrera $M$ et al. Supported discharge shortens hospital stay in patients hospitalized because of an exacerbation of COPD. Eur Respir J 2001;17:1138-1142.

32. Ansari K, Shamssain M, Farrow $M$ et al. Hospital-at-home care for exacerbations of chronic obstructive pulmonary disease: an observational cohort study of patients managed in hospital or by nurse practitioners in the community. Chron Respir Dis 2009;6:69-74.

33. Intermediate care--Hospital-at-Home in chronic obstructive pulmonary disease: British Thoracic Society guideline. Thorax 2007;62:200-210.

34. Frick KD, Burton LC, Clark R et al. Substitutive Hospital at Home for older persons: effects on costs. Am J Manag Care 2009;15:49-56.

35. Puig-Junoy J, Casas A, Font-Planells J et al. The impact of home hospitalization on healthcare costs of exacerbations in COPD patients. Eur J Health Econ 2007;8:325-332.

36. Shepperd S, Harwood D, Gray A et al. Randomised controlled trial comparing hospital at home care with inpatient hospital care. II: cost minimisation analysis. BMJ 1998;316:1791-1796.

37. Mushlin Al, Black ER, Connolly CA et al. The necessary length of hospital stay for chronic pulmonary disease. JAMA 1991;266:80-83.

38. van der Molen T, Willemse BW, Schokker S et al. Development, validity and responsiveness of the Clinical COPD Questionnaire. Health Qual Life Outcomes 2003;1:13.

39. Stichting Ketenkwaliteit COPD. Richtlijn Ketenzorg COPD [Guideline Transmural Care COPD]. Alphen aan de Rijn: Van Zuiden Communications B.V. 2005.

40. Kocks JW, Tuinenga MG, Uil SM et al. Health status measurement in COPD: the minimal clinically important difference of the clinical COPD questionnaire. Respir Res 2006;7:62.

41. Brooks R. EuroQol: the current state of play. Health Policy 1996;37:53-72.

42. Robinson BC. Validation of a Caregiver Strain Index. J Gerontol 1983;38:344-348.

43. Charlson ME, Pompei $\mathrm{P}$, Ales $\mathrm{KL}$ et al. A new method of classifying prognostic comorbidity in longitudinal studies: development and validation. J Chronic Dis 1987;40:373-383.

44. Schreurs PJG, van de Willige G, Brosschot JF, Tellegen B, Graus GMH. De Utrechtse Coping Lijst: UCL; Omgaan met problemen en gebeurtenissen. Lisse: Swets en Zeitlinger B.V. 1993.

45. Hood S, Parsons S, Fulop NJ. Shifting care: GP opinions of hospital at home. Br J Gen Pract 1999;49:221-222.

46. Lamers LM, Stalmeier PF, McDonnell J et al. [Measuring the quality of life in economic evaluations: the Dutch EQ-5D tariff]. Ned Tijdschr Geneeskd 2005;149:1574-1578.

47. DiCiccio TJ, Efron B. Bootstrap Confidence Intervals. Statistical Science 1996;11:189-212.

48. van Hout BA, Al MJ, Gordon GS et al. Costs, effects and C/E-ratios alongside a clinical trial. Health Econ 1994;3:309-319. 
49. Hensher DA, Rose JM, Greenough WB. Applied choice analysis: a primer. Cambridge: Cambridge University Press 2005.

50. Louviere JL, Hensher DA, Swait JD. Stated Choice Methods: Analysis and Applications. cambridge: Cambridge University Press 2000.

51. OECD Health Data. http://stat.oecd.org/index last accessed:

52. Wong AW, Gan WQ, Burns J et al. Acute exacerbation of chronic obstructive pulmonary disease: influence of social factors in determining length of hospital stay and readmission rates. Can Respir J 2008;15:361-364.

53. Centraal Bureau voor de Statistiek [Statistics Netherlands] (CBS). http://statline.cbs.nl/ StatWeb/publication/?DM=SLNL\&PA=71859NED\&D1=6,8\&D2=0\&D3=0,I\&D 4=106\&D5=926\&HDR=T\&STB=G1,G2,G3,G4\&VW=T last accessed: 15-1-2010.

54. Crockett AJ, Cranston JM, Moss JR et al. An association between length of stay and co-morbidity in chronic airflow limitation. Int J Qual Health Care 2000;12:41-46.

55. Mannino DM, Thorn D, Swensen A et al. Prevalence and outcomes of diabetes, hypertension and cardiovascular disease in COPD. Eur Respir J 2008;32:962-969.

56. The Royal College of Physicians of London, British Thoracic Society, and British Lung Foundation: Report of the National Chronic Obstructive Pulmonary Disease Audit 2008: clinical audit of COPD exacerbations admitted to acute NHS units across the UK [http://www.rcplondon.ac.uk/clinicalstandards/ceeu/Current-work/ncrop/Documents/Report-of-The-National-COPD-Audit-2008clinical-audit-of-COPD-exacerbations-admitted-to-acute-NHS-units-across-the-UK.pdf]. 


\section{EARLY ASSISTED DISCHARGE WITH COMMUNITY NURSING} FOR CHRONIC OBSTRUCTIVE PULMONARY DISEASE EXACERBATIONS: RESULTS OF A RANDOMISED CONTROLLED TRIAL

Cecile MA Utens, Lucas MA Goossens, Frank WJM Smeenk, Maureen PMH Rutten-van Mölken, Monique van Vliet, Maria W Braken, Loes MGA van Eijsden and Onno CP van Schayck 


\section{Abstract}

Objectives: To determine effectiveness of early assisted discharge for COPD exacerbations, with home care provided by generic community nurses, compared to usual hospital care.

Design: Prospective, randomised controlled, multi-centre trial with 3-months followup.

Setting: Five hospitals and 3 home care organisations in the Netherlands.

Participants: Patients admitted to the hospital with an exacerbation of Chronic Obstructive Pulmonary Disease. Patients with no or limited improvement of respiratory symptoms and patients with severe unstable comorbidities, social problems or those unable to visit the toilet independently were excluded and not randomised.

Intervention: Early discharge from hospital after 3 days inpatient treatment. Home visits by generic community nurses. Primary outcome measure was change in health status measured by the Clinical COPD Questionnaire (CCQ). Treatment failures, readmissions, mortality and change in generic health-related quality of life (HRQL) were secondary outcome measures.

Results: 139 patients were randomised. No difference between groups was found in change in CCQ score at day 7 (difference in mean change $-0.29(95 \% \mathrm{Cl}-0.61$ to 0.03$)$ ) or at 3 months (difference in mean change -0.04 ( $95 \% \mathrm{Cl}-0.49$ to 0.41 )). No difference was found in secondary outcomes. At day 7 there was a significant difference in change in generic HRQL, favouring usual hospital care.

Conclusion: While patients' disease-specific health status after 7 days treatment tended to be somewhat better in the usual hospital care group, the difference was small and not clinically relevant or statistically significant. After 3 months, the difference had disappeared. A significant difference in generic health-related quality of life at the end of the treatment had disappeared after 3 months and there was no difference in treatment failures, readmissions or mortality. Early assisted discharge with community nursing is feasible and an alternative to usual hospital care for selected patients with an acute COPD exacerbation.

Trial registration: NetherlandsTrialRegister NTR 1129 


\section{Introduction}

Chronic Obstructive Pulmonary Disease (COPD) is a chronic disease with high prevalence [1], mortality and morbidity [2,3]. Exacerbations of the disease have negative effects on patient outcomes [4-6] and are the main cause for hospitalisation [7]. Hospitalisations are not only the main cost driver in COPD, they also put pressure on scarce hospital beds, especially during winters [8]. Several studies have shown that some patients with an exacerbation, who would otherwise be admitted to the hospital, can be treated at home safely after examination in the emergency department or a short hospital admission [9-16]. This is called hospital-at-home. Hospital-at-home aims to avoid admission, or reduce length of stay (early assisted discharge schemes). Previous studies found no differences in readmissions, mortality and disease-specific quality of life between hospital-at-home and usual hospital care [9-11,15,16]. Most published hospital-at-home studies originate from the United Kingdom and Spain, where this service is mainly provided by hospital-based respiratory nurses who visit patients at home. Davison et al. [17] and Nicholson et al. [18] suggested the use of non-specialised 'generic' community nursing teams for home supervision to increase the capacity of hospital-at-home schemes.

The Netherlands has a nation-wide, good infrastructure for community nursing, which could be used for hospital-at-home. Therefore we designed an early assisted discharge hospital-at-home scheme for COPD exacerbations, mainly operated by generic community nurses who performed the home visits [19]. Main objective of the GO AHEAD study (GO AHEAD is the acronym for Assessment Of Going Home under Early Assisted Discharge) was to determine the effectiveness and cost-effectiveness of early assisted discharge followed by community-based nursing care at home. In addition, evaluation of patient satisfaction and preferences, carer strain and preferences and an evaluation among professional care providers was performed. The focus of this paper is on the effectiveness of early assisted discharge, with the Clinical COPD Questionnaire (CCQ) as the primary outcome measure. In addition, treatment failures, readmissions, mortality and generic quality of life were assessed as secondary outcomes.

\section{Methods}

GO AHEAD was a randomised controlled trial comparing usual hospital care with early assisted discharge for COPD exacerbations. Five hospitals and 3 home care organisations participated. Treatment consisted of 7 days in-hospital care as usual or 3 days in-hospital treatment followed by 4 days care at home. Patients were followed until 3 months after randomisation. 
All patients admitted to 1 of the participating hospitals with a COPD exacerbation, as diagnosed by the reviewing physician, were screened for potential eligibility on their first day of admission according to the inclusion and exclusion criteria (table 1). On day 3 of admission, clinical stability was assessed in patients who gave written informed consent (see randomisation criteria in table 1). For each hospital separately, participating patients were randomised on day 3 of admission, in a 1:1 ratio using a block-size of 6 . Randomisation was performed by the study nurses. The randomisation sequence was computer-generated a priori by an independent researcher. Allocation sequence was placed in sealed envelopes. The study was approved by the Ethics Committee of the Catharina Hospital, the Netherlands, approval number M07-1755.

\section{Table 1 Inclusion and exclusion criteria (applied at admission) and randomisation criteria} (applied at day 3 of admission).

\begin{tabular}{|c|c|}
\hline Inclusion criteria (checked on day 1) & Exclusion criteria (checked on day 1) \\
\hline Age $\geq 40$ years & $\begin{array}{l}\text { Major uncontrolled comorbidity, including } \\
\text { pneumonia that is prominent, heart failure that is } \\
\text { prominent or acute changes on elctro cardiogram } \\
\text { and (suspected) underlying malignancy }\end{array}$ \\
\hline Competent to give informed consent & $\begin{array}{l}\text { Mental disability, including dementia, impaired level } \\
\text { of consciousness and acute cnfusion }\end{array}$ \\
\hline $\begin{array}{l}\text { Diagnosed with COPD. COPD was defined as at least } \\
\text { GOLD stage I and } 10 \text { pack years of smoking }\end{array}$ & $\begin{array}{l}\text { Living outside care region of the home care } \\
\text { organisation }\end{array}$ \\
\hline Hospitalisation for COPD exacerbation & Inability to understand the program \\
\hline & $\begin{array}{l}\text { Indication for admission to intensive care unit or for } \\
\text { non invasive ventilation }\end{array}$ \\
\hline & Active alcohol and/or drug abuse \\
\hline & Insufficient availability of informal care at home \\
\hline \multicolumn{2}{|l|}{ Randomisation criteria (checked on day 3 ) } \\
\hline \multicolumn{2}{|l|}{ Completed Informed Consent on day 3 of admission } \\
\hline $\begin{array}{l}\text { Acceptable general health: } \\
\text { Decrease physical complaints } \\
\text { Non dependency of therapies that cannot be given at } \\
\text { oxygen) } \\
\text { Being able to visit toilet independently }\end{array}$ & ome (intravenous therapy and newly prescribed \\
\hline \multicolumn{2}{|c|}{$\begin{array}{l}\text { Normal or moderately increased blood sugar levels, defined as } \leq 15 \mathrm{mmol} / \mathrm{L} \text { or } \geq 15 \mathrm{mmol} / \mathrm{L} \text {, but patient is } \\
\text { capable to regulate blood sugar levels independently }\end{array}$} \\
\hline $\begin{array}{l}\text { Respiratory complaints of dyspnoea, wheezing and rh } \\
\text { admission }\end{array}$ & hi must have decreased in comparison with day of \\
\hline
\end{tabular}

During the first 3 days of the admission all patients were treated in the hospital according to the study protocol [19]. Treatment consisted of systemic corticosteroids, nebulised bronchodilators and antibiotics and oxygen upon indication. Exacerbation symptoms were scored each day. Physiotherapists visited all patients for instruction of breathing and coughing techniques. On the fourth day of admission all randomised patients switched to oral medication and metered dosed inhalations. Patients randomised to early assisted discharge were discharged home on the fourth day of admission and further treated at home. Community nurses visited or contacted the 
patient at least once daily on the day of discharge and the 3 consecutive days. They continued to score exacerbation symptoms and provided reassurance and counselling. Furthermore, medication compliance and inhalation techniques were addressed. Community nurses had the highest levels of generic nursing training in the Netherlands. No additional training was provided for the trial. The nurses could contact the hospital to discuss the patient's condition. If necessary, patients were readmitted to the hospital. For patients a 24-hour telephone access to the hospital respiratory ward was installed for emergencies.

Patients in the usual hospital care group received care as usual at the discretion of the hospital staff. General practitioners were informed about the patient's participation in the trial and the discharge date. Clinical responsibility during home care remained with the respiratory physician. A detailed description of the research protocol and the early assisted discharge intervention has been published previously [19].

Primary outcome was the change in CCQ scores between baseline ( $\mathrm{TO}=$ day 3 of admission) and the end of the supervised treatment ( $T+4$ days). The CCQ is a diseasespecific questionnaire measuring health status [20]. It consists of 10 questions in 3 domains: symptoms, functional state and mental state, resulting in a overall, continuous score varying from 6 (worst score) to 0 (best score) [20]. In order to produce a valid overall score, 3,3, and 2 questions on the symptoms domain, functional state and mental state domain, respectively, need to be answered. The CCQ has proved to be responsive to change. The minimal clinical important difference is 0.4 [21]. Secondary outcomes were: 1) change in CCQ scores between baseline and 3 months after randomisation ( $T+90$ days); 2 ) number of treatment failures (i.e. either death or clinical deterioration leading to prolonged hospital stay beyond the standardised 7 days (usual hospital care) or death or readmission during the 4 days treatment at home (early discharge)); 3) mortality and 4) readmissions during the 3month follow-up; and 5) generic health-related quality of life measured by the EuroQol-5D (EQ-5D)[22] at baseline, $T+4$ days and $T+90$ days. Utilities were calculated using the Dutch value set [22]. Higher scores represent better generic quality of life.

\section{Statistical analysis}

To detect a difference of 0.4 in CCQ change scores between the 2 groups, in favour of the early discharge group, with a power of 0.80 and alpha of 0.05 , with a standard deviation in the usual hospital care group of 0.922 and 0.988 in the early assisted discharge group, the required sample size was 165 [19]. Change in CCQ scores and EQ5D scores was analysed using a linear repeated measures model with correlated errors. An unstructured covariance matrix for the residuals was used. Backward selection of covariates was applied. In addition to time (i.e. measurement at T+4 days, 
end of treatment, and $T+90$ days, end of follow-up), the interaction of time and treatment, the following variables were tested: baseline CCQ or EQ-5D score, treatment centre, age, gender, comorbidity, smoking status, living situation, availability informal caregiver, presence of home care prior to admission, course of oral corticosteroids and/or antibiotics prior to admission. Variables were retained in the model if their exclusion led to a $10 \%$ change in the estimated treatment effect [23]. For the analysis of CCQ scores, only baseline score was included in the final model. For the analysis of EQ-5D scores, baseline score, comorbidity and gender were included. Results are presented as mean differences in change and $95 \%$ confidence intervals $(95 \% \mathrm{Cl})$. Numbers of patients with treatment failures, readmissions and mortality were analysed using multiple logistic regression analysis. Numbers of readmissions per patient in each group were analysed in a Poisson regression. Time to readmission was analysed with a Cox proportional hazards model. Results are presented as odds ratios (OR) or hazard ratios (HR) with $95 \% \mathrm{Cl}$. Again, backward selection was used to select covariates. Only baseline CCQ score was retained in the models. The significance level for a difference between treatment groups was set at $p \leq 0.05$. All analyses were performed using the Statistical Package for Social Sciences (SPSS), version 17.0, IBM.

\section{Results}

In total, 1371 patients were screened for eligibility between November 2007 and March 2011, of whom 508 met the criteria for eligibility on day 1. Figure 1 shows an overview of the patient flow during the trial from hospital admission to the end of the follow-up. Three patients in the early assisted discharge group and 7 in the usual hospital care group were not satisfied with the allocated place of treatment and withdrew consent immediately after randomisation. The total dropout over the study period was $16 \%, 25 \%$ in the usual hospital care group and $10 \%$ in the early assisted discharge group. Baseline CCQ scores of patients dropping out were not different from those who completed the study, but they did have more comorbidities. At T+4 days 118 of 129 still participating patients produced a valid overall score on the CCQ and were included in the analysis. The other patients did not withdraw consent and continued to participate in the study in order to contribute to the other analyses and to produce a valid score at other measuring points. This approach fits with the intention-to-treat principle and the repeated measures analysis. At T+90 days, 101 of 115 patients produced a valid overall CCQ score. Table 2 shows the baseline characteristics of randomised patients by treatment group. These were comparable across the groups. At end of the follow-up period lung function testing was performed by which classification of disease severity according to the GOLD criteria [2] could be made (see table 3). 


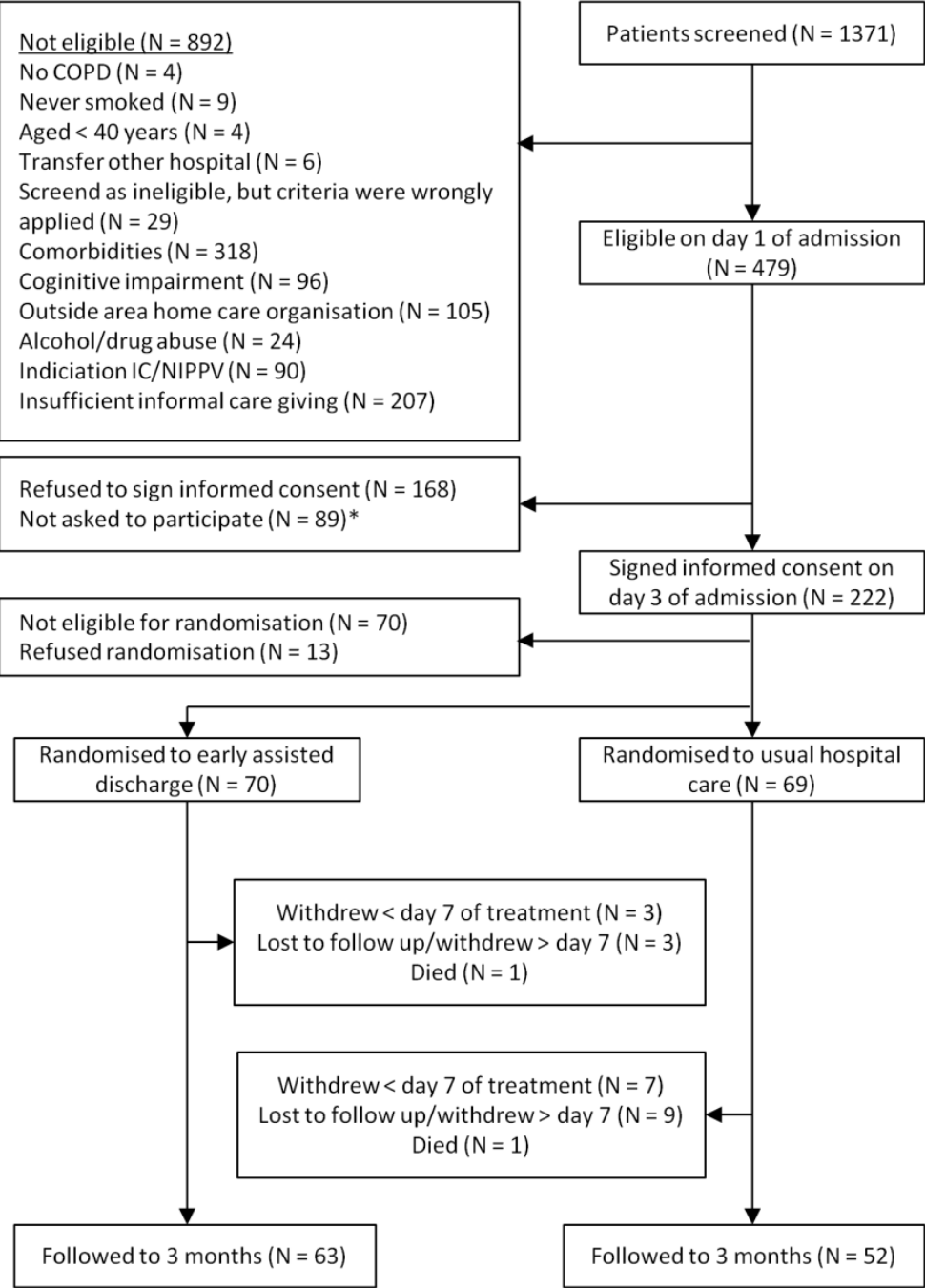

* Not asked to participate because of logistical reasons (e.g. no study staff available or patient not admitted to respiratory ward)

Figure 1. Patient flow through study. 
Table 2. Baseline characteristics and treatment at admission. Values represent mean (SD), unless stated otherwise.

\begin{tabular}{|c|c|c|}
\hline Characteristic & $\begin{array}{l}\text { Usual hospital care } \\
\qquad(\mathrm{N}=69)\end{array}$ & $\begin{array}{c}\text { Early assisted } \\
\text { discharge }(\mathrm{N}=70)\end{array}$ \\
\hline Age (years) & $67.8(11.3)$ & $68.3(10.3)$ \\
\hline Men $\mathrm{n}(\%)$ & $38(55.1)$ & $48(68.6)$ \\
\hline \multicolumn{3}{|l|}{ Smoking history: } \\
\hline Current smokers n (\%) & $27(39.1)$ & 23 (32.9) \\
\hline Pack years, median & 37 & 44 \\
\hline inter quartile range & 36.9 & 26.7 \\
\hline Body Mass Index $\left(\mathrm{kg} / \mathrm{m}^{2}\right)$ & $25.6(4.3)$ & $25.0(5.1)$ \\
\hline Charlson comorbidity score $[30]^{\dagger}$ & $1.68(1.1)$ & $1.74(1.1)$ \\
\hline Comorbidity score of $1 \mathrm{n}(\%)$ & $42(60.0)$ & $38(54.0)$ \\
\hline Comorbidity score > $1 \mathrm{n}(\%)$ & $27(39.0)$ & $32(46.0)$ \\
\hline \multicolumn{3}{|l|}{ Living situation: } \\
\hline Living alone $\mathrm{n}(\%)$ & $21(30.4)$ & $22(31.4)$ \\
\hline Receiving care at home before admission $\mathrm{n}(\%)$ & $16(23.2)$ & $17(24.3)$ \\
\hline \multicolumn{3}{|l|}{ Treatment at admission: } \\
\hline Long term oxygen treatment $\mathrm{n}(\%)$ & $4(5.8)$ & $5(7.1)$ \\
\hline Oral steroids n (\%) & $5(7.2)$ & $10(14.3)$ \\
\hline $\begin{array}{l}\text { Course of oral steroids prior to } \\
\text { admission } n(\%)\end{array}$ & $34(50.0)$ & $35(50.7)$ \\
\hline Course antibiotics prior to admission $n(\%)$ & $31(45.6)$ & $32(46.4)$ \\
\hline Inhaled $\beta 2$-agonist (LABA) n (\%) & $9(13.0)$ & $7(10.0)$ \\
\hline Inhaled corticosteroid n (\%) & $3(12.0)$ & $3(15.0)$ \\
\hline Inhaled corticosteroid/LABA combination n (\%) & $44(63.7)$ & $50(71.4)$ \\
\hline \multicolumn{3}{|l|}{ Inhaled anticholinergic $\mathrm{n}(\%)$} \\
\hline Tiotropium & $31(44.9)$ & $36(51.4)$ \\
\hline Ipratropium & $12(17.4)$ & $13(18.6)$ \\
\hline $\begin{array}{l}\text { Followed rehabilitation program in year prior } \\
\text { to admission } n(\%)\end{array}$ & $10(14.9)$ & $12(17.4)$ \\
\hline Heart Rate (beats/minute) & $91.0(14.2)$ & $95.6(18.4)$ \\
\hline Arterial blood gas": & $\mathrm{N}=37$ & $\mathrm{~N}=42$ \\
\hline $\mathrm{pH}$ & $7.44(0.05)$ & $7.43(0.04)$ \\
\hline $\mathrm{pO}_{2}(\mathrm{mmHg})$ & $70.7(13.2)$ & $67.3(8.1)$ \\
\hline $\mathrm{pCO}_{2}(\mathrm{mmHg})$ & $37.2(6.2)$ & $39.1(5.3)$ \\
\hline Saturation & $94(2.5)$ & $94(3.6)$ \\
\hline
\end{tabular}

Table 3. Lung function testing at end of 3-month follow-up. Values represent mean (SD), unless stated otherwise.

\begin{tabular}{|l|c|c|}
\hline & Usual hospital care & $\begin{array}{c}\text { Early assisted } \\
\text { discharge }\end{array}$ \\
\hline Postbronchodilator FEV (litres) $_{\text {\% of predicted post bronchodilator FEV }}$ & $1.25(0.07)$ & $1.21(0.07)$ \\
\hline \% GOLD stage I, n (\%) & $50.29(2.71)$ & $45.20(2.13)$ \\
\hline \% GOLD stage II, n (\%) & $7(10.3)$ & $2(2.9)$ \\
\hline$\%$ GOLD stage III, n (\%) & $22(32.4)$ & $23(32.9)$ \\
\hline$\%$ GOLD stage IV, $\mathrm{n}(\%)$ & $28(41.2)$ & $31(44.3)$ \\
\hline
\end{tabular}


Table 4 shows the unadjusted CCQ scores at the different measuring points. At day 1 of admission average CCQ scores was 3.35 (1.08). At TO CCQ scores were 2.22 (0.97) for the usual hospital care group and 2.63 (1.06) for the early discharge group. Figure 2 shows the change in CCQ scores from T0, adjusted for baseline score. CCQ scores improved between T0 and $\mathrm{T}+4$ days for the usual hospital care group, and were almost stable for the early assisted discharge group, but there was no significant difference between the groups at $\mathrm{T}+4$ days (difference in mean change from $\mathrm{T} 00.29,95 \% \mathrm{Cl}-0.03$ to $0.61, p=0.078$ ). At $T+90$ days, CCQ scores of both groups scores were slightly higher in comparison to T0. There was no difference between the groups at 3 months (difference in mean change from T0 $0.04,95 \% \mathrm{Cl}-0.40$ to $0.49, \mathrm{p}=0.858$ ).

Table 4. Unadjusted CCQ total scores (SD) at each time of measurement by treatment group.

$\begin{array}{lcr}\text { Time of measurement } & \text { Usual hospital care } & \text { Early assisted disch } \\ \text { T- } 2 \text { days } & 3.21(1.07) & 3.49(1.07) \\ \text { T0 } & 2.22(0.97) & 2.63(1.06) \\ \text { T+ } 4 \text { days } & 2.00(1.09) & 2.55(1.21) \\ \text { T+ } 90 \text { days } & 2.41(1.14) & 2.70(1.32)\end{array}$

CCQ total score range is 0-6; 0 represents best possible score and 6 represents worst possible score

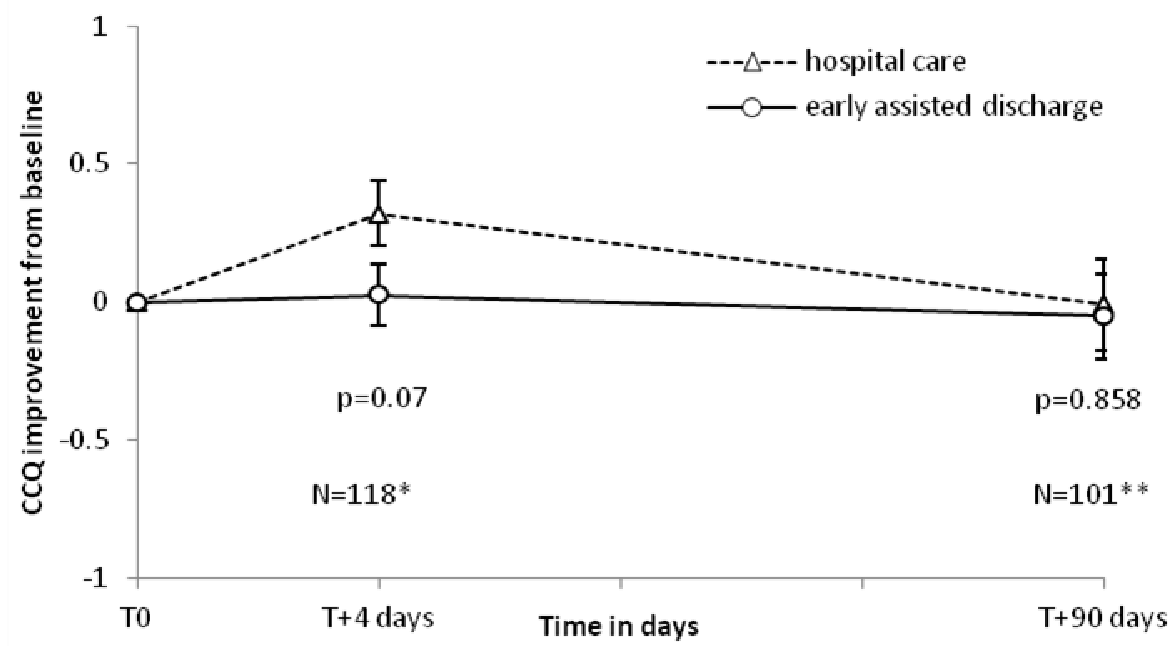

Error bars represent standard errors. P values based on repeated measures analysis, adjusted for baseline value.

*Number of patients at $\mathrm{T}+4$ days that completed questionnaire that produced valid total score; ${ }^{* *}$ Number of patients at $T+90$ days that completed questionnaire that produced valid total score

NOTE: for interpretation reason the sign of the CCQ has been reversed. Positve change in CCQ scores represents improvement in patient's condition, which is a decrease in CCQ scores

Figure 2. CCQ total score, differences in mean change from baseline. 
Treatment failed in 5 patients. One patient in the early discharge group needed readmission to the hospital because of deterioration of respiratory symptoms, before the end of the home treatment and 4 patients in the usual hospital care group required hospital admission beyond the 7 days that were stated in the protocol $(2$ because of deterioration of respiratory symptoms, 2 patients because of deterioration of general condition due to gastroenteritis). This difference was not significant (OR early discharge group $0.27,95 \% \mathrm{Cl} 0.026-2.70, \mathrm{p}=0.263$ ). Table 5 shows the number of readmissions during follow-up. Seventeen patients in each group had 1 or more readmission to the hospital of which 14 first readmissions were due to an exacerbation or other pulmonary indication (OR early discharge group $0.80,95 \% \mathrm{Cl} 0.36-1.79$, $\mathrm{p}=0.592$ ). There was no difference in the number of readmissions per patient between the groups, or in the total number of readmissions in each group. There was no difference in time to first readmission between the 2 groups (HR early discharge group $0.77,95 \% \mathrm{Cl} 0.39$ to $1.53, \mathrm{p}=0.461)$.

Table 5. Readmissions during follow-up. Values are numbers of patients (\%), unless stated otherwise.

\begin{tabular}{|c|c|c|}
\hline & Usual hospital care & Early assisted discharge \\
\hline Patients with readmission & $17(25)$ & $17(24)$ \\
\hline \multicolumn{3}{|l|}{ Patients with 1,2 or $\geq 3$ readmissions } \\
\hline 1 readmission & 11 & 12 \\
\hline 2 readmissions & 4 & 3 \\
\hline 3 or more readmissions & 2 & 2 \\
\hline Average (SD) time to first readmission in days & $61(36.5)$ & $59(33.8)$ \\
\hline
\end{tabular}

No patient died during the hospital or home treatment, but 1 patient from each group died during follow-up. Cause of death was unknown in 1 case (patient died during sleep at home) and an acute abdomen in the other. Both were not related to the trial.

EQ-5D utility scores (SD) at T0 were $0.713(0.22)$ for the usual hospital care group and $0.664(0.26)$ for the early assisted discharge group. Table 6 shows the mean changes and mean difference in change from baseline of EQ-5D utility. In the usual hospital care group, mean utility scores improved from T0 to $\mathrm{T}+4$ days and decreased to baseline at $\mathrm{T}+90$ days. In the early assisted discharge group mean utility scores remained close to baseline. The mean change in utility scores on $T+4$ days was significantly greater in the usual hospital care group. At $\mathrm{T}+90$ days this difference between treatment groups had disappeared. 
Table 6. Mean changes and mean differences in change for EQ-5D.

\begin{tabular}{|c|c|c|c|c|}
\hline & \multicolumn{2}{|c|}{ Mean change from baseline (SE) } & \multirow{2}{*}{$\begin{array}{c}\text { Adjusted mean }(95 \% \mathrm{Cl}) \\
\text { difference in change from } \\
\text { baseline* }\end{array}$} & \multirow[t]{2}{*}{$p$ value } \\
\hline Utility & $\begin{array}{c}\text { Usual } \\
\text { hospital care }\end{array}$ & $\begin{array}{c}\text { Early } \\
\text { assisted discharge }\end{array}$ & & \\
\hline $\mathrm{T}+4$ days $^{+}$ & $0.051(0.0261)$ & $-0.005(0.029)$ & 0.0746 (0.010 to 0.139$)$ & 0.024 \\
\hline$T+90$ days $^{\ddagger}$ & $-0.036(0.0447)$ & $0.008(0.039)$ & $-0.022(-0.116$ to 0.072$)$ & 0.639 \\
\hline \multicolumn{5}{|c|}{$\begin{array}{l}\text { * Results from repeated measures analysis, adjusted for baseline value; }{ }^{\dagger} \text { hospital care } \mathrm{N}=57 \text {, early discharge } \\
\mathrm{N}=61 ;{ }^{*} \text { hospital care } \mathrm{N}=47 \text {, early discharge } \mathrm{N}=54 \\
\text { SE: Standard Error; } 95 \% \mathrm{Cl}: 95 \% \text { Confidence Interval. }\end{array}$} \\
\hline
\end{tabular}

\section{Discussion}

This is the first randomised controlled trial that investigated the effectiveness of early assisted discharge for COPD exacerbations with supervision at home by community nurses. In addition, this is the first evaluation of early discharge for this disease in the Dutch health care system. While patients' disease-specific health status as expressed in the mean CCQ score after 7 days treatment tended to be somewhat better in the usual hospital care group, the difference was small, not clinically relevant and not statistically significant. After 3 months, the difference had disappeared. The same pattern was found in generic health-related quality of life measured with the EQ-5D, although this difference was statistically significant at the end of the supervised treatment. The difference had disappeared at the end of the 3-month follow up period. There was no difference in treatment failures, readmissions or mortality.

These study results confirm previously published positive results by Davison et al. [17] and Nicholson et al. [18], but these 2 studies were either not randomised [17] or included a small number of patients [18]. We found no significant difference in CCQ scores, which corresponds with the findings of Davies et al. [9] and Hernandez et al. [16], who found no differences in disease-specific quality of life measured with the St George's Respiratory Questionnaire. Furthermore, our results are in line with those of earlier studies involving specialised hospital-based nurses [9-12,15,16,24,25]. The readmission rate in our study was $25 \%$, which is comparable to the $30 \%$ in previously published studies [9-11]. Characteristics like age, smoking history and living situation of patients in our study were similar to those in studies from the United Kingdom [9-12] and to that of a survey on hospital-at-home services in British hospitals by Quantrill et al. [26].

Earlier studies did not measure the impact of hospital-at-home on generic healthrelated quality of life. We found a significant difference between the 2 groups, in favour of usual hospital care, at the end of the hospital and home treatment. This difference had disappeared after 3 months. The utility scores are in line with O'Reilly et 
al. [27], but they found much worse scores at admission than in our study, probably because we did not include patients with more severe exacerbations. Utility and CCQ scores in both groups follow the same pattern. The greater improvement in CCQ and EQ-5D scores of the usual hospital care group at the end of the hospital treatment in comparison to the early discharge group may reflect a true difference in recovery, in which case usual hospital care is the preferred treatment. However, an alternative explanation could be that patients who were discharged early were confronted with their symptoms and limitations earlier and more intensely when they tried to pick up normal life at home. Furthermore, some patients have difficulties viewing hospital care followed by early discharge as 1 treatment period [28]. Expecting to be in a certain state at discharge, and experiencing this is not the case, might be expressed in worse scores on the CCQ and the EQ-5D.

In our trial multiple hospitals participated with different socioeconomic and geographic characteristics, which makes it likely that our sample is representative of eligible patients. The percentage of admissions initially considered to be eligible for early discharge at admission was similar to that of previous studies $( \pm 37 \%)$. Early discharge is possible when the exacerbation is the main problem and comorbidities are (relatively) stable. The percentage of patients living alone suggests that this is not an absolute reason for exclusion, provided that patients have a sufficiently functioning social support system. Still, $25 \%$ of screened patients were considered ineligible, because of living in a nursing home, overburden of informal caregiver(s) or living alone with insufficient social support. This suggests that social environment is an important factor when deciding for admission and (early) discharge. Finally, 37\% of screened patients was ineligible because of comorbidities.

Considering the very low number of treatment failures in the early discharge group it might be possible to relax the inclusion criteria and randomisation criteria. In our trial, criteria were applied very strictly for safety reasons, but more patients with comorbidities might be eligible in daily practice. Furthermore, the strict review and exclusion of patients at day 1 of admission (e.g. those treated with NIV), precluded patients from early discharge even if they had become eligible at day 3 of admission. Therefore, review of eligibility for early discharge should be performed after a few days of hospital treatment. Thirty percent of patients who consented to participate were not randomised because they showed insufficient recovery and/or were depending on oxygen supply. Unlike in the British hospital-at-home schemes, patients were not sent home with nebulisers or oxygen cylinders, unless these were already part of their treatment. Extension of the treatment possibilities at home may enable early discharge of patient with more severe disease. However, it would also require more expertise of the nursing staff supervising patients at home, which might 
currently not be present in community-based home care organisations. Future research should focus on determining which treatments can be safely provided at home, which treatments require the supervision of generic or specialised nurses and which criteria should be applied for selecting eligible patients. In addition, a direct comparison between early discharge with generic and early discharge with specialised nursing care would provide more information on which scheme is most safe and effective.

Our study has some limitations. Firstly, in total 139 patients were randomised, where a number of 165 was calculated to be needed to detect a difference of 0.4 in CCQ change scores between the 2 groups. A post-hoc power analysis with these 139 patients and the actual variances in CCQ scores showed that the power to detect a difference in change from baseline of 0.4 between the groups was $73 \%$ instead of $80 \%$, which was aimed for. We believe that this slight reduction in power does not have a substantial influence on our final results, because the difference between the groups was only 0.29. It is highly unlikely that this difference would have increased to the clinically relevant difference of 0.4 with an additional 26 patients. In previous randomised studies of early discharge in patients diagnosed with COPD numbers varied between 25 and 222, and only 15 to 35\% of admitted patients was randomised [9-12,16,29]. Secondly, our study was not an equivalence trial, which would determine best whether hospital care and early discharge care are equally effective. However, in order to demonstrate equal effectiveness with CCQ score, over 500 patients would have been needed, which is beyond what is attainable in this population. Thirdly, $16 \%$ of patients dropped out after randomisation. However, comparison of patients who dropped out with patients who completed the study only revealed more comorbidities for those who dropped out. CCQ scores were not different. Finally, due to the nature of the intervention, patients and health care staff could not be blinded to the allocated group.

In conclusion, we found no significant short-term or long-term differences in outcomes between early discharge and usual hospital care, except for generic health-related quality of life at the end of treatment ( $T+4$ days). Early assisted discharge with home visits by community nurses can reduce length of hospital stay for a selected group of patients admitted with a COPD exacerbation and is an alternative to usual hospital care. The decision to implement early assisted discharge with community nursing does not only depend on the results of the effectiveness analysis. Costs and costeffectiveness evaluations are of high importance as well. An economic evaluation is currently being performed and results will be published separately. 


\section{References}

1. Buist AS, McBurnie MA, Vollmer WM et al. International variation in the prevalence of COPD (the BOLD Study): a population-based prevalence study. Lancet 2007;370:741-750.

2. Rabe KF, Hurd S, Anzueto A et al. Global strategy for the diagnosis, management, and prevention of chronic obstructive pulmonary disease: GOLD executive summary. Am J Respir Crit Care Med 2007;176:532-555.

3. Lopez AD, Shibuya K, Rao C et al. Chronic obstructive pulmonary disease: current burden and future projections. Eur Respir J 2006;27:397-412.

4. Seemungal TA, Donaldson GC, Paul EA et al. Effect of exacerbation on quality of life in patients with chronic obstructive pulmonary disease. Am J Respir Crit Care Med 1998;157:1418-1422.

5. Donaldson GC, Seemungal TA, Bhowmik A et al. Relationship between exacerbation frequency and lung function decline in chronic obstructive pulmonary disease. Thorax 2002;57:847-852.

6. Esteban C, Quintana JM, Moraza J et al. Impact of hospitalisations for exacerbations of COPD on health-related quality of life. Respir Med 2009;103:1201-1208.

7. Toy EL, Gallagher KF, Stanley EL et al. The economic impact of exacerbations of chronic obstructive pulmonary disease and exacerbation definition: a review. COPD 2010;7:214-228.

8. Jordan RE, Hawker JI, Ayres JG et al. Effect of social factors on winter hospital admission for respiratory disease: a case-control study of older people in the UK. Br J Gen Pract 2008;58:400402.

9. Davies L, Wilkinson $\mathrm{M}$, Bonner $\mathrm{S}$ et al. "Hospital at home" versus hospital care in patients with exacerbations of chronic obstructive pulmonary disease: prospective randomised controlled trial. BMJ 2000;321:1265-1268.

10. Cotton MM, Bucknall CE, Dagg KD et al. Early discharge for patients with exacerbations of chronic obstructive pulmonary disease: a randomized controlled trial. Thorax 2000;55:902-906.

11. Skwarska E, Cohen G, Skwarski KM et al. Randomized controlled trial of supported discharge in patients with exacerbations of chronic obstructive pulmonary disease. Thorax 2000;55:907-912.

12. Ojoo JC, Moon T, McGlone S et al. Patients' and carers' preferences in two models of care for acute exacerbations of COPD: results of a randomised controlled trial. Thorax 2002;57:167-169.

13. British Thoracic Society. Intermediate care--Hospital-at-Home in chronic obstructive pulmonary disease: British Thoracic Society guideline. Thorax 2007;62:200-210.

14. Diaz LS, Gonzalez LF, Gomez Mendieta MA et al. [Evaluation of a home hospitalization program in patients with exacerbations of chronic obstructive pulmonary disease]. Arch Bronconeumol 2005;41:5-10.

15. Gravil JH, Al-Rawas OA, Cotton MM et al. Home treatment of exacerbations of chronic obstructive pulmonary disease by an acute respiratory assessment service. Lancet 1998;351:1853-1855.

16. Hernandez C, Casas A, Escarrabill J et al. Home hospitalisation of exacerbated chronic obstructive pulmonary disease patients. Eur Respir J 2003;21:58-67.

17. Davison AG, Monaghan M, Brown D et al. Hospital at home for chronic obstructive pulmonary disease: an integrated hospital and community based generic intermediate care service for prevention and early discharge. Chron Respir Dis 2006;3:181-185.

18. Nicholson C, Bowler S, Jackson C et al. Cost comparison of hospital- and home-based treatment models for acute chronic obstructive pulmonary disease. Aust Health Rev 2001;24:181-187.

19. Utens CM, Goossens LM, Smeenk FW et al. Effectiveness and cost-effectiveness of early assisted discharge for Chronic Obstructive Pulmonary Disease exacerbations: the design of a randomised controlled trial. BMC Public Health 2010;10:618.

20. van der Molen T, Willemse BW, Schokker S et al. Development, validity and responsiveness of the Clinical COPD Questionnaire. Health Qual Life Outcomes 2003;1:13.

21. Kocks JW, Tuinenga MG, Uil SM et al. Health status measurement in COPD: the minimal clinically important difference of the clinical COPD questionnaire. Respir Res 2006;7:62. 
22. Lamers LM, McDonnell J, Stalmeier PF et al. The Dutch tariff: results and arguments for an effective design for national EQ-5D valuation studies. Health Econ 2006;15:1121-1132.

23. Rothman KJ, Greenland S, Lash TL. Modern Epidemiology (3rd edition). Philidelphia: Lippincott Williams \& Wilkins 2008.

24. Ansari K, Shamssain M, Farrow M et al. Hospital-at-home care for exacerbations of chronic obstructive pulmonary disease: an observational cohort study of patients managed in hospital or by nurse practitioners in the community. Chron Respir Dis 2009;6:69-74.

25. Sala E, Alegre L, Carrera $M$ et al. Supported discharge shortens hospital stay in patients hospitalized because of an exacerbation of COPD. Eur Respir J 2001;17:1138-1142.

26. Quantrill SJ, Lowe D, Hosker HS et al. Survey of early discharge schemes from the 2003 UK National COPD Audit. Respir Med 2007;101:1026-1031.

27. O'Reilly JF, Williams AE, Rice L. Health status impairment and costs associated with COPD exacerbation managed in hospital. Int J Clin Pract 2007;61:1112-1120.

28. Clarke A, Sohanpal R, Wilson G et al. Patients' perceptions of early supported discharge for chronic obstructive pulmonary disease: a qualitative study. Qual Saf Health Care 2010;19:95-98.

29. Aimonino RN, Tibaldi V, Leff B et al. Substitutive "hospital at home" versus inpatient care for elderly patients with exacerbations of chronic obstructive pulmonary disease: a prospective randomized, controlled trial. J Am Geriatr Soc 2008;56:493-500.

30. Charlson ME, Pompei P, Ales KL et al. A new method of classifying prognostic comorbidity in longitudinal studies: development and validation. J Chronic Dis 1987;40:373-383 



\section{COST-EFFECTIVENESS OF EARLY ASSISTED DISCHARGE FOR COPD EXACERBATIONS IN THE NETHERLANDS}

Lucas MA Goossens, Cecile MA Utens, Frank, WJM Smeenk, Onno CP van Schayck, Monique van Vliet, Wiel Seezink, Walter van Litsenburg, Maria W Braken, Maureen PMH Rutten-van Mölken 


\section{Abstract}

Objectives: Hospital admissions for exacerbations of chronic obstructive pulmonary disease (COPD) are the main cost drivers of the disease. An alternative is to treat suitable patients at home instead of in the hospital. This paper reports on the costeffectiveness and cost-utility of early assisted discharge (EAD) in the Netherlands.

Methods: In the multi-centre randomised controlled GO AHEAD trial ( $n=139), 1$ group received 7 days of inpatient hospital treatment (HOSP), and 1 group was discharged after 3 days and treated at home by community nurses for 4 days. Health care resource use, productivity losses and informal care were recorded in cost diaries. Microcosting was performed for inpatient day costs.

Results: Seven days after admission, mean change from baseline Clinical COPD Questionnaire (CCQ) score was better for HOSP, but not statistically significantly: 0.29 (95\% Cl: $-0.04 ; 0.61)$. The difference in the probability of having a clinically relevant improvement was significant, in favour of HOSP: $19.0 \%$-point (0.5\%; 36.3\%). After 3months follow-up, differences in effectiveness had almost disappeared. The difference in quality-adjusted life years (QALYs) was $0.0054(-0.021 ; 0.0095)$. From a health care perspective, EAD was cost-saving: - $€ 244$ (treatment phase, $\mathrm{Cl}:-315$; $-€ 168$ ) and $-€ 168$ (3 months, $\mathrm{Cl}:-€ 1253$; €922). Societal perspective: $€ 65$ (treatment phase, $\mathrm{Cl}:-€ 152$; $€ 25)$ and $+€ 908$ ( 3 months, $\mathrm{Cl}:-€ 553$; €2296). The costs per QALY for HOSP vs. EAD were $€ 31,111$ from a health care perspective. From a societal perspective, HOSP was dominant.

Conclusions: No clear evidence was found to conclude that either treatment was more effective or less costly. 


\section{Introduction}

Hospital admissions for exacerbations of chronic obstructive pulmonary disease (COPD) are the main drivers of the high treatment costs for the disease [1-5]. These admissions put great pressure on scarce hospital beds of respiratory wards, especially during winter months [6]. From an economic and organisational point of view, it may be attractive to treat suitable patients at home instead of in the hospital, if this is medically possible and responsible.

Treatment schemes in which patients are treated and supervised at home, as an alternative to usual hospital treatment, are often called hospital-at-home $[7,8]$. These schemes may either avoid admission completely or discharge patients from the hospital early and continue treatment at home. According to British guidelines, approximately $30 \%$ of admissions for a COPD exacerbation could be eligible for these schemes [9].

Studies on the costs and cost-effectiveness of hospital-at-home services for patients with a COPD exacerbation have shown varying results. Shepperd et al. [10] concluded that a particular scheme in England led to significantly higher costs, while Skwarska et al. [11] found cost savings in a different scheme in the same country. Significant cost savings were reported for hospital-at-home services in Australia [12], Spain [13,14] and the United States [15]. The results in an Italian study were inconclusive [16]. Although these studies were performed in different countries and in different health care systems, they had some aspects in common. They all took a health care perspective; the costs or value of resources used outside of the health care sector were not taken into account. Secondly, the length of treatment was variable in each study. Physicians and/or nurses decided on the timing of discharge from the hospital or from treatment at home, depending on the patient's recovery.

The current paper reports on the cost-effectiveness and cost-utility of an early discharge scheme that is different in the 2 aspects mentioned above. The study was performed in the Netherlands as part of the GO AHEAD trial (ㅅssessment of GOing Home under Early Assisted Discharge). In this multi-centre randomised controlled trial, 1 group of COPD patients received usual inpatient hospital treatment for 7 days. The other group was discharged after 3 days and was treated and supervised at home for the remaining 4 days. The Netherlands have a nation-wide infrastructure for community nursing provided by home care organisations. Dutch hospitals do not deliver health care in the community. Therefore, the care at home in this trial was provided by community-based home care organisations which employ mostly generically-trained nurses and few specialised nurses. The clinical results of this study have been presented in detail elsewhere [17]. 


\section{Methods}

\section{Study design}

The GO AHEAD study was a randomised, controlled, multi-centre trial comparing 2 management strategies for patients admitted to the hospital for a COPD exacerbation [18]. After 3 days of usual hospital treatment patients were randomised to be either discharged home with home care or to continue hospital treatment. The total duration of this initial treatment phase was 7 days for both groups, unless the treatment failed and patients had to be either re-admitted or had to prolong their hospital stay. Patients were followed for 3 months, with outcome measurements scheduled after 7 days and 3 months.

\section{Patients}

Patients admitted to 1 of the participating hospitals because of an exacerbation of their COPD, were screened for eligibility. On the day of admission they were considered potentially eligible for early discharge if they met the following inclusion criteria: age $\geq 40$, sufficiently competent to consider informed consent, and a smoking history of $\geq 10$ pack years. In order to be randomised on day 3 of the admission, their physical and respiratory complaints (dyspnoea, wheezing and rhonchi) had to be improved compared to the day of admission, they should not be depending on therapies that could not be administered at home and they should be able to visit the toilet independently. Also, blood sugar level had to be normal or only moderately increased ( $\leq 15 \mathrm{mmol} / \mathrm{L}$ or regulated independently at home).

Exclusion criteria were: major uncontrolled comorbidity, mental disability, active alcohol or drug abuse, inability to understand the program, living outside the region of the participating home care organisation, indication for admission to the intensive care unit or non-invasive ventilation and insufficient availability of informal care at home.

\section{Intervention}

During the first 3 days of the treatment all patients received usual hospital care. The pharmacological part of this treatment consisted of systemic corticosteroids (10 days), nebulised bronchodilators, subcutaneous thrombosis prophylaxis and stomach protection. If necessary, oxygen therapy and/or antibiotics were prescribed. Nonpharmacologic usual care consisted of physiotherapy for all patients for breathing- and coughing instructions and dietary advice if indicated (Body Mass Index $\leq 21$ or $10 \%$ unintended weight loss in the 6 months prior to admission).

Patients randomised to the early assisted discharge group were transferred home on day 4 of admission. Treatment was continued at home and supervised by nurses. Main objective of the supervision of the home treatment was the observation of the patient's recovery and providing counselling and reassurance to the patient and the 
primary informal caregiver. The nurses also addressed medication compliance and inhalation techniques, provided support in applying the breathing and coughing techniques that patients learned during the first 3 days of hospital care. If applicable, they provided support in adhering to dietary advice. In case COPD symptoms suddenly worsened, the patients could contact the respiratory hospital ward directly and roundthe-clock. The general practitioner was informed about the early discharge, but the respiratory physician of the hospital kept the final responsibility.

\section{Effects}

The following outcome measures were used: 1) the incremental change from day of randomisation in Clinical COPD Questionnaire (CCQ) score at day 7 and 3 months, 2) the incremental proportion of patients with a clinically relevant improvement in CCQ score (i.e. $\geq 0.4$ units) [19] on day 7 and at 3 months, and 3) the gain in qualityadjusted life years (QALYs) after 3 months using utilities as measured by the EQ-5D questionnaire using the Dutch tariff for the valuation of health states [20]. The CCQ score can range from 0 (best possible score) to 6 (worst possible score). Based on the Dutch tariff, the EQ-5D score can range from -0.329 (worst possible utility) to 1 (perfect health).

\section{Costs}

Costs were calculated from 2 perspectives: the health care perspective and the societal perspective. The former included only the direct health care costs within 3 months after randomisation. The latter includes direct health care costs, non-health care costs and costs of productivity loss of patients and caregivers for the 3-months follow-up period. This is in accordance with the Dutch recommendations that economic evaluations should be conducted from a societal perspective [21].

In the 7-day treatment phase, the duration of hospital admission and the amount of community nursing care were recorded. Patients randomised to early discharge, were asked to record all additional formal health care as well as informal care and days of absence from paid work of the informal caregiver in a 4-day cost diary. During the follow-up phase, the following types of resource use were recorded in monthly cost diaries: number and length of hospital readmissions, number of visits to the emergency department, number of contacts with pulmonologist and other specialist physicians, general practitioner, respiratory nurse, home care, dietician, physiotherapist, and social worker, number of ambulance rides and medication use. Direct non-health care costs recorded in these diaries were paid and unpaid domestic help, including the time spent by the primary informal caregiver. Indirect costs were costs of productivity losses. The days a patient and the informal caregiver were absent from paid work were recorded. 
Costs (in 2009 Euros) were calculated by multiplying the volume of resource use (such as hospital days, physician visits, time spent by formal and informal caregivers) by a cost per unit that includes total, not marginal costs. Except for inpatient hospital days, standard unit costs from the Dutch Manual for Costing Studies [22] were used for all health care resource use. Unit costs are presented in table 1. Medication prices were based on the official list prices of drugs obtained from retail pharmacists which were published on the internet [21], including value added tax and increased by a standard prescription reimbursement for the pharmacist. Costing for permanent medication was based on 1 prescription per 3 months.

Table 1. Unit costs (Euros 2009) [22].

\begin{tabular}{|ll}
\hline Type of resource & Unit costs \\
\hline GP, consultation & 28 \\
\hline GP, home visit & 43 \\
\hline GP, phone call & 14 \\
\hline Specialist, consultation & 64 \\
\hline Specialist, hour & 135.50 \\
\hline Resident, hour & 27.85 \\
\hline Nurse in hospital, hour & 26.75 \\
\hline Physiotherapist, consult & 36 \\
\hline Dietician, consult & 27 \\
\hline Pulmonary nurse, consult & 36 \\
\hline Social worker & 36 \\
\hline Emergency room, visit & 151 \\
\hline Ambulance transport & 504 \\
\hline Community nurse, hour & 65 \\
\hline Domestic community care, per hour & 24 \\
\hline Informal care, hour & 12.5 \\
\hline Production loss, hour (informal caregiver)* & 28.28 \\
\hline Production loss, hour (patient)* & 29.72 \\
\hline Inpatient hospital day, standard price & 435 \\
\hline *Costs per hour of production loss is based on age- and sex-specific averages, which are different for \\
\hline patients and informal caregivers. & \\
\hline
\end{tabular}

\section{Costs of inpatient hospital days}

Costs for each inpatient hospital day were estimated using the microcosting methodology, which provides cost estimates that most accurately reflect actual costs by identifying cost components at the most detailed level [23,24]. First, during interviews with health care professionals participating in the trial, all steps in the treatment and nursing process were identified. Then, at the 2 hospitals which recruited the most patients, which were the Catharina Hospital in Eindhoven and Atrium Medical Centre in Heerlen, pulmonologists, residents, nurses and laboratory staff who participated in the trial and were very familiar with the type of COPD patients enrolled, were asked to provide best estimates of resource utilisation. Separate estimates were made for each inpatient hospital day, in order to detect possible changes in care intensity over the course of the stay. Using standardised 
reporting templates, the participants were asked how many minutes they spent on each component of care per average patient. Additionally, nurses were asked what proportion of their yearly working hours were 'indirect treatment time', i.e. time not spent directly caring for patients, but for instance on trainings and department meetings. Indirect treatment time was then allocated to patients by adding a mark-up of $24.5 \%$ to the amount of direct treatment time they received. This mark-up was calculated as the proportion of time spent on indirect treatment (averaged over all nurses), divided by the proportion of time spent on direct treatment (averaged over all nurses) [24]. Labour time was valued using standardised costs per minute, which reflected national average incomes per profession (including social premiums, fees for irregular working hours, and the costs of replacement during illness) divided by the number of workable minutes per year. For consulting physicians, the standardised time-costs included a $43 \%$ mark-up for indirect treatment time. For residents, a markup of $30 \%$ was applied. The latter percentage was chosen to be in-between those for physicians and nurses. For hotel and nutrition costs, the national reference costs from the Dutch Manual for Costing Studies was used. For the first and last day of hospital admission, only half of these costs were taken into account. Finally, labour and hotel costs for each hospital day were supplemented with a proportional mark-up for overhead and capital costs (42\%), which was the national reference percentage [22]. In these cost calculations, the day of admission was considered as day 1 when patients were admitted before 12:00 pm. If the patient was admitted after $12 \mathrm{pm}$, the day of admission was considered day 0 and the following day as day 1 . Hence, costs of day 1 were calculated separately for patients who were admitted on day 1 , and for patients who were admitted on day 0 . For inpatient day 4, separate calculations were performed for the patients who were discharged and those who remained in hospital.

\section{Statistical analysis}

\section{Effects}

The change from day of randomisation in CCQ score and the EQ-5D score were analysed in repeated measurement analyses. In these linear models with correlated errors, the covariance structure was unstructured. Explanatory variables were treatment, CCQ score or EQ-5D score at day of randomisation, time (moment of measurement), the interaction of treatment and time, and Charlson comorbidity score (1 or $>1$, only in the EQ-5D model) [25].

In the CCQ model the coefficient for treatment could directly be interpreted as the marginal difference in change from the day of randomisation to day 7 , i.e. the difference between the hypothetical situations in which all patients were treated at home or all received usual hospital treatment. The marginal difference in change from day of randomisation at 3 months was the sum of the coefficient for treatment and the 
coefficient for the interaction of treatment and measurement. In order to calculate the mean marginal difference in EQ-5D score per measurement, scores were predicted for all patients for each measurement: 1 score for each treatment. To calculate QALYs the mean utility of 2 subsequent measurements was multiplied with the number of days between these measurements, the sum of which was divided by 365.25 . The probability of experiencing improvement $\geq 0.4$ units in CCQ between the day of randomisation and day 7 and month 3 was analysed with logistic regression analyses. Explanatory variables were treatment and the CCQ score on day of randomisation. The results of these regression analyses were used to predict the probabilities in each treatment group, based on the CCQ score distribution of the full sample ( 2 treatment groups combined).

\section{Costs}

In the usual care group, total costs during the 7-day treatment phase include all hospital costs. In the early discharge group, these costs were calculated as the sum of the hospital costs, the community care costs and the costs of health care utilisation as recorded in the diaries for the 4-day period of home care. Total costs during the follow-up phase were calculated as the sum of the predicted monthly treatment costs, the predicted medication costs and the costs of readmissions. To obtain the predicted costs, the monthly cost diaries were analysed in a linear repeated measures model with correlated error terms and unstructured covariance. The dependent variable was the costs in a certain month. The explanatory variables were the time (first, second or third month) and the interaction of treatment and time. The results were used to predict the mean costs per treatment group for each month. Monthly medication costs were analysed in the same way.

\section{Intention-to-treat}

Data analysis was performed according to the intention-to-treat principle. Data from patients who died, quit participation or were otherwise lost to follow-up were included in the analysis up to the point of drop-out. Missing observations were handled by the repeated measurement analysis, which uses the covariance structure of the existing data to adjust the estimates.

\section{Cost-effectiveness and cost-utility}

Health outcomes on day 7 were related to costs of the initial treatment phase; health outcomes after 3 months were related to total costs of the initial treatment phase and the follow-up period combined. If 1 of the treatment options was more effective and also more costly, results were presented in incremental cost-effectiveness ratios (ICERs): the additional cost per additional unit of health gain, which was calculated as the difference in mean costs divided by the difference in mean health outcomes. 
Uncertainty around the estimates of costs and health outcomes was addressed by bootstrapping the data $[26,27]$. All statistical analyses were performed on each of 1000 bootstrap replications. The mean values of incremental costs and effects from the bootstrap replications were used as the point estimates. The $95 \%$ confidence interval around the difference in mean total costs and health outcomes was determined by taking the $2.5^{\text {th }}$ percentile and the $97.5^{\text {th }}$ percentile of these bootstrap replications. The bootstrap replicates for the outcomes and costs after 3 months were plotted in costeffectiveness planes (CE-planes) [28]. The information from the CE-planes on incremental costs per QALY was summarised in cost-effectiveness acceptability curves, which represent the likelihood that early assisted discharge is the most cost-effective option at different values of the maximum acceptable willingness to pay (WTP) for a health outcome [29].

\section{Sensitivity analyses}

Several sensitivity analyses were performed. Firstly, the costs of informal care in the follow-up period were left out of the total costs in the societal perspective (SA1). Secondly, a different unit cost per inpatient hospital day was used instead of the costs from the microcosting study (SA2). This cost was the standard unit price from the Dutch Manual for costing studies [22], which is based on a broad spectrum of diagnoses and is constant for all days during an admission. Additionally, in order to express the uncertainty about the estimate of the costs per inpatient hospital day, sensitivity analyses were performed using the estimates of the respondent with the highest (SA3) and lowest (SA4) costs (most costly and least costly health care provider), and the highest (SA5) and lowest (SA6) estimates of all aspects of care across respondents (most costly and least costly scenario).

\section{Results}

\section{Patients}

From December 2007 to March 2011, 139 patients were randomised. In the usual care group, $75 \%$ of patients completed the entire trial. In the hospital-at-home group, $90 \%$ remained in the trial until the end of the follow-up period. Due to early drop-out or failure to complete questionnaires, no effectiveness data were available for $1 \%$ of patients and no cost data for $12 \%$. The characteristics of all randomised patients are presented in table 2 . 
Table 2. Baseline characteristics.

\begin{tabular}{|lcc|}
\hline Age in years (SD) & $\begin{array}{c}\text { Usual hospital care } \\
(\mathbf{N = 6 9 )}\end{array}$ & $\begin{array}{c}\text { Early assisted discharge } \\
\text { (N=70) }\end{array}$ \\
\hline Male & $67.80(11.30)$ & $68.31(10.34)$ \\
\hline Current smoker & $55.1 \%$ & $68.9 \%$ \\
\hline Pack years (SD) & $39.1 \%$ & $32.9 \%$ \\
\hline Body Mass Index (SD) & $44.52(31.04)$ & $46.97(27.27)$ \\
\hline Receiving home care before admission & $25.57(4.33)$ & $24.97(5.14)$ \\
\hline Charlson comorbidity score (SD) & $23.2 \%$ & $24.3 \%$ \\
\hline \multicolumn{1}{|c|}{ Score >1 } & $1.68(1.10)$ & $1.74(1.10)$ \\
\hline CCQ (SD) & $39.1 \%$ & $45.7 \%$ \\
\hline EQ-5D (SD) & $2.22(0.97)$ & $2.63(1.03)$ \\
\hline
\end{tabular}

\section{Costs of inpatient hospital days}

Table 3 shows that the first day of the hospital admission was the most costly. After that, the intensity of care by physicians and nurses decreased, which is reflected in lower costs per day. The total inpatient hospital costs during the 7-day treatment phase were $€ 1430$ for the usual hospital care group and $€ 976$ for the early assisted discharge group.

Table 3. Costs per inpatient hospital day.

\begin{tabular}{|c|c|c|c|}
\hline Day & $\begin{array}{l}\text { Usual hospital } \\
\text { care }\end{array}$ & $\begin{array}{l}\text { Early assisted } \\
\text { discharge }\end{array}$ & Difference \\
\hline 0 (with admission after noon) & $€ 319$ & $€ 319$ & \\
\hline 1 (with admission before noon) & $€ 323$ & $€ 323$ & \\
\hline 1 (for patients admitted on day 0 ) & $€ 195$ & $€ 195$ & \\
\hline 2 & $€ 192$ & $€ 192$ & \\
\hline 3 & $€ 178$ & $€ 178$ & \\
\hline 4 & $€ 162$ & $€ 188$ & \\
\hline 5 & $€ 157$ & - & \\
\hline 6 & $€ 156$ & - & \\
\hline 7 & $€ 167$ & - & \\
\hline Total costs for admission* & $€ 1430$ & $€ 976$ & $€ 454$ \\
\hline $\mathrm{SA} 2 * *$ & $€ 2828$ & $€ 1088$ & $€ 1740$ \\
\hline SA3** & $€ 1721$ & $€ 1122$ & $€ 599$ \\
\hline SA $4 * *$ & $€ 1228$ & $€ 858$ & $€ 370$ \\
\hline SA $5 * *$ & $€ 2312$ & $€ 1534$ & $€ 778$ \\
\hline SA6** & $€ 952$ & $€ 655$ & $€ 297$ \\
\hline
\end{tabular}

*Totals are based on the assumption that $50 \%$ of patients are admitted on day 0 and $50 \%$ on day 1 . This does not affect the difference between the treatment arms, because the same assumption is made for both groups. ${ }^{*}$ SA2 (sensitivity analysis 2): standard costs per inpatient hospital day instead of costs from microcosting study. SA3/4 cost estimates from most and least costly health care provider in microcosting study. SA5/6: highest and lowest estimates of care costs across respondents. 


\section{Effects}

The mean improvement in CCQ scores between days 3 and 7 was larger in the hospital group than in the early assisted discharge group $(-0.303$ versus -0.013$)$, but this difference was of only borderline significance (see table 4). Both groups showed an almost equal improvement in CCQ score between day 3 and 3 months. There was

Table 4. Cost-effectiveness of early assisted discharge versus usual inpatient hospital care in patients with a COPD exacerbation.

\begin{tabular}{|c|c|c|c|}
\hline & $\begin{array}{l}\text { Usual } \\
\text { hospital care }\end{array}$ & $\begin{array}{c}\text { Early } \\
\text { assisted } \\
\text { discharge }\end{array}$ & Difference \\
\hline \multicolumn{4}{|l|}{ Effects } \\
\hline $\begin{array}{l}\text { Mean change in CCQ score, } \\
\text { day } 7\end{array}$ & -0.303 & -0.013 & $0.290(-0.03 ; 0.61)$ \\
\hline $\begin{array}{l}\text { Mean change in CCQ score, } \\
\text { end of follow-up }\end{array}$ & 0.024 & 0.065 & $0.041(-0.41 ; 0.48)$ \\
\hline Probability of improved CCQ score, day 7 & $51.3 \%$ & $32.7 \%$ & $-19.41 \%(-36.25 \% ;-0.50 \%)$ \\
\hline $\begin{array}{l}\text { Probability of improved CCQ score, end } \\
\text { of follow-up }\end{array}$ & $39.9 \%$ & $35.8 \%$ & $-4.17 \%(-21.94 \% ; 15.27 \%)$ \\
\hline QALYs & 0.175 & 0.170 & $-0.005(-0.021 ; 0.0095)$ \\
\hline Health care perspective & $\begin{array}{l}\text { Usual } \\
\text { hospital care }\end{array}$ & $\begin{array}{c}\text { Early } \\
\text { assisted } \\
\text { discharge }\end{array}$ & Difference \\
\hline Costs of initial episode & $€ 1463$ & $€ 1219$ & $-€ 244(-€ 315 ;-€ 168)$ \\
\hline Costs of initial episode plus follow-up & $€ 4297$ & $€ 4129$ & $-€ 168(-€ 1253 ; € 922)$ \\
\hline \multicolumn{4}{|l|}{ Incremental cost-effectiveness ratios* } \\
\hline $\begin{array}{l}\text { Point improvement in mean CCQ score, } \\
\text { day } 7\end{array}$ & & $€ 842$ & \\
\hline $\begin{array}{l}\text { Point improvement in mean CCQ score, } \\
\text { end of follow-up }\end{array}$ & & $€ 4098$ & \\
\hline Patient with improved CCQ score, day 7 & & $€ 1257$ & \\
\hline $\begin{array}{l}\text { Patient with improved CCQ score, end of } \\
\text { follow-up }\end{array}$ & & $€ 4000$ & \\
\hline Costs per QALY & & $€ 31,111$ & \\
\hline Societal perspective & $\begin{array}{l}\text { Usual } \\
\text { hospital care }\end{array}$ & $\begin{array}{c}\text { Early } \\
\text { assisted } \\
\text { discharge }\end{array}$ & Difference \\
\hline Costs of initial episode & $€ 1463$ & $€ 1398$ & $-€ 65(-€ 152 ; € 25)$ \\
\hline Costs of initial episode plus follow-up & $€ 5395$ & $€ 6304$ & $€ 908(-€ 553 ; € 2296)$ \\
\hline \multicolumn{4}{|l|}{ Incremental cost-effectiveness ratios } \\
\hline $\begin{array}{l}\text { Point improvement in mean CCQ score, } \\
\text { day } 7\end{array}$ & & $€ 224$ & \\
\hline $\begin{array}{l}\text { Point improvement in mean CCQ score, } \\
\text { end of follow-up }\end{array}$ & \multicolumn{3}{|c|}{ Usual hospital care is dominant } \\
\hline Patient with improved CCQ score, day 7 & & $€ 335$ & \\
\hline $\begin{array}{l}\text { Patient with improved CCQ score, end of } \\
\text { follow-up }\end{array}$ & \multicolumn{3}{|c|}{ Usual hospital care is dominant } \\
\hline Costs per QALY & \multicolumn{3}{|c|}{ Usual hospital care is dominant } \\
\hline
\end{tabular}


a statistically significant difference between the groups in the probability of having a clinically relevant improvement in CCQ score between days 3 and 7 (51.3\% in the usual hospital care group versus $31.7 \%$ in the early discharge group). It was not significant between day 3 and 3 months (39.9\% versus 35.8\%, respectively). The difference in QALYs was very small and not statistically significant.

\section{Costs}

The costs for the first hospital admission were, obviously, lower in the early assisted discharge group than in the usual hospital care group. Hospital costs were reduced by $€ 462$ per patient (table 5). These savings were partly offset by the costs of community nursing care, which were $€ 211$, resulting in a net cost reduction of $€ 244$. During the follow-up phase, the early discharge group had somewhat higher costs than the usual hospital care group. In total, from a health care perspective, early assisted discharge led to mean costs savings of $€ 168$ (95\% confidence interval $(\mathrm{Cl})$ : $-€ 1253 ;+€ 922)$ per patient (table 5).

From a societal perspective, savings in hospital costs during the 7-day treatment phase were not only offset by the costs of community nursing, but also by the costs of informal care and production losses. From this perspective the initial treatment phase was only $€ 65$ less costly in the early discharge group. Including the costs during the follow-up phase, which were $€ 973$ higher in the early discharge group led to a total estimated cost increase of $€ 908(-€ 552 ;+€ 2295)$ per patient in the early discharge group, from a societal perspective. This is primarily due to the higher costs of informal care and the greater productivity loss (table 5).

Table 5. Treatment costs (in euros, 2009).

\begin{tabular}{|c|c|c|c|}
\hline Initial treatment phase & $\begin{array}{c}\text { Usual } \\
\text { hospital care }\end{array}$ & $\begin{array}{l}\text { Early assisted } \\
\text { discharge }\end{array}$ & Difference \\
\hline Inpatient days^^${ }^{\wedge}$ & $€ 1463$ & $€ 1001$ & $-€ 462$ \\
\hline Community nursing & - & $€ 211$ & $€ 211$ \\
\hline $\begin{array}{l}\text { Other costs of home treatment } \\
\text { (societal perspective) }\end{array}$ & - & $€ 186$ & $€ 186$ \\
\hline $\begin{array}{l}\text { Other costs of home treatment (health } \\
\text { care perspective) }\end{array}$ & - & $€ 6$ & $€ 6$ \\
\hline Total (health care perspective) & $€ 1463$ & $€ 1219$ & $\begin{array}{c}-€ 244 \\
(-315 ;-168)\end{array}$ \\
\hline Total (societal perspective) & $€ 1463$ & $€ 1398$ & $\begin{array}{c}-€ 65 \\
(-152 ; 25)\end{array}$ \\
\hline \multicolumn{4}{|l|}{ Follow-up period } \\
\hline GP & $€ 46$ & $€ 71$ & $€ 25$ \\
\hline Pulmonologist & $€ 86$ & $€ 107$ & $€ 21$ \\
\hline Specialist & $€ 114$ & $€ 99$ & $-€ 15$ \\
\hline Paramedic care & $€ 191$ & $€ 314$ & $€ 123$ \\
\hline Emergency room & $€ 52$ & $€ 48$ & $-€ 4$ \\
\hline Ambulance & $€ 80$ & $€ 25$ & $-€ 55$ \\
\hline Medication & $€ 346$ & $€ 396$ & $€ 50$ \\
\hline Community nursing & $€ 971$ & $€ 932$ & $-€ 39$ \\
\hline
\end{tabular}




\begin{tabular}{|lccc|}
\hline Readmissions & $€ 941$ & $€ 941$ & $€ 0$ \\
\hline Informal care & $€ 973$ & $€ 1488$ & $€ 515$ \\
\hline Production loss, patient & $€ 71$ & $€ 466$ & $€ 395$ \\
\hline Production loss, informal caregiver & $€ 29$ & $€ 58$ & $€ 28$ \\
\hline Total* (health care perspective) & $€ 2834$ & $€ 2910$ & $€ 76$ \\
\hline Total* (societal perspective) & $€ 3933$ & $€ 4906$ & $\begin{array}{c}€ 973 \\
\text { (-€1005; } € 1159)\end{array}$ \\
\hline Total study period (initial treatment phase plus follow up-period) & & -168 \\
\hline Health care perspective* & $€ 4297$ & $€ 4129$ & $(-€ 1253 ; € 922)$ \\
\hline Societal perspective* & & & 908 \\
\hline
\end{tabular}

$\wedge$ These costs are higher than in table 3 because the costs of prolonged hospital stay beyond 7 days (usual hospital care group) and the costs of readmission during the initial treatment phase (usual hospital care group) were included

*Totals for follow-up period are based on regression analysis; means per cost category are not.

\section{Cost-effectiveness}

From a health care perspective, all point-estimates of cost and effects pointed towards lower costs but somewhat less effects for early assisted discharge. Therefore, we calculated the ICERs for usual hospital care compared to early assisted discharge. After 7 days, the incremental costs per unit improvement in CCQ were $€ 842$, at 3 months this ratio was $€ 4098$. The incremental costs per additional patient with a clinically relevant improvement in CCQ score were $€ 1257$ after 7 days and $€ 4000$ at 3 months. The incremental costs per QALY were $€ 31,111$. The probability that early assisted discharge was cost-saving from a health care perspective was $61.2 \%$.

From the societal perspective, no ICERs were calculated for the outcomes after the follow-up period because the point-estimates of costs and effects pointed towards dominance of the usual hospital care group. The probability that early assisted discharge was cost-saving was $12 \%$ from this perspective.

After 7 days, the incremental costs per unit improvement in CCQ were €224 when usual hospital care was compared to early assisted discharge. The incremental costs per additional patient with a clinically relevant improvement in CCQ score were $€ 335$.

There is considerable uncertainty around incremental costs and effects, as is presented in CE planes, for both perspectives (figure 1). From the health care perspective, there is a greater probability that early assisted discharge leads to net cost saving than from the societal perspective, as is shown by a greater proportion of the dots below the $x$ axis. When adopting the health care perspective, the largest proportion of all dots was located in the southwest quadrant, with lower costs and less optimal health outcomes for early assisted discharge. From the societal perspective, the majority of simulated 
outcomes were found in the northwest quadrant, with higher costs and less optimal health outcomes for early assisted discharge.

The cost-effectiveness acceptability curves in figures 2 and 3 show that, from a societal perspective, early assisted discharge is unlikely to be considered cost-effective compared to usual hospital care at any threshold of maximum costs per QALY gained. In the base case, this probability is close to $10 \%$ for all thresholds.

From a health care perspective, early assisted discharge is more likely to be costeffective in the range of thresholds considered. Early assisted discharge is more likely to be cost-effective than usual hospital care for thresholds up to $€ 46,000$.

a.

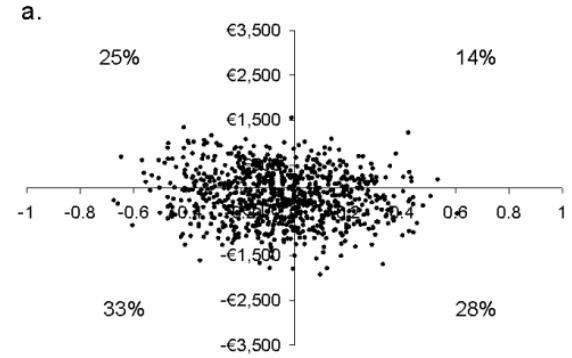

b.

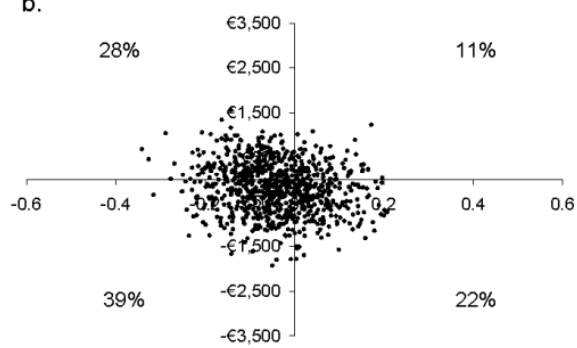

c.

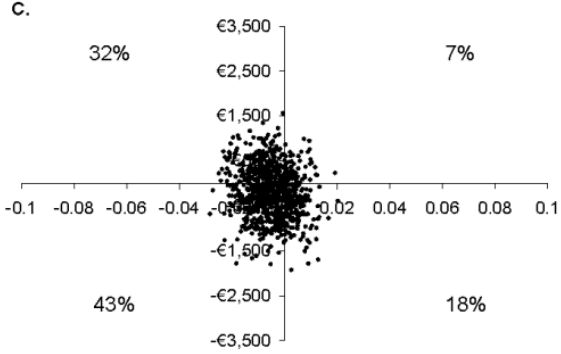

d.

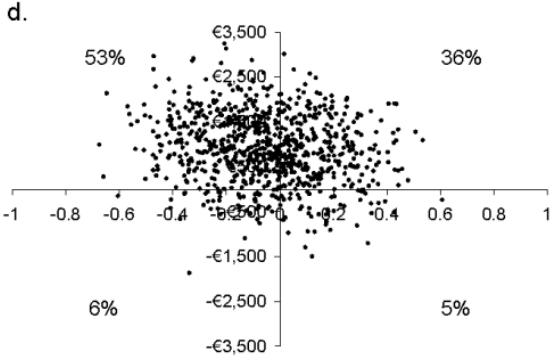

e.

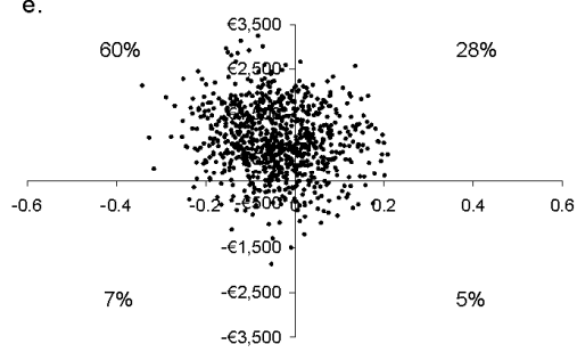

f.

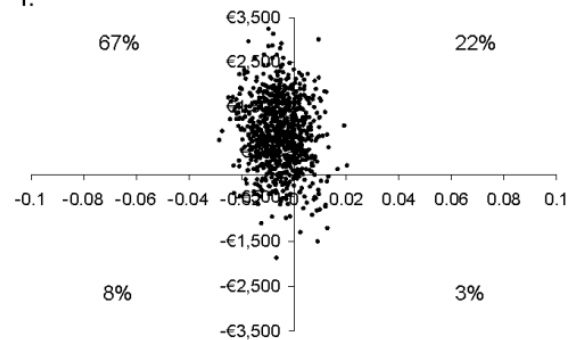

Health care perspective, incremental costs set against: a) incremental improvement in CCQ-score, month 3, b) incremental proportion of patients with clinically relevant improvement, month 3; c) incremental QALYs. Societal perspective, incremental costs set against: d) incremental improvement in CCQ-score, month 3, e) incremental proportion of patients with clinically relevant improvement, month 3; f) incremental QALYs. Note: positive effectiveness on $\mathrm{x}$-axis represents improvement (lower score) on CCQ.

Figure 1. CE planes. 


\section{Sensitivity analyses}

Table 6 shows the results of the sensitivity analyses. The ICERs for usual hospital care compared to early assisted discharge, were sensitive to changes in the assumptions. In the initial treatment phase, early assisted discharge was almost certain to lead to cost savings from a health care perspective, under any of the alternative assumptions about the costs of inpatient hospital days, similar to the base case analysis. From a societal perspective, costs savings were very likely to occur, except if mean costs per hospital day were assumed to be much lower than in the base case analysis (SA4 and SA6).

Table 6. Sensitivity analyses.

\begin{tabular}{|c|c|c|c|}
\hline & $\begin{array}{l}\text { Cost difference (EAD } \\
\text { minus HOSP) }\end{array}$ & ICER* & $\begin{array}{l}\text { Probability of cost-savings } \\
\text { for early discharge }\end{array}$ \\
\hline \multicolumn{4}{|c|}{ Health care costs, initial episode } \\
\hline Base case & $-€ 244$ & & $100 \%$ \\
\hline SA2 & $-€ 1522$ & & $100 \%$ \\
\hline SA3 & $-€ 389$ & & $100 \%$ \\
\hline SA4 & $-€ 160$ & & $100 \%$ \\
\hline SA5 & $-€ 568$ & & $100 \%$ \\
\hline SA6 & $-€ 86$ & & $99.0 \%$ \\
\hline \multicolumn{4}{|c|}{ Societal costs, initial episode } \\
\hline Base case & $-€ 65$ & & $93.2 \%$ \\
\hline SA1 & $-€ 65$ & & $93.2 \%$ \\
\hline SA2 & $-€ 1343$ & & $100 \%$ \\
\hline SA3 & $-€ 210$ & & $100 \%$ \\
\hline SA4 & $€ 19$ & & $33.9 \%$ \\
\hline SA5 & $-€ 389$ & & $100 \%$ \\
\hline SA6 & $€ 93$ & & $2.0 \%$ \\
\hline \multicolumn{4}{|c|}{ Health care costs, 3 months } \\
\hline Base case & $-€ 168$ & $€ 31,111$ & $61.2 \%$ \\
\hline SA2 & $-€ 1464$ & $€ 271,111$ & $99.8 \%$ \\
\hline SA3 & $-€ 313$ & $€ 57,963$ & $69.2 \%$ \\
\hline SA4 & $-€ 84$ & $€ 15,556$ & $55.1 \%$ \\
\hline SA5 & $-€ 492$ & $€ 91,111$ & $81.2 \%$ \\
\hline SA6 & $-€ 10$ & $€ 1,852$ & $50.0 \%$ \\
\hline \multicolumn{4}{|c|}{ Societal costs, 3 months } \\
\hline Base case & $€ 908$ & Dominance & $11.5 \%$ \\
\hline SA1 & $€ 398$ & Dominance & $25.4 \%$ \\
\hline SA2 & $-€ 388$ & $€ 71,852$ & $69.9 \%$ \\
\hline SA3 & $€ 763$ & Dominance & $15.7 \%$ \\
\hline SA4 & $€ 992$ & Dominance & $9.8 \%$ \\
\hline SA5 & $€ 584$ & Dominance & $21.6 \%$ \\
\hline SA6 & $€ 1066$ & Dominance & $8.1 \%$ \\
\hline
\end{tabular}

Over the entire 3-month period, cost savings were more likely to occur than cost increases from a health care perspective. This likelihood was more or less comparable 
across sensitivity analyses, except when the standard unit costs for inpatient hospital days were applied (SA2). In this sensitivity analysis, the likelihood that early assisted discharge led to cost savings was $99.8 \%$

From a societal perspective, cost savings were unlikely to occur under all assumptions except when the standard unit costs for inpatient hospital days were used (SA2). This is the only sensitivity analysis in which early assisted discharge was not dominated by usual hospital care.

The cost-effectiveness acceptability curves in figures 2 and 3 make it clear that assumptions on the costs of inpatients days do not have a strong impact on the probability that early assisted discharge is to be cost-effective.

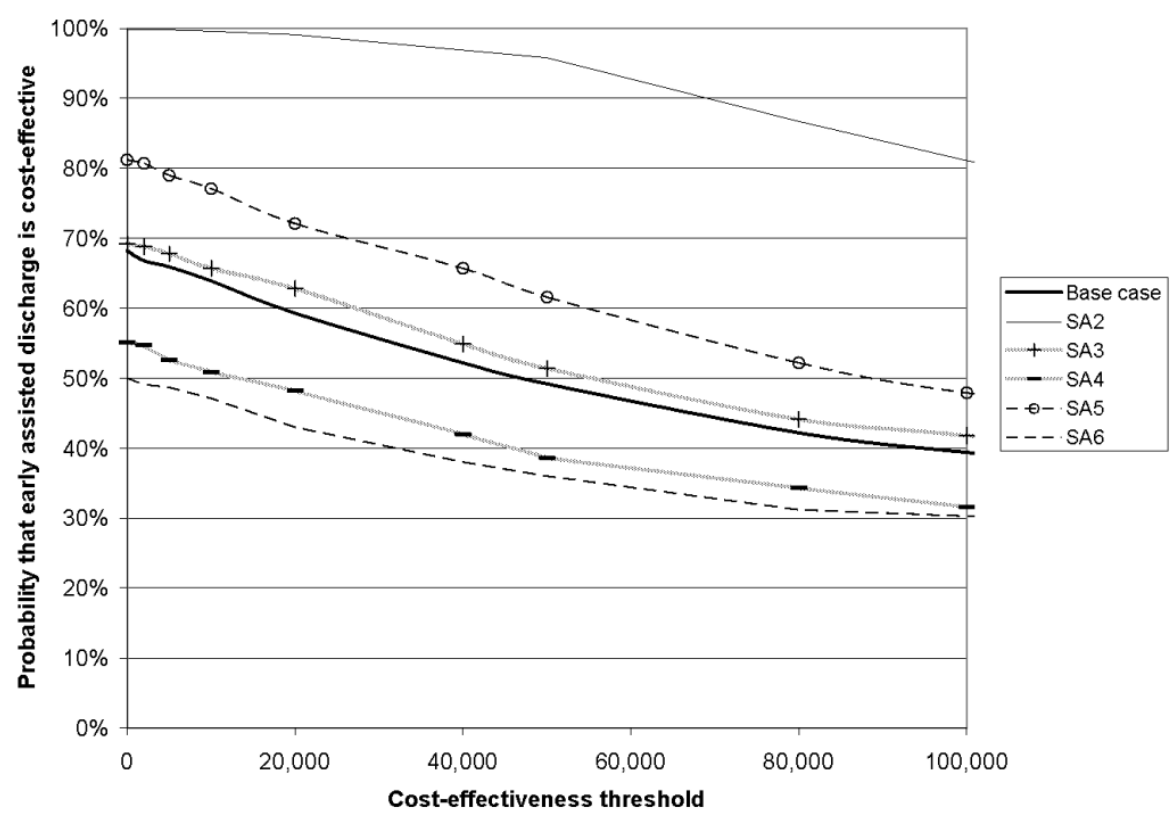

Figure 2. Cost-effectiveness acceptability curves for costs per QALY gained, health care perspective. 


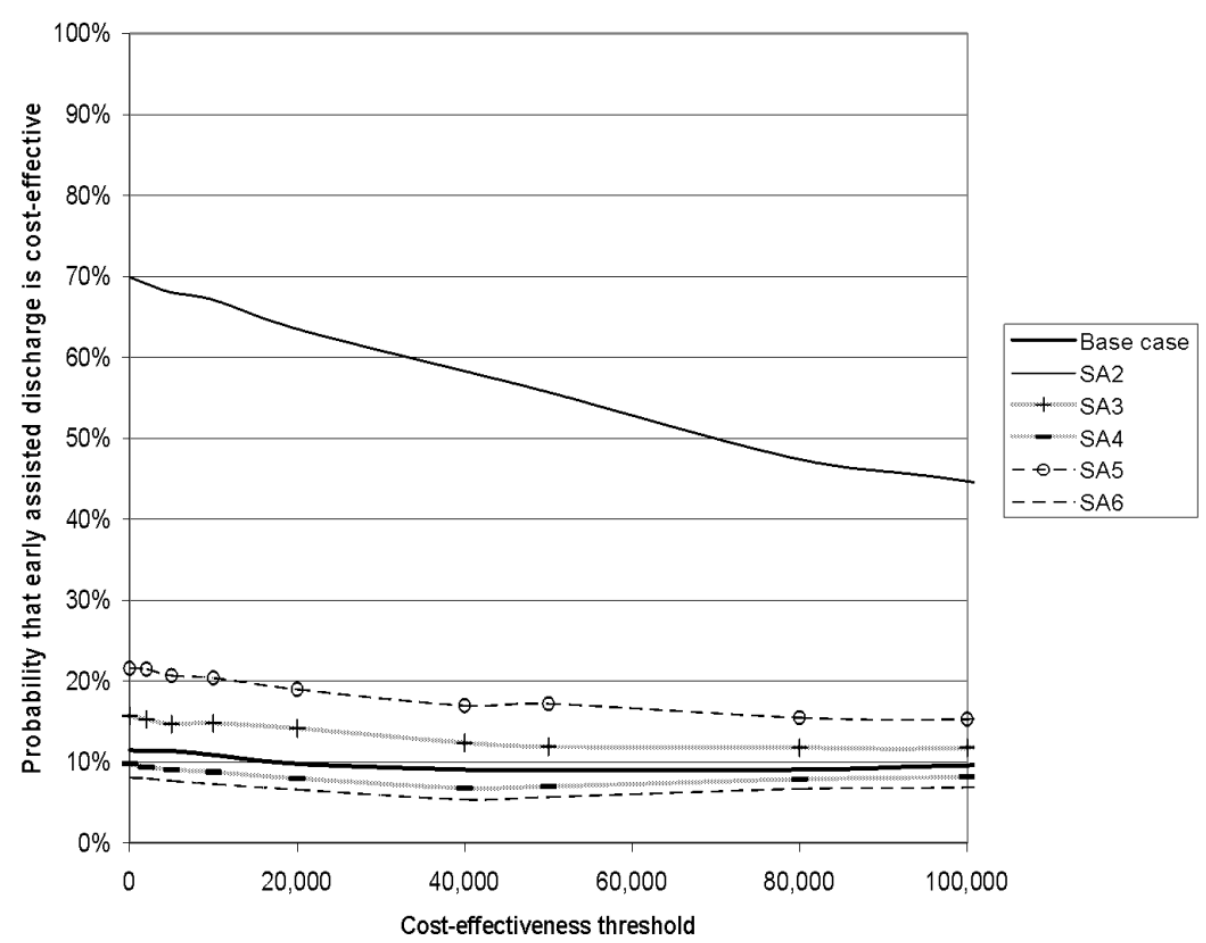

SA2 (sensitivity analysis 2): standard costs per inpatient hospital day instead of costs from microcosting study. SA3/4 cost estimates from most and least costly health care provider in microcosting study. SA5/6: highest and lowest estimates of care costs across respondents.

Figure 3. Cost-effectiveness acceptability curves, societal perspective.

\section{Discussion}

This study compared the costs and health effects of 2 treatments for patients who were admitted to the hospital with a COPD exacerbation. Patients stayed in the hospital for 7 days, or went home after 3 days where they were supervised and treated by community nurses. No clear evidence was found to conclude that either treatment was more effective or less costly than the other.

Against the obvious savings in inpatient hospital costs, there were extra costs for community nursing, and, from a societal perspective, informal care. While costs from a societal perspective were higher among patients who were discharged early, this difference was not statistically significant. Cost savings in the health care perspective were not significant either. However, early discharge was much more likely to reduce health care costs than it was to reduce total societal costs.

No clear and clinically relevant differences in health effects were found. At the end of the 7-day treatment phase, all outcomes measures had improved more in the patients in the usual hospital treatment group than in patients in the early discharge group. 
However, this difference was not statistically significant, except for the probability of having a clinically relevant improvement in CCQ-score on day 7. By the end of the follow-up period, at 3 months, the difference had disappeared.

From a societal perspective, no incremental cost-effectiveness ratios were calculated for outcomes after the follow-up period because early assisted discharge led to higher mean costs as well as less optimal health outcomes: it was dominated by usual hospital treatment. This was illustrated by the large proportion of bootstrap samples in the northwest quadrant of the CE plane and by the low acceptability curves. The verdict of dominance is often fatal for the conclusion on the treatment to which it is applied. In this case, however, it might be given less weight, since the dominance is based on a very small difference in effects. Analogously, it could be argued that the position of the majority of bootstrap replications on the CE plane should not be described as the northwestern quadrant of the CE plane, but rather as the proximity of the $y$-axis and the origin.

ICERs could be calculated for outcomes after 7 days from a societal perspective and for all outcome measures from a health care perspective. The costs per QALY gained, for usual hospital care compared to early assisted discharge, was close to the threshold values below which an ICER is generally considered to be cost-effective.

This is the first study to include the costs of informal care in the costs of the early assisted discharge scheme. The impact of this was considerable. In the 7-day treatment phase, the cost savings for early assisted discharge decreased from €244 to €65 per patient. For the full treatment period, cost savings turned into cost increases.

The costs of informal care during the follow-up phase were much higher in the early assisted discharge group. We have no good explanation for this finding. Although it might be a true difference, it is also possible that informal caregivers in the early assisted discharge group were more primed to record their activities as informal care, due to the attention it may have got during the initial treatment phase at home. For this reason, we performed a sensitivity analysis in which informal care costs during the follow-up period were excluded from the calculations. In this analysis, total costs for the early discharge group were still higher, mostly because of the higher number of patient work days lost. The difference was smaller than in the base case, as was the probability of a cost increase. How to value informal care is still debated. Different estimation methods have lead to different estimates [30]. Following Dutch guideline recommendations, we used a shadow price of $€ 12.50$ per hour, which was based on the standard tariff for the reimbursement of house cleaning costs for chronic patients. When it is applied to informal care, it reflects the assumption that informal caregivers 
cannot match the efficiency of professionals, who would require a higher hourly tariff. While our cost estimates are dependent on the assumed hourly unit costs of informal care, the unit costs we have used are in the center of the range of costs (€7 to $€ 17$ ) that were estimated by Koopmanschap et al. [30] using different valuation methods.

In our study, the duration of hospital or home treatment was fixed. Whenever possible, patients were discharged or home care was stopped after 7 days. It is conceivable that the threshold for adding another day of treatment may be lower for treatment at home. In other studies, in which no fixed treatment duration was used and physicians were fully free to decide on the duration of treatment, different durations were observed for each treatment group and the total duration of treatment in hospital-at-home was longer than that in usual hospital care. Such an approach may have commingled the effects of the treatment per se with the effects of the length of stay or even with the timing of health measurements. Treating patients for a longer time may lead to better health, but measuring their health at a later time may also lead to better results. Our design made it possible to make the comparison exclusively on the basis of where and by whom treatment was provided. Four patients in the usual hospital care group remained in the hospital for a longer period of time. One patient who was discharged early needed to be re-admitted within the 7 days of initial treatment. The additional costs of these patients were included in the costs of the initial treatment phase. No patient required home care beyond 7 days.

This study has shown the potential impact of a detailed unit cost calculation of an inpatient hospital day based on treatment-intensity compared to standard tariffs or references prices. A sensitivity analysis using Dutch reference costs, which represent average costs of a hospital day based on all patients irrespective of their diseases [22], led to much larger savings for early assisted discharge. From the societal perspective, the cost increase due to early assisted discharge disappeared almost entirely. From the health care perspective, the finding that early assisted discharge led to cost savings was surrounded by almost no uncertainty. However, using standard costs of a hospital day would not be opportune in this study, because only the least-costly inpatient days were substituted by home care. Furthermore, hospital care for patients with COPD exacerbations that meet the in- and exclusion criteria of our trial are likely to be less intensive than the hospital care for the average admitted patient. The calculations for the costs per inpatient day were not based on a large sample of patients, whose treatment was actually timed and recorded. This was not feasible in this study, due to the unpredictability of hospital admissions, the relatively small number of patients eligible for the study, and the large number of treatment aspects that would have to be recorded. It would have required researchers permanently present in the hospitals for a long period of time. Instead, we interviewed hospital care providers with much 
experience in treating this patient group. A standardised questionnaire was used, in which all aspects of care on a particular day were distinguished. Respondents were not asked to estimate the total amount of time they spent on each patient but on an average patient. Tan et al. [23] concluded that this method leads to a good balance between feasibility and reliability. A problem with this method is, however, that it does not yield measures of variability on a patient level. This means that the uncertainty about the costs of treatment in the hospital, which inevitably exists, was not represented in the uncertainty around the total costs of treatment. While this may always be the case when fixed unit costs are used, inpatient hospital days are different. They contain a large number of separate elements - not just capital costs, hotel services and overhead costs, which could be fairly similar for all patients, but also time from several health care providers for many different aspects of care. It is conceivable that the price of a general practitioner consultation does not differ much across patients because all more or less take the same amount of time, whereas inpatient hospital days are much more different for different patients. This may not be a problem when hospital costs are merely a relatively infrequent element in the total costs of care, but in the initial treatment episode for COPD exacerbations the costs of inpatient hospital days are virtually the only cost driver. Therefore, we performed sensitivity analyses assuming different unit cost prices per inpatient hospital day. These gave an indication about the range of possible costs savings and increases.

Most of the other cost studies of hospital-at-home found larger cost savings than we did, also from a health care perspective [10-16]. This may be explained by the design of our study - early assisted discharge, not admission avoidance, which brought a reduction of 4 inpatient hospital days. In some other studies, this reduction was larger. In England, 2 economic evaluations were performed. Skwarska et al. [11] calculated savings of $£ 876$ per patient by eliminating 5 inpatient days (median) in an admission avoidance program (no statistical testing was done). In contrast, Shepperd et al. [10] found significant cost increases (difference between medians £1176) for an early assisted discharge scheme, in which 5 inpatient days were substituted for care at home as well. The cost increases in this study were mostly due to the large proportion of patients who were readmitted to the hospital after having been discharged early compared to usual treatment, which makes it plausible that the health effects of treatment were better in the usual hospital care group. Although differences were not statistically significant in their small sample, almost all health indicators were in favor of usual hospital care. In a Spanish study, significant savings of around $€ 800$ were reported, the exact amount depending on the analysis $[13,14]$. In this scheme an average of 3.8 inpatient hospital days was substituted by 1.7 home visits and 2.3 phone calls per patient. Some patients were discharged early, while others avoided admission completely. In this study, even some patients who were randomised to the 
usual hospital treatment, did not spend a night in the hospital. In an Australian admission avoidance study, in which community nurses were employed instead of hospital-based staff, the savings were AUS\$1696 [12]. Aimonino Ricauda et al. [16] examined an admission avoidance program in Italy. The cost difference of US\$215 was not significant. However, the hospital-at-home scheme contained visits by physicians and a transport home by ambulance for all patients, which made the cost difference smaller. In a non-randomised study in the United States - all previously mentioned studies were randomised - Frick et al. [15] found the largest savings, US\$2314 per patient.

In conclusion, transferring hospital care for a COPD exacerbation to the patient's home is likely to lead to modest savings in health care costs in the Netherlands, without jeopardizing the patient's long-term health. When the societal costs of informal care and productivity losses are taken into account, the cost savings decrease considerably or even turn into cost increases. Since there is no compelling reason - from a medical or economic point of view - to recommend either the early supported discharge treatment or usual hospital care, patients' preferences should play an important role in deciding where (s)he is treated. If home care is preferred, this study has shown that the wide-spread network of home care organizations in the Netherlands, which employs community nurses, is able to meet this preference. 


\section{References}

1. Toy EL, Gallagher KF, Stanley EL et al. The economic impact of exacerbations of chronic obstructive pulmonary disease and exacerbation definition: a review. COPD 2010;7:214228.

2. Celli BR, MacNee W. Standards for the diagnosis and treatment of patients with COPD: a summary of the ATS/ERS position paper. Eur Respir J 2004;23:932-946.

3. Miravitlles M, Murio C, Guerrero T et al. Costs of chronic bronchitis and COPD: a 1 year follow-up study. Chest 2003;123:784-791.

4. Nielsen R, Johannessen A, Benediktsdottir B et al. Present and future costs of COPD in Iceland and Norway: results from the BOLD study. Eur Respir J 2009;34:850-857.

5. Dal Negro RW, Tognella S, Tosatto R et al. Costs of chronic obstructive pulmonary disease (COPD) in Italy: the SIRIO study (social impact of respiratory integrated outcomes). Respir Med 2008;102:92-101.

6. Jordan RE, Hawker JI, Ayres JG et al. Effect of social factors on winter hospital admission for respiratory disease: a case-control study of older people in the UK. Br J Gen Pract 2008; 58: 400-402.

7. Shepperd S, Doll H, Angus RM et al. Admission avoidance hospital at home. Cochrane Database Syst Rev 2008;CD007491.

8. Shepperd S, Doll H, Broad J et al. Early discharge hospital at home. Cochrane Database Syst Rev 2009;CD000356.

9. British Thoracic Society. Intermediate care--Hospital-at-Home in chronic obstructive pulmonary disease: British Thoracic Society guideline. Thorax 2007;62:200-210.

10. Shepperd S, Harwood D, Gray A et al. Randomised controlled trial comparing hospital at home care with inpatient hospital care. II: cost minimisation analysis. BMJ 1998;316:1791-1796.

11. Skwarska E, Cohen G, Skwarski KM et al. Randomized controlled trial of supported discharge in patients with exacerbations of chronic obstructive pulmonary disease. Thorax 2000;55:907912.

12. Nicholson C, Bowler S, Jackson C et al. Cost comparison of hospital- and home-based treatment models for acute chronic obstructive pulmonary disease. Aust Health Rev 2001;24:181-187.

13. Hernandez C, Casas A, Escarrabill J et al. Home hospitalisation of exacerbated chronic obstructive pulmonary disease patients. Eur Respir J 2003;21:58-67.

14. Puig-Junoy J, Casas A, Font-Planells J et al. The impact of home hospitalization on healthcare costs of exacerbations in COPD patients. Eur J Health Econ 2007;8:325-332.

15. Frick KD, Burton LC, Clark R et al. Substitutive Hospital at Home for older persons: effects on costs. Am J Manag Care 2009;15:49-56.

16. Aimonino RN, Tibaldi V, Leff B et al. Substitutive "hospital at home" versus inpatient care for elderly patients with exacerbations of chronic obstructive pulmonary disease: a prospective randomized, controlled trial. J Am Geriatr Soc 2008;56:493-500.

17. Utens CM, Goosens LM, Smeenk FW et al. Early assisted discharge with community nursing for Chronic Obstructive Pulmonary Disease exacerbations: results of a randomised controlled trial. Provisionallu accepted for publication in BMJ open 2012.

18. Utens CM, Goossens LM, Smeenk FW et al. Effectiveness and cost-effectiveness of early assisted discharge for Chronic Obstructive Pulmonary Disease exacerbations: the design of a randomised controlled trial. BMC Public Health 2010;10:618.

19. Kocks JW, Tuinenga MG, Uil SM et al. Health status measurement in COPD: the minimal clinically important difference of the clinical COPD questionnaire. Respir Res 2006;7:62.

20. Lamers LM, McDonnell J, Stalmeier PF et al. The Dutch tariff: results and arguments for an effective design for national EQ-5D valuation studies. Health Econ 2006;15:1121-1132. 
21. College Voor Zorgverzekeraars: Guidelines for pharmecoeconomic research. Diemen: 2006.

22. Hakkaart- van Roijen L, Tan SS, Bouwmans CAM. Handleiding voor kostenonderzoek. Methoden en standaard kostprijzen voor economische evaluaties in de gezondheidszorg. Geactualiseerde versie. Rotterdam/Diemen: iMTA, Erasmus Universiteit/College voor zorgverzekeringen 2010.

23. Tan SS, Rutten FF, van Ineveld BM et al. Comparing methodologies for the cost estimation of hospital services. Eur J Health Econ 2009;10:39-45.

24. Tan SS, Van Gils CW, Franken MG et al. The unit costs of inpatient hospital days,outpatient visits, and daycare treatments in the fields of oncology and hematology. Value Health 2010;13:712-719.

25. Charlson ME, Pompei $\mathrm{P}$, Ales $\mathrm{KL}$ et al. $\mathrm{A}$ new method of classifying prognostic comorbidity in longitudinal studies: development and validation. J Chronic Dis 1987; 40:373-383.

26. Briggs $\mathrm{AH}$, Wonderling $\mathrm{DE}$, Mooney $\mathrm{CZ}$. Pulling cost-effectiveness analysis up by its bootstraps: a non-parametric approach to confidence interval estimation. HealthEcon 1997;6: 327-340.

27. DiCiccio TJ, Efron B. Bootstrap Confidence Intervals. Statistical Science 1996;11:189-212.

28. Briggs A, Fenn P. Confidence intervals or surfaces? Uncertainty on the cost- effectiveness plane. Health Econ 1998;7:723-740.

29. van Hout BA, AI MJ, Gordon GS et al. Costs, effects and C/E-ratios alongside a clinical trial. Health Econ 1994;3:309-319.

30. Koopmanschap MA, van Exel JN, van den Berg B et al. An overview of methods and applications to value informal care in economic evaluations of healthcare. Pharmacoeconomics 2008;26:269-280. 



\section{EARLY ASSISTED DISCHARGE FOR CHRONIC OBSTRUCTIVE PULMONARY DISEASE EXACERBATIONS: PATIENT SATISFACTION AND PREFERENCE FOR TREATMENT PLACE}

Cecile MA Utens, Onno CP van Schayck, Lucas MA Goossens, Maureen PMH Ruttenvan Mölken, Walter van Litsenburg, Annet Janssen, Anouschka van der Pouw, Frank WJM Smeenk 


\begin{abstract}
Background: In the absence of clear differences in effectiveness and cost-effectiveness between hospital-at-home schemes and usual hospital care, patient preference plays an important role. This study investigates patient preference for treatment place, associated factors and patient satisfaction with a community-based hospital-at-home scheme for COPD exacerbations.
\end{abstract}

Methods: The study is part of a larger randomised controlled trial. Patients were randomised to usual hospital care or early discharge which incorporated discharge at day 4 and visited at home until day 7 of treatment ( $T+4$ days). The hospital care group received care as usual and was discharged from hospital at day 7. Patients were followed for 90 days ( $T+90$ days). Patient preference for treatment place and patient satisfaction (overall and per item) were assessed quantitatively and qualitatively using questionnaires at $T+4$ days and $T+90$ days. Factors associated with patient preference were analysed in the early discharge group.

Results: 139 patients were randomised. No difference was found in overall satisfaction. At $\mathrm{T}+4$ days, patients in the early discharge group were less satisfied with care at night and were less able to resume normal daily activities. At T+90 days there were no differences for the separate items. Patient preference for home treatment at $\mathrm{T}+4$ days was $42 \%$ in the hospital care group and $86 \%$ in the early discharge group and $35 \%$ and $59 \%$ at T+90 days. Patients' mental state was associated with preference.

Conclusion: Results support the wider implementation of early discharge for COPD exacerbations and this treatment option should be offered to selected patients that prefer home treatment. 


\section{Introduction}

Internationally, there are trends to deliver care in the community and more closely to the patients' home. Combined with a pressure on hospital beds and continuous need to constrain health care costs, this has lead to the development of alternatives for hospital care. Schemes aimed at avoiding hospital admission or reduce length of stay by treating and supervising patients at home, instead of the hospital, are called hospital-at-home schemes [1,2]. Studies have proved that these schemes are safe and have no negative effects on patient outcomes [1-3]. Chronic Obstructive Pulmonary Disease (COPD) exacerbations are responsible for a great number of annual hospital admissions, and accompanying health care costs [4]. Therefore, $44 \%$ of British hospitals runs a hospital-at-home scheme for COPD exacerbations to reduce the pressure on hospital beds [5]. Patient satisfaction with hospital-at-home schemes is high, but results are mainly derived from studies evaluating general schemes, admitting patients with various conditions [6-9]. Three British studies evaluated patient satisfaction with hospital-at-home schemes admitting only patients with COPD exacerbations [10-12]. All studies reported high patient satisfaction. However, the schemes were hospital-based outreach schemes, with specialised respiratory nurses performing visits at home. Recently we have reported that a community-based hospital-at-home scheme for COPD exacerbations, with community nurses performing home visits, has similar patient outcomes as usual hospital care [13]. The economic evaluation, that was performed as part of this clinical trial, also did not show a large cost difference between the 2 treatments [14]. Therefore, the choice between the 2 treatments should be largely based on patient preference. In this study we compared satisfaction with the community-based hospital-at-home scheme and usual hospital care. Furthermore, because satisfaction is a component that influences preference for treatment place, and little is known about the preference for treatment place and which factors influence this preference we also investigated patient preference for treatment place and associated factors. The evaluation took place within a multicentre randomised controlled trial.

\section{Methods}

\section{Design and patients}

The current study was part of a randomised controlled trial, investigating the effectiveness of early assisted discharge for patients admitted to the hospital with a COPD exacerbation [15]. The study was conducted between November 2007 and March 2011 in 5 hospitals and 3 home care organisations. Patients that were considered eligible according to the inclusion and exclusion criteria at admission, and those meeting the criteria of clinical stability on day 3 of admission, were randomised to usual hospital care or early discharge. Those randomised to early discharge, were 
discharged home on the fourth day of admission and visited at home by community nurses that same day and the next 3 days. After a total of 7 days of hospital and home treatment, patients were discharged from the scheme. Patients randomised to usual hospital care continued the hospital treatment for 4 days and were then discharged home. Patients were followed up for 3 months. A detailed description of the trial and the early discharge intervention has been published elsewhere [15]. The trial was approved by the Medical Ethics Committee of the Catharina Hospital Eindhoven, the Netherlands.

\section{Measurements}

Baseline characteristics were collected at admission. Characteristics that were obtained are age, gender, living situation, care at home prior to admission, income, education, coping style with the Utrecht Coping List [16], health status with the Clinical COPD Questionnaire (CCQ) [17], measuring 3 domains: symptoms, functional state and mental state, and comorbidity with the Charlson comorbidity index [18]. Patients' satisfaction and preference for treatment place were measured with a, for this study adapted, questionnaire by Ojoo et al. [10]. Furthermore, we added questions for the early discharge group to evaluate the care received at home. The total questionnaire consisted of 3 parts. The first part consisted of 2 open-end questions asking for 3 aspects that patients were most satisfied and most dissatisfied. The second part consisted of 15 questions, with 5 response options varying from a very positive to a very negative response. The final part was a hypothetical question on where patients would want to be treated if they could choose: in the hospital and partly at home or entirely in the hospital. At the end of the home treatment, the early discharge group received an additional 6 questions for the evaluation of the home care, which covered overall satisfaction, satisfaction with the total number of days that home care was provided, the number of visits each day and the duration of the daily visits (see appendix 1). The questionnaire was completed at 2 moments; at the end of the home or hospital treatment ( $T+4$ days) and after 3-months follow-up ( $T+90$ days).

\section{Analysis}

Each of the answer options of the second part of the satisfaction questionnaire was assigned as score between 1 (completely negative answer) and 5 (completely positive answer) and an overall score was calculated by dividing the total score by the total number of valid questions. Six missing values were allowed. Differences in the overall satisfaction score and differences on the different items were tested using MannWhitney tests. The additional 6 questions for the evaluation of the home care from the early discharge group are reported as percentage of total responses. The comparison of the percentage of patients in both groups preferring home treatment in the hypothetical situation that they could choose between treatments, was analysed using 
Chi-square test. The analysis of which factors influence the preference was only performed with patients from the early discharge group because we wanted to investigate drivers of preference in patients who had actually experienced home treatment. First we performed univariate logistic analyses to determine possible influential factors. Factors that have been tested are: age, gender, living situation (alone vs. with someone), presence of informal caregiver, presence of home care prior to admission, coping styles (active, avoidant and passive style), income, education, number of years diagnosed with COPD, CCQ scores (symptoms, functional state and mental state) at randomisation, and comorbidity (COPD vs. COPD and 1/multiple comorbidities). Factors with $\mathrm{p} \leq 0.1$ in the univariate analysis were included in the multivariate logistic regression. Dependent variable was either preference at $T+4$ days or $\mathrm{T}+90$ days.

Responses to the 2 open-end questions were analysed using deductive content analysis $[19,20]$. Responses were coded and grouped according to the 7 categories described by Sofaer and Firminger [21], namely patient-centred care; access; communication and information; courtesy and emotional support; technical quality; efficiency of care/organisation; and structure and facilities.

\section{Results}

In total 139 patients were randomised, 69 to usual hospital care and 71 to early assisted discharge care. Table 1 provides an overview of the patient characteristics. Both groups appeared to be comparable on baseline characteristics. Immediately after randomisation 7 patients in the usual hospital care group and 3 patients in the early discharge group withdrew consent, because they were not satisfied with the allocated place of treatment. These 7 patients were not different from the other patients in the usual hospital care group, but the 3 patients in the early discharge group that withdrew consent immediately after randomisation had a worse comorbidity score than other patients in this treatment group.

\section{Patient satisfaction}

For 34 patient in the usual care group and 29 patients in the early discharge group, a satisfaction score could be calculated. Overall satisfaction was $70 \%$ in the usual hospital care group and $71 \%$ in the early discharge group (table 2). Two differences in satisfaction items between groups were found. During nights, patients in the early discharge group felt significantly more unsafe in comparison to patients that received usual hospital care. Significantly more patients in the early discharge group felt unable to resume normal daily activities. 
Table 1. Patient characteristics. Scores represent number (\%), unless stated otherwise.

\begin{tabular}{|c|c|c|}
\hline Characteristic & $\begin{array}{l}\text { Usual hospital care } \\
\qquad(\mathrm{N}=69)\end{array}$ & $\begin{array}{c}\text { Early assisted } \\
\text { discharge }(\mathrm{N}=70)\end{array}$ \\
\hline Age (years), mean (SD) & $67.8(11.30)$ & $68.31(10.34)$ \\
\hline Sex: male & $38(55.1)$ & $48(68.6)$ \\
\hline \multicolumn{3}{|l|}{ Charlson comorbidity score ${ }^{\dagger}$} \\
\hline Patients with score $=1$ & $42(60.0)$ & $38(54.0)$ \\
\hline Patients with score $>1$ & $27(39.0)$ & $32(46.0)$ \\
\hline CCQ symptoms (range 0-6), mean (SD)‡ & $2.25(1.05)$ & $2.50(1.05)$ \\
\hline CCQ functional state (range $0-6$ ), mean (SD) $\ddagger$ & $2.61(1.33)$ & $3.33(1.42)$ \\
\hline CCQ mental state (range $0-6$ ), mean (SD) $\ddagger$ & $1.38(1.28)$ & $1.49(1.45)$ \\
\hline \multicolumn{3}{|l|}{ Coping \pm} \\
\hline Active coping style (range 7-28), mean (SD) & $16.72(3.26)$ & $17.98(4.14)$ \\
\hline Passive coping style (range 7-28), mean (SD) & $12.30(3.04)$ & $12.25(3.99)$ \\
\hline Avoidant coping style (range 8-32), mean (SD) & $17.24(3.94)$ & $17.67(3.62)$ \\
\hline \multicolumn{3}{|l|}{ Living situation } \\
\hline Living alone & $21(30.4)$ & $22(31.4)$ \\
\hline Living with partner & $44(63.8)$ & $42(60.0)$ \\
\hline Living with child(ren) & $1(1.4)$ & $2(2.8)$ \\
\hline Living with partner and child(ren) & $3(4.3)$ & $4(5.7)$ \\
\hline \multicolumn{3}{|l|}{ Presence of informal care } \\
\hline Yes & $62(89.9)$ & $62(88.6)$ \\
\hline No & $7(10.1)$ & $8(11.4)$ \\
\hline \multicolumn{3}{|l|}{ Care at home before admission } \\
\hline None & $54(78.3)$ & $53(75.7)$ \\
\hline Nursing care or help with activities of daily living & $2(2.9)$ & $7(10.0)$ \\
\hline Domestic help & $10(14.5)$ & $7(10.0)$ \\
\hline Both & $3(4.3)$ & $3(4.3)$ \\
\hline \multicolumn{3}{|l|}{ Income* } \\
\hline Low & $17(40.5)$ & $18(40.9)$ \\
\hline Medium & $12(28.6)$ & $11(25.0)$ \\
\hline High & $13(31.0)$ & $15(34.1)$ \\
\hline \multicolumn{3}{|l|}{ Education level** } \\
\hline Low & 20 (33.9) & $21(35.0)$ \\
\hline Medium & $26(44.1)$ & $27(45.0)$ \\
\hline High & $15(22.0)$ & $12(20.0)$ \\
\hline \multicolumn{3}{|c|}{$\begin{array}{l}\text { † score of } 1 \text { means COPD only, score }>1 \text { means COPD and other comorbidities; } \neq 0 \text { represents best possible } \\
\text { score and } 6 \text { worst possible score; } \pm \text { higher scores mean higher level of trait; *low refers to monthly family } \\
\text { income } \leq € 1249 \text {, medium refers to monthly family income between } € 1250 \text { and } € 1749 \text {, high refers to monthly } \\
\text { family income } \geq € 1750 \text {. Data are missing or patient did not want to specify in } 27 \text { cases; }{ }^{* * l o w} \text { refers to } \\
\text { (parts) of primary school only, medium refers to lower vocational education or intermediate general } \\
\text { education, high refers to intermediate vocational education or higher general education or higher vocational } \\
\text { training or university. }\end{array}$} \\
\hline
\end{tabular}

More than $60 \%$ of all the patients were very or completely satisfied with the received medication and oxygen treatment. However, 19 of the 102 patients that provided comments in both groups had negative comments about medication errors and the timely distribution of medication, the information on medication and the types of medication. The majority of patients was (very) satisfied with the medical and nursing treatment and care they received in the hospital and/or at home. 


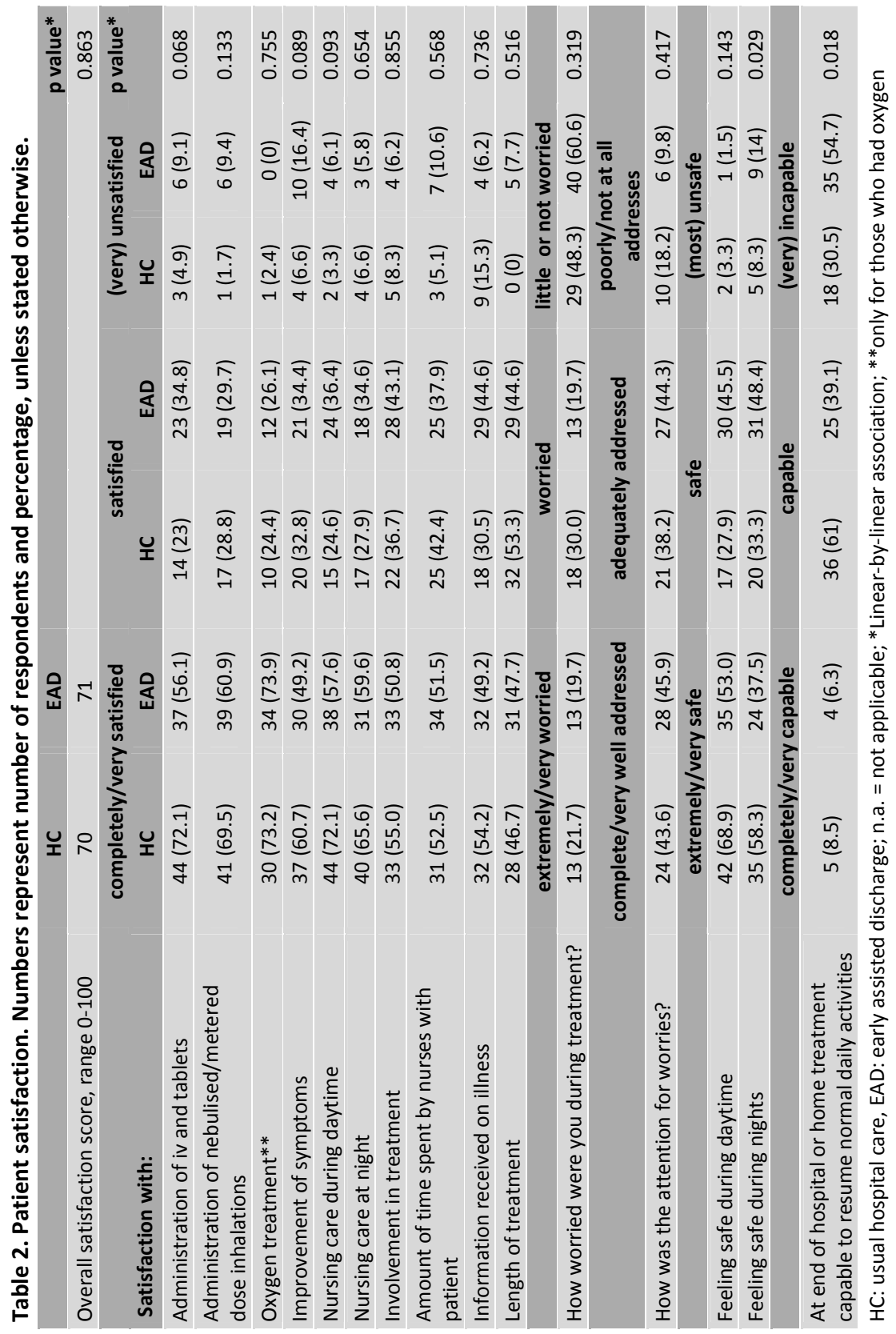


There were positive comments on the clear explanations of staff, the provided information and the counselling patients received. Patients in both groups had negative comments on the information exchange. Early discharged patients experienced problems in the transfer of information between hospital and home, whereas patients that received only hospital care commented that there was unstructured information exchange between professionals.

At $T+90$ days, overall satisfaction was $72 \%$ and $70 \%$ for usual hospital care patients ( 29 valid scores) and early discharge patients (33 valid scores), respectively. No differences between groups were found for the separate questions (data not shown). Patients had positive comments on the respiratory nurses (both from the home care organisation and the hospital). Furthermore patients in both groups commented that they had seen many different doctors and nurses during their treatment or were not seen by their 'own' pulmonologist.

\section{Evaluation of early discharge}

Eighty-five percent of patients that received home care was (very) satisfied. The possibility to go home was appreciated and patients were satisfied with the care they received. Particularly the receive at home by the community nurses was praised. Furthermore, the regular check-ups and visits by the community nurses made patients feel looked after at home.

The average number of home visits per day was 1 . The total number of days that patients received home visits and the number of visits per day was valued as sufficient by $83 \%$ and $97 \%$ of patients. The majority valued the duration of the home visits as sufficient.

\section{Preference for place of treatment}

Figure 1a shows that at $\mathrm{T}+4$ days, $42 \%(\mathrm{~N}=25)$ of patients allocated to hospital treatment and $86 \%(\mathrm{~N}=56)$ of patients allocated to home treatment preferred to be treated at home, if they could choose. Table 3 shows the results of the multivariate analysis on associated factors for preference in the early discharge group. Only CCQ mental state was significantly associated with preference for home treatment. Patients with worse scores were less likely to choose home treatment. The trend for income was inconsistent. At $\mathrm{T}+90$ days the percentage of patients preferring home treatment had decreased to $35 \%(\mathrm{~N}=17)$ and $59 \%(\mathrm{~N}=33)$ in the hospital treatment and home treatment group, respectively (figure $1 \mathrm{~b}$ ). At $\mathrm{T}+90$ days, no variables were associated with preference in the multivariate analysis. 
Table 3. Odds ratios and $95 \%$ confidence intervals for factors associated with patient preference for early assisted discharge

\begin{tabular}{|c|c|c|c|c|}
\hline Preference at day $7 *$ & $\mathbf{N}$ & OR & $95 \% \mathrm{Cl}$ & $p$ value \\
\hline \multicolumn{5}{|c|}{ Long Term Oxygen Treatment } \\
\hline $\mathrm{No}^{\mathrm{a}}$ & 37 & 1 & & \\
\hline Yes & 3 & 0.030 & $0.001-1.302$ & 0.068 \\
\hline \multicolumn{5}{|l|}{ Income } \\
\hline Low $^{a}$ & 17 & 1 & & \\
\hline Medium & 9 & 0.032 & $0.001-0.785$ & 0.035 \\
\hline High & 14 & 3.737 & $0.057-244.181$ & 0.536 \\
\hline \multicolumn{5}{|l|}{ Living situation } \\
\hline With somebody ${ }^{a}$ & 23 & 1 & & \\
\hline Alone & 17 & 0.348 & $0.022-5.411$ & 0.451 \\
\hline CCQ Mental state & 40 & 0.349 & $0.135-0.904$ & 0.030 \\
\hline
\end{tabular}

*Results from multivariate logistic regression; ${ }^{a}$ reference category

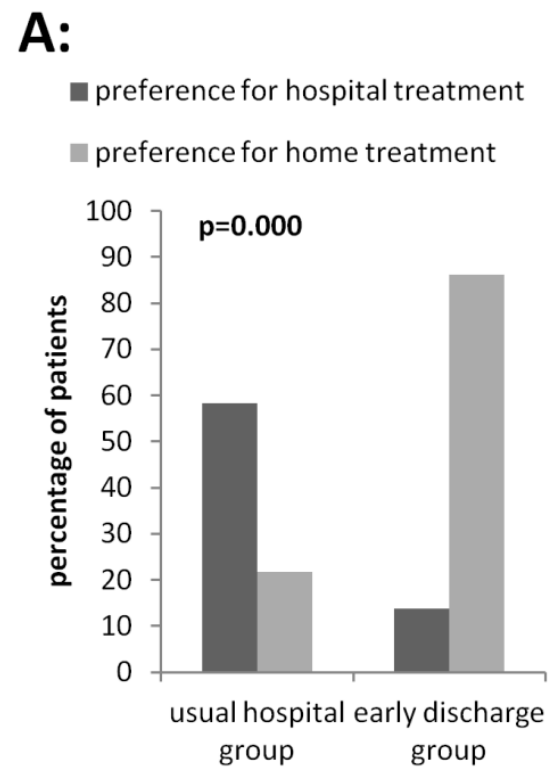

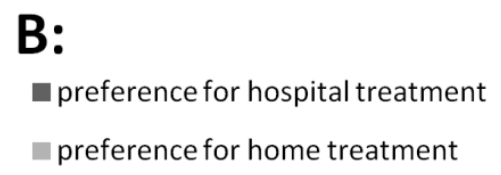

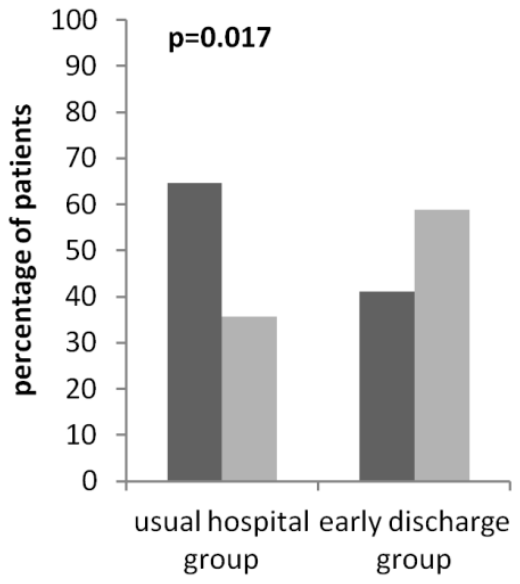

A: $T+4$ days; $B: T+90$ days.

Figure 1. Number of patients preferring hospital and home treatment.

\section{Discussion}

This study shows that patient satisfaction with hospital and home care was high; there was no difference in overall satisfaction between the 2 groups. Safety at night and ability to resume activities was valued significantly worse by patients in the early discharge group. Early discharge was appreciated and satisfaction scores were high. Forty-two percent hospital-treated patients and $86 \%$ of home-treated patients 
preferred home treatment if they could have chosen. In home-treated patients, this preference was influenced by their mental state.

Home-treated patients did not, like hospital-treated patients, have access to nursing care during nights. This may have caused them feeling unsafe during nights. Previous studies showed that help at night is important and an advantage of hospital treatment [22]. When designing and implementing hospital-at-home schemes, nights should be appropriately addressed. On-call night cover could be installed, or, if not possible, patients should be instructed on what problems they might experience at home at night, how to avoid these problems and how to act upon. In our study, a 24-hour telephone access to the hospital was installed. However, no patient used this possibility during the nights.

Patients treated at home reported significantly more often not being capable to resume their normal daily activities. Median time to symptomatic recovery of exacerbations is 7 days [23]. However, complete recovery of health status may take up to 90 days $[23,24]$ and many patients experience difficulties with their daily activities after hospital admission [12]. Hospital-treated patients had not been confronted yet with possible difficulties at home when they completed the questionnaire, which may have overestimated their capabilities to resume normal daily activities. At the end of the 90 days follow up, the difference between the groups regarding this item had disappeared, supporting this explanation. Despite feeling unsafe during nights and being less able to resume activities, most patients in the early discharge still prefer to be treated at home. It is likely that the benefits and advantages patients experience from being treated at home outweigh these disadvantages.

Overall satisfaction with hospital and home care was high, and not different between groups. Many negative responses in both groups were related to medication. Most of these comments could be linked to the hospital. These were not a result of the introduction of early discharge and most likely have been present before.

Overall, patients were very satisfied with the early discharge care. However, patients' comments revealed aspects that could be improved. Coordination of the logistics of the community nursing hampered in several cases. Within the home care organisation separate teams are responsible for defined geographic areas. Teams should be timely informed about the patients' discharge, and visiting arrangements should be confirmed before the patient is discharged. While some patients commented that care at home was not necessary and nurses only came to check upon them, others experienced difficulties at home alone and expected more care, especially in the domestic field. This wide difference in opinion was also found in the study by Taylor at al. [25]. Patients should be explicitly informed about the purpose and objectives of 
early discharge and home treatment and which care can be expected at home. If this is insufficient, the patient should not be early discharged or additional services should be arranged. Patients from both groups commented on the hampering information transfer from hospital to home or between hospital staff. It has been shown that this is an important issue in transfers from secondary to primary care [26,27]. Health care professionals from secondary and primary care should pay attention to this topic, in order to make flawless transitions from hospital to home possible.

Although patients that were treated in the hospital had no experience with home treatment, over half of all patients prefers home treatment, if they would have had the opportunity to choose. This confirms previous results of Ojoo et al. [10] and Schofield et al. [11]. Patients who were treated at home, and were able to make a true comparison, preferred home treatment significantly more often. Patients find it difficult to imagine that at home similar treatment is possible as in the hospital [22], but often adjust their opinion once they have experience home treatment [11].

In the group of home-treated patients we found that patients with worse scores on the mental state domain of the CCQ were less likely to prefer home treatment. Home treatment appeals on the ability of patients to manage with the disease more independently. Schofield et al. [11] found a correlation between attitude towards home care and emotional functioning and coping skills. We found no such association. However, we did find an association between worse emotional functioning and passive coping style. Patients with more negative or anxious thoughts and feelings are less confident that they will be able to manage at home when problems occur. Patients who are better able to ration the purpose of early discharge in relation to hospital care and have better insight in their own role in the scheme, are better able to cope with difficulties at home [11]. Previous studies revealed that patients living alone were treated more often in the hospital [11] and that patients choose to be treated at home as long as informal care giving was present [7]. In our study $30 \%$ of patients lived alone, which did not withhold them from participation to the trial. Fried et al. [22] stated that in patients that prefer home treatment and live alone, without support network, strong self-reliance is an important factor. This supports the conclusion that patients who are better able to manage their symptoms and difficulties will more often choose home treatment.

This study has some limitations. Firstly, the current evaluation was part of a randomised controlled trial. Patients with strong resistance against early discharge and home treatment did not consent to participate, which may have caused selection of patient with positive attitudes towards home treatment. Furthermore, the design of the study was for the comparison of the effectiveness, and therefore not optimal for the comparison of preference. Therefore the analysis of factors influencing preference 
was only performed in patients that experienced both treatments. Secondly, the number of patients in which the preference analysis was performed was small, which might have influenced results. However, this was a pragmatic study reflecting the real situation enhancing validity of results. Finally, because a validated questionnaire for measuring satisfaction with hospital-at-home was not available, we had to develop one ourselves. Our questionnaire contained specific questions on items of the care, which provided a clear view on patients' values. However, like in many patient satisfaction evaluations, we found high satisfaction scores among patients, which may mask real opinions on certain subjects as patients' positive views may be constructed by the perception on different attributes [28]. Satisfaction is determined by the ratio between patients' expectations of care and their perceptions of the actual care received, influenced by previous experiences and personal values [29]. Further research is needed to evaluate hospital-at-home on specific items and to gain more insight in what influences patients satisfaction.

In conclusion, we found no large differences between patients' evaluation of homeand hospital care, but attention should be paid to feeling safe at night during home treatment. Fifty percent of hospital-treated patients over $86 \%$ of home-treated patients preferred home treatment, suggesting an overall preference for home treatment. Mental state is associated with preference for home treatment which is most likely to be associated with being better able to manage the disease independently. In the absence of clear differences in outcomes between hospital-athome and usual hospital care, patient preference plays an important role in the decision to implement hospital-at-home. Results from this study support the wider implementation of hospital-at-home for COPD exacerbations and this treatment option should be offered to selected patients that prefer home treatment over hospital treatment. 


\section{References}

1. Shepperd S, Doll H, Angus RM et al. Admission avoidance hospital at home. Cochrane Database Syst Rev 2008;CD007491.

2. Shepperd S, Doll H, Broad J et al. Early discharge hospital at home. Cochrane Database Syst Rev 2009;CD000356.

3. Ram FS, Wedzicha JA, Wright J et al. Hospital at home for acute exacerbations of chronic obstructive pulmonary disease. Cochrane Database Syst Rev 2003;CD003573.

4. Toy EL, Gallagher KF, Stanley EL et al. The economic impact of exacerbations of chronic obstructive pulmonary disease and exacerbation definition: a review. COPD 2010;7:214-228.

5. Quantrill SJ, Lowe D, Hosker HS et al. Survey of early discharge schemes from the 2003 UK National COPD Audit. Respir Med 2007;101:1026-1031.

6. Montalto M. Patients' and carers' satisfaction with hospital-in-the-home care. Int J Qual Health Care 1996;8:243-251.

7. Dubois A, Santos-Eggimann B. Evaluation of patients' satisfaction with hospital-at-home care. Eval Health Prof 2001;24:84-98.

8. Wilson A, Wynn A, Parker H. Patient and carer satisfaction with 'hospital at home': quantitative and qualitative results from a randomised controlled trial. Br J Gen Pract 2002;52:9-13.

9. Leff B, Burton L, Mader S et al. Satisfaction with hospital at home care. J Am Geriatr Soc 2006;54:1355-1363.

10. Ojoo JC, Moon T, McGlone S et al. Patients' and carers' preferences in two models of care for acute exacerbations of COPD: results of a randomised controlled trial. Thorax 2002;57:167-169.

11. Schofield I, Knussen C, Tolson D. A mixed method study to compare use and experience of hospital care and a nurse-led acute respiratory assessment service offering home care to people with an acute exacerbation of chronic obstructive pulmonary disease. Int J Nurs Stud 2006;43:465-476.

12. Clarke A, Sohanpal R, Wilson G et al. Patients' perceptions of early supported discharge for chronic obstructive pulmonary disease: a qualitative study. Qual Saf Health Care 2010;19:95-98.

13. Utens CM, Goosens LM, Smeenk FW et al. Early assisted discharge with community nursing for Chronic Obstructive Pulmonary Disease exacerbations: results of a randomised controlled trial. Provisionally accepted for publication BMJ open 2012.

14. Goosens LM, Utens CM, Smeenk FW et al. Cost-effectiveness of early assisted discharge for COPD exacerbations in the Netherlands. submitted 2012.

15. Utens CM, Goossens LM, Smeenk FW et al. Effectiveness and cost-effectiveness of early assisted discharge for Chronic Obstructive Pulmonary Disease exacerbations: the design of a randomised controlled trial. BMC Public Health 2010;10:618.

16. Schreurs PJG, van de Willige G, Brosschot JF, Tellegen B, Graus GMH. De Utrechtse Coping Lijst: UCL; Omgaan met problemen en gebeurtenissen. Lisse: Swets en Zeitlinger B.V. 1993.

17. van der Molen T, Willemse BW, Schokker S et al. Development, validity and responsiveness of the Clinical COPD Questionnaire. Health Qual Life Outcomes 2003;1:13.

18. Charlson ME, Pompei P, Ales KL et al. A new method of classifying prognostic comorbidity in longitudinal studies: development and validation. J Chronic Dis 1987;40:373-383.

19. Graneheim UH, Lundman B. Qualitative content analysis in nursing research: concepts, procedures and measures to achieve trustworthiness. Nurse Educ Today 2004;24:105-112.

20. Elo S, Kyngas H. The qualitative content analysis process. J Adv Nurs 2008;62:107-115.

21. Sofaer S, Firminger K. Patient perceptions of the quality of health services. Annu Rev Public Health 2005;26:513-559.

22. Fried TR, van DC, Tinetti ME et al. Older persons' preferences for site of treatment in acute illness. J Gen Intern Med 1998;13:522-527. 


\section{Chapter 6}

23. Seemungal TA, Donaldson GC, Bhowmik A et al. Time course and recovery of exacerbations in patients with chronic obstructive pulmonary disease. Am J Respir Crit Care Med 2000;161:16081613.

24. Seemungal TA, Donaldson GC, Paul EA et al. Effect of exacerbation on quality of life in patients with chronic obstructive pulmonary disease. Am J Respir Crit Care Med 1998;157:1418-1422.

25. Taylor S, Eldridge S, Chang YM et al. Evaluating hospital at home and early discharge schemes for patients with an acute exacerbation of COPD. Chron Respir Dis 2007;4:33-43.

26. Berendsen AJ, de Jong GM, Meyboom-de JB et al. Transition of care: experiences and preferences of patients across the primary/secondary interface - a qualitative study. BMC Health Serv Res 2009;9:62.z

27. Preston C, Cheater F, Baker R et al. Left in limbo: patients' views on care across the primary/secondary interface. Qual Health Care 1999;8:16-21.

28. Fitzpatrick R. Surveys of patients satisfaction: I--Important general considerations. BMJ 1991;302:887-889.

29. Carr-Hill RA. The measurement of patient satisfaction. J Public Health Med 1992;14:236-249. 


\section{INFORMAL CAREGIVER EVALUATION OF AN EARLY}

\section{DISCHARGE HOSPITAL-AT-HOME SCHEME FOR CHRONIC} OBSTRUCTIVE PULMONARY DISEASE (COPD)

\section{EXACERBATIONS}

Cecile MA Utens, Onno CP van Schayck, Lucas MA Goossens, Maureen PMH Ruttenvan Mölken, Dirk RAJ DeMunck, and Frank WJM Smeenk 


\begin{abstract}
Introduction: Informal caregivers play an important role in hospital-at-home schemes. However, little is known about the effects of these scheme on their strain, and whether this treatment is preferred by them. Hospital-at-home for Chronic Obstructive Pulmonary Disease (COPD) exacerbations is widely implemented in some countries and specific evaluations are necessary to determine the effects of these schemes on carer strain, to determine preference for treatment place and satisfaction in hospital-athome schemes.
\end{abstract}

Methods: Concurrently with a randomised controlled trial studying the effectiveness and cost-effectiveness of a community-based early assisted discharge, carer strain, measured with the Caregiver Strain Index, preference for treatment place and satisfaction was measured at the end of the hospital or home treatment (day 7 of treatment, $T+4$ days) and the end of the 3-month follow-up period ( $T+90$ days).

Results: Of the 139 patients, 124 had an informal caregiver, of whom three-quarter was the patients' spouse. There was no significant difference in carer strain at $\mathrm{T}+4$ days (mean difference $0.47,95 \% \mathrm{Cl}-0.96$ to 1.91 ) or at $\mathrm{T}+90$ days (mean difference -0.36 . $95 \% \mathrm{Cl}-1.85$ to 1.35 ). At $\mathrm{T}+4$ days, $33 \%$ of carers of patients allocated to hospital treatment and $71 \%$ of carers of patients allocated to home treatment preferred home treatment, if they could have chosen. At $T+90$ days, this was $44 \%$ and $60 \%$, respectively. Carers were satisfied with home treatment.

Conclusions: In this community-based hospital-at-home scheme there are no differences in carer strain. The majority of carers in this study preferred home treatment over hospital treatment and were satisfied with the treatment the patient received. These results support the dissemination of hospital-at-home for COPD exacerbations. 


\section{Introduction}

Hospital-at-home is an alternative for hospital treatment. Admission avoidance schemes and early assisted discharge schemes aim to reduce the number of admissions and/or the duration of hospital stay. Several studies have shown that these schemes have no adverse effects on patient outcomes, and that patients are satisfied with these types of care [1,2].

Informal caregivers play an important role in hospital-at-home schemes, often providing (additional) care for needs unmet by professional facilities [3]. Although the shift of care from hospital to home might impact carer burden, limited results are available on informal caregivers' experiences in hospital-at-home schemes. Previous studies on informal caregiver strain and burden in hospital-at-home schemes found no differences between hospital-at-home care and hospital care [4,5]. In 1 study caregivers favoured hospital-at-home on several aspects [6]. Furthermore, caregivers were satisfied with the care received within hospital-at-home compared to hospital care [6-12]. However, the studies evaluating informal caregiver strain and satisfaction in hospital-at-home schemes, were schemes that admit patients with several conditions and treatments. Chronic conditions, like Chronic Obstructive Pulmonary Disease (COPD), already have a considerable impact on informal caregivers in general $[13,14]$. Shepperd et al. [5] showed differences in baseline caregiver strain among patient groups in their hospital-at-home evaluation, with carers of COPD patients having much worse scores than the other groups at baseline. In some countries, hospital-at-home for COPD exacerbations is a widely implemented alternative for hospital treatment. Specific evaluations of effects on informal caregivers of COPD patients are needed to evaluate to which extend hospital-at-home has an effect on them. In addition, results on caregiver preference for treatment place and satisfaction with care are limited and little is known on preference for treatment place.

The current study evaluates a community-based hospital-at-home scheme from the perspective of the informal caregivers. The early discharge scheme included only patients admitted to the hospital with an exacerbation of their COPD. This study has 3 objectives:

Firstly, to compare informal caregiver strain in early assisted discharge and usual hospital care. Secondly, to compare informal caregivers' preference for treatment place and which factors are associated with this preference. Thirdly, to compare informal caregivers' satisfaction with early assisted discharge care and hospital care. 


\section{Methods}

\section{Design}

The current study was part of a randomised controlled trial evaluating the effectiveness and cost-effectiveness of early assisted discharge for COPD exacerbations. Patients eligible for early assisted discharge and consenting to participate, were randomised on the third day of admission to usual hospital care or early assisted discharge care. Patients in the early discharge group were discharged home the next day and visited that day and the 3 consecutive days by community nurses at home. The total hospital or hospital and home treatment was 7 days, followed by 3-months follow-up. A full and detailed description of the trial and the early assisted discharge intervention has been published elsewhere [15]. During the first 3 days of the admission patients were asked if they had an informal caregiver, and if so, who was the main informal caregiver. Main informal caregiver is someone close to the patient who provides additional support. The support could be emotional, physical or practical.

\section{Measurements}

Informal caregivers were asked to complete a questionnaire on 2 time points. The first was at the end of the hospital or home treatment (overall the $7^{\text {th }}$ day of the treatment, $T+4$ days) when patients were discharged from the hospital or from the early discharge scheme. Second measurement was at the end of the 3-month follow-up period. The questionnaire consisted of 3 parts. The first part was the Caregiver Strain Index (CSI) [16]. The CSI is a 13-item questionnaire with yes/no answering options. It measures different elements of carer strain and calculates an overall strain score. A score of 7 or more indicates that there is substantial burden and possibly overburden [17]. Second part of the survey was a single question on where informal caregivers preferred the patient to be treated if they could have chosen: hospital or home. Third part of the questionnaire consisted of 13 questions with 5 response options varying from very positive to very negative, evaluating informal caregiver' satisfaction with hospital and home treatment. This part was based on a questionnaire by Ojoo et al. [8] and adapted for this study. Finally 2 open-end question asked caregivers to write down the 3 things they were most satisfied and dissatisfied about concerning the care the patient received. Informal caregivers in the early assisted discharge group were asked to complete an additional set of 5 questions, evaluating the home visits. The questions covered overall satisfaction with early discharge and specific topics such as satisfaction with the total number of home visits, the number of home visits per day and the duration of visits. 


\section{Statistical analysis}

Differences in the proportion of caregivers answering 'yes' to each of the CSI items, and differences in the proportion of caregivers with scores of $\geq 7$ were analysed with Chi-square tests and presented as \% of total. Total CSI scores were presented as means (SD). Differences in total CSI score were analysed using ANCOVA, including covariates with $\mathrm{p} \leq 0.1$ after backward deletion. Covariates that were tested are caregivers' gender, living situation of caregiver (with patient or not with patient), relation of caregiver to patient (spouse, child or other), presence of home care for patient prior to admission, family income, patients' age, Charlson comorbidity score [18] for patient (only COPD or COPD and other comorbidity), number of years patient is diagnosed with COPD, patients' CCQ symptoms score, CCQ mental state and CCQ functional state $[19,20]$. At $T+4$ days patients' age and CCQ functional state were retained in the final analysis model, at $\mathrm{T}+90$ days patients' age, patients' comorbidity and number of years with diagnosis were retained in the model. The comparison of the percentage of informal caregivers in both groups hypothetically preferring home treatment was analysed using Chi-square test. The analysis of which factors influence the preference was only performed with caregivers from the early discharge group to create a homogeneous group that had experienced both hospital and home treatment. First we performed univariate logistic analyses to determine possible influential factors. Factors that were tested were the same as in the CSI analysis, extended with CSI score and preference of patient. Factors with $p \leq 0.1$ in the univariate analysis were included in the multivariate logistic regression analysis. Dependent variable was either preference at $T+4$ days or $T+90$ days. Each of the answer options of the satisfaction questionnaire was assigned as score between 1 (completely negative answer) and 5 (completely positive answer) and an overall satisfaction score was calculated by dividing the total score by the total number of questions. The maximum of missing values was 4 . Differences in the overall satisfaction score and differences in satisfaction scores for each item was performed using Mann-Whitney tests. Responses from the early discharge group to the additional questions evaluating the home care were analysed as percentage of total responses. Responses to the open-end questions were analysed using qualitative content analysis. First and second level coding were used to explore the data and identify themes.

\section{Results}

In total 139 patients were randomised to either usual hospital care $(\mathrm{N}=69)$ or early assisted discharge $(\mathrm{N}=70)$. Sixty-two patients in the usual hospital care group had an informal caregiver and 62 in the early assisted discharge group. Table 1 shows the patients' and informal caregivers' characteristics. The percentage of female informal caregivers was higher in the early assisted discharge group in comparison to the usual 
hospital care group (79.1\% vs. $59.7 \%$ ), but there were more male patients in the early discharge group. The majority of caregivers was the patients' spouse.

Table 1. Characteristics of patients and their informal caregivers. Numbers represent the number (\%) of patients/carers, unless stated otherwise.

\begin{tabular}{|c|c|c|}
\hline Patients & $\begin{array}{l}\text { Usual hospital care } \\
\qquad N=69\end{array}$ & $\begin{array}{l}\text { Early assisted discharge } \\
\qquad \mathrm{N}=70\end{array}$ \\
\hline Males & $38(55.1)$ & $48(68.6)$ \\
\hline Patients living alone & $21(30.4)$ & $22(31.4)$ \\
\hline Patients with no direct caregiver & $7(101)$ & $8(11.4)$ \\
\hline \multicolumn{3}{|l|}{ Family income* } \\
\hline Low & $17(40.5)$ & $18(40.9)$ \\
\hline Medium & $12(28.6)$ & $11(25.0)$ \\
\hline High & $13(31.0)$ & $15(34.1)$ \\
\hline \multicolumn{3}{|l|}{ Comorbidity scores [18] } \\
\hline Charlson score $=1^{* *}$ & $42(60.9)$ & $38(54.3)$ \\
\hline Charlson score $>1 * *$ & $27(39.1)$ & $32(45.7)$ \\
\hline $\begin{array}{l}\text { Number of years diagnosed with COPD, } \\
\text { mean (SD) }\end{array}$ & $8.3(1.0)$ & $8.2(1.0)$ \\
\hline \multicolumn{3}{|l|}{ Clinical COPD Questionnaire score $[20]^{* * *}$} \\
\hline Symptoms, mean (SD) & $2.25(1.05)$ & $2.50(1.05)$ \\
\hline Functional state, mean (SD) & $2.61(1.33)$ & $3.33(1.42)$ \\
\hline Mental state, mean (SD) & $1.38(1.28)$ & $1.49(1.45)$ \\
\hline Informal caregivers & $\begin{array}{l}\text { Usual hospital care } \\
\qquad N=62\end{array}$ & $\begin{array}{l}\text { Early assisted discharge } \\
\qquad N=62\end{array}$ \\
\hline Female & $37(59.7)$ & 49 (79.0) \\
\hline \multicolumn{3}{|l|}{ Relation to patient } \\
\hline Spouse & $45(72.6)$ & $46(74.2)$ \\
\hline Child (son or daughter) & $10(16.1)$ & $14(22.6)$ \\
\hline Sister/brother & $1(1.6)$ & $1(1.6)$ \\
\hline Non-family & $3(4.8)$ & $1(1.6)$ \\
\hline Unknown & $3(4.8)$ & $0(0.0)$ \\
\hline Living with patient & $46(74.2)$ & $48(77.4)$ \\
\hline \multicolumn{3}{|c|}{$\begin{array}{l}\text { *Low refers to monthly family income } \leq € 1249 \text {, medium refers to monthly family income between } € 1250 \\
\text { and } € 1749 \text {, high refers to monthly family income } \geq € 1750 \text {. Data are missing or patient did not want to } \\
\text { specify in } 27 \text { cases; }{ }^{* *} \text { Score of } 1 \text { means COPD only, score of }>1 \text { means co-existing morbidities besides } \\
\text { COPD. Higher scores means more comorbidities; }{ }^{* *} \text { Clinical COPD Questionnaire measures health status. } \\
\text { Score of } 0 \text { is best possible score, score of } 6 \text { is worst possible score. }\end{array}$} \\
\hline
\end{tabular}

\section{Informal caregiver burden}

Table 2 shows the results of the CSI measured at T+4 days and T+90 days. There were no differences in the proportion of caregivers answering 'yes' to the different CSI items. ANCOVA analysis of difference in CSI score at $\mathrm{T}+4$ days showed no difference between the groups (mean difference $0.47,95 \% \mathrm{Cl}-0.96$ to 1.91 ), nor at $\mathrm{T}+90$ days (mean difference $-0.36,95 \% \mathrm{Cl}-1.85$ to 1.35 ). At discharge from hospital or the early discharge scheme, 12 informal caregivers (25\%) from the early discharge group and 7 $(17 \%)$ in the usual hospital care group had scores indicating substantial burden (scores $\geq 7)$. At $\mathrm{T}+90$ days this was $8(20 \%)$ and $3(9 \%)$. 
Informal Caregiver Evaluation 121

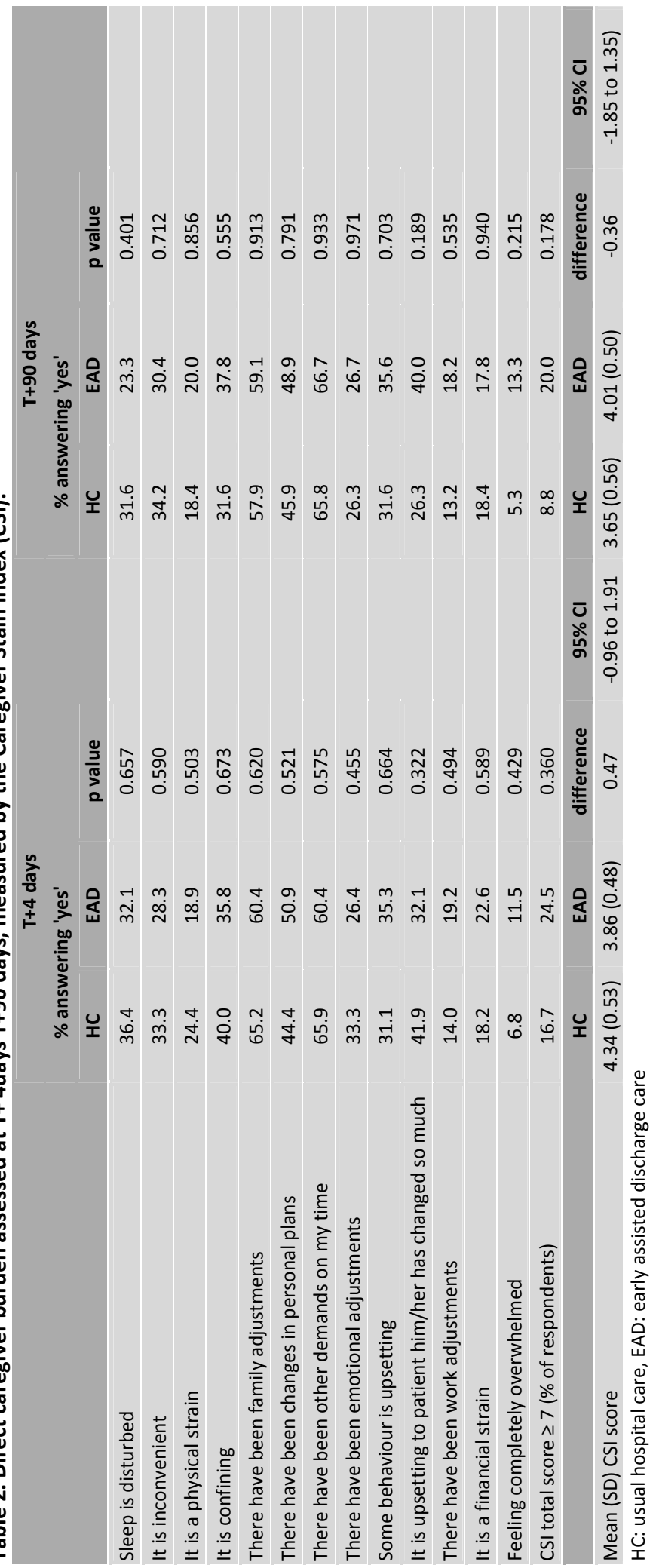




\section{Preference for place of treatment}

At the end of the hospital or home treatment, 33.3\% of informal caregivers of patients allocated to hospital treatment and $71.2 \%$ of informal caregivers of patients who were allocated to home treatment answered that they would have wanted to be treated at home if they could choose $(p=0.000)$. Table 3 shows the results of the multivariate logistic regression in the early discharge group on which factors are associated with caregiver preference. At $\mathrm{T}+4$ days comorbidity lost significance in the multivariate analysis and only patient preference was associated with caregiver preference. Informal caregivers of patients that preferred home treatment more often preferred home treatment as well. At ( $\mathrm{T}+90$ days), $44 \%$ of caregivers in the hospital group and $60 \%$ of carers in the early discharge group preferred home treatment if they could choose $(p=0.033)$. In the multivariate no factors appeared to be significantly associated with caregiver preference.

Table 3. Odds ratios and $95 \%$ confidence intervals for factors associated with informal caregiver preference for early assisted discharge at day 7 of treatment and at 3-months follow up.

\begin{tabular}{|c|c|c|c|c|}
\hline Preference at day $7, T+4$ days* & $\mathbf{N}$ & OR & $95 \% \mathrm{Cl}$ & $p$ value \\
\hline \multicolumn{5}{|l|}{ Patient preference } \\
\hline Preference hospital care ${ }^{a}$ & 31 & 1 & & \\
\hline $\begin{array}{l}\text { Preference early assisted } \\
\text { discharge care }\end{array}$ & 64 & 11.16 & 3.32 to 37.51 & 0.000 \\
\hline \multicolumn{5}{|l|}{ Co morbidity (patient) } \\
\hline Charlson score $=1^{\mathrm{a}}$ & 55 & 1 & & \\
\hline Charlson score $>1$ & 40 & 1.94 & 0.68 to 5.37 & 0.217 \\
\hline Preference at follow-up, $\mathrm{T}+90$ days* & $\mathbf{N}$ & OR & $95 \% \mathrm{Cl}$ & $p$ value \\
\hline \multicolumn{5}{|l|}{ Patient preference } \\
\hline Preference hospital care ${ }^{a}$ & 12 & 1 & & \\
\hline $\begin{array}{l}\text { Preference early assisted } \\
\text { discharge care }\end{array}$ & 25 & 5.19 & 0.84 to 32.05 & 0.076 \\
\hline CSI at follow-up & 37 & 0.64 & 0.31 to 1.34 & 0.240 \\
\hline CCQ mental state at randomisation & 37 & 0.82 & 0.63 to 1.06 & 0.128 \\
\hline
\end{tabular}

*Results from multivariate logistic regression; ${ }^{2}$ Reference category

\section{Informal caregiver satisfaction}

At $\mathrm{T}+4$ days overall satisfaction was $64 \%$ in the usual hospital care group and $60 \%$ in the early discharge group. At $\mathrm{T}+90$ days this was $59 \%$ and $58 \%$, respectively. Table 4 shows the results of the separate items of the informal caregiver evaluation at the end of the hospital and home treatment. For only 1 aspect there was found a significant difference between caregivers from patients in usual hospital care and early assisted discharge. Informal caregivers from patients that were early discharged were significantly less satisfied with the duration of treatment. Informal caregivers were worried during the treatment and in over $40 \%$ of caregivers these worries were poorly addressed. Those caregivers who cared for patients that were early discharged were 
\begin{tabular}{l|l} 
Informal Caregiver Evaluation & 123
\end{tabular}

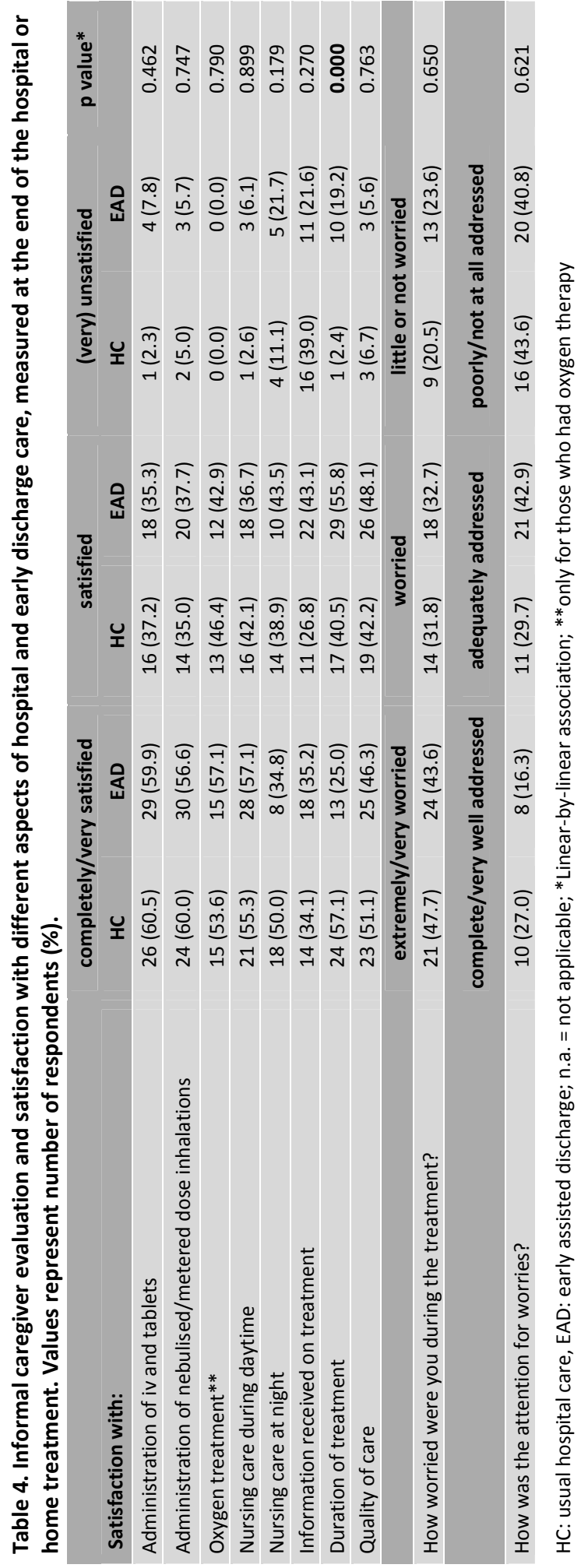


less satisfied with the nursing care during nights. At $T+90$ days there were no differences in valuation between the groups (data not shown).

Forty-two informal caregivers from hospital care and 53 informal caregivers from early discharge provided responses to the open-end questions on what they were most satisfied and dissatisfied about. There were positive comments from informal caregivers in both groups on the 'care' and the 'treatment' the patient received. Caregivers randomised to usual hospital care were very pleased with the nursing care and nursing staff that treated them and the patient kindly, correctly and attentively. Informal caregivers that experienced early discharge had many positive comments on both the hospital care and the home care, of which many focussed on the counselling patients received at the hospital and at home

The contact with the nurse, that the nurses were within easy reach and that the nurses took the personal preferences of patients and carers into consideration was much appreciated. Informal caregivers appreciated the possibility for patients to be early discharged and the follow-up nursing care at home. Several advantages of early discharge for themselves and the patient they cared for were mentioned. The patient being at home meant less travelling up and down the hospital for them. Others appreciated the quiet, homely environment that felt safe and the better sleep the patient got at home. Also the reciprocal support between spouses and the companionship was appreciated when the patient was at home instead of the hospital.

The majority of informal caregivers experienced the number of days that home visits were performed as sufficient. In addition, the number of visits per day and the duration of each visits was experienced as sufficient by $89 \%$ of the caregivers. Three carers from the early assisted discharge group said it was very clear to them where to go to in case of emergencies and were reassured by the possibility to ask questions to the (respiratory) nurses and that there was always a bed for the patients if necessary. There were also negative comments on the care at home. Some commented that the nurses had insufficient knowledge on early discharge or the treatment, others had negative experiences with the logistics of the home visits (no visit or nurses that were late). Also disadvantages of early discharge were mentioned. Informal caregivers commented that they felt that the patient was discharged home too early or that the number of visits per day was too little. Others said that the dyspnoea of the patient was scaring/alarming for them.

Overall, informal caregivers in both groups had negative comments on the medication (errors, type of medication, the delivery, information on medication) and hospital facilities (hygiene, small and crowded rooms and lack of privacy). Caregivers in both 
groups also had negative comments on the coordination and continuity of care. This was specified to information transfer between hospital and general practitioners or other care facilities and to contacts between hospital specialists and general practitioners.

\section{Discussion}

To our knowledge this is the first study that evaluates strain of informal caregivers within an early discharge scheme that only admits patients with a COPD exacerbation. There was no difference in caregiver strain between early assisted discharge and usual hospital care. The majority of informal caregivers preferred home treatment. Patient preference for home treatment is strongly associated with informal caregivers' preference for home treatment. Overall, informal caregivers were satisfied with early assisted discharge.

In our study, which focussed only on informal caregivers from patients with COPD, we found no difference between caregiver strain in early assisted discharge and usual hospital care. This corresponds with the results from previous studies evaluating hospital-at-home schemes that admitted patients with various conditions [4-6,21-23]. This weakens claims of increased caregiver strain in hospital-at-home schemes. The earlier discharge of patients to home might be accompanied by a (temporary) increased activities by carers, but as Leff et al. [6] stated, this does not necessarily lead to increased strain. Furthermore, Werner et al. [24] showed that informal caregivers also may gain satisfaction (utility) from the process of informal caregiving rather than from a positive health outcome only. Finally, although hospital treatment might relieve caregivers from some of the caring tasks, hospital treatment also has disadvantages for caregivers as was revealed by the caregivers' responses in our study and previous literature [10]. These results suggest that informal caregivers balance the positive and negative aspects of hospital care and hospital-at-home care, leading to a neutral outcome with regard to strain.

We found that significantly more caregivers from the early discharge group prefer home treatment, if they could have chosen $(71.2 \%$ in the early discharge vs. $33.3 \%$ in usual hospital care group), which confirms results of previous studies $[8,25]$. Consistent with previous results, informal caregivers were more likely to prefer home treatment when the patients' preference for treatment place was home $[25,26]$. Informal caregivers are often in a conducive position towards patients, especially when they are female (wives and daughters), and make choices for the benefit of the person they care for. This was also revealed in our study in the remarks of benefits of home treatment that mainly focussed on benefits for the patient rather than for the caregiver selves. As was stated by Montalto [9], there is a risk that informal caregivers 
feel pressured by the patients' preferences or choice. Informal caregivers for COPD patients are often accustomed to increased caring tasks $[14,27,28]$ and at risk for overburden. Hospital staff should take into consideration caregivers' position and ability to bear the care at home when selecting patients for early discharge.

Satisfaction with early assisted discharge care and hospital care was high. This confirms the results of Lemelin et al. [26]. However, results are difficult to compare because of difference in questionnaires and study subjects. In our study, the only difference in satisfaction was found in satisfaction on duration of treatment. Informal caregivers in the early assisted discharge group were less satisfied with the duration. However, responses on the questions on the number of days that care at home was received showed that for over $90 \%$ ( 25 of 27 responses) this was a sufficient number of days. Literature has shown that patients, and probably caregivers as well, often do not interpret care in the hospital followed by 4 days care at home as 1 treatment episode but rather as 2 separate periods [29]. This should be addressed during the hospital stay in order to prevent unmet expectations on the care at home.

Informal caregivers from both groups had negative comments on the coordination and continuity of care. This is a known problem in health care and not necessarily associated with hospital-at-home. However, because of the involvement of 2 types of care providers (hospitals and home care organisation) on different levels of care (secondary care and primary care), care in community-based hospital-at-home schemes is more at risk for discontinuities and coordinative problems. When implementing hospital-at-home schemes, attention should be paid to the coordination and continuity of care.

Strength of this study is that our hospital-at-home scheme only admits patients admitted to the hospital with a COPD exacerbation. Therefore we are better able to draw conclusions on the effect of hospital-at-home on informal caregivers and their preferences. However, a weakness might be that the study population involved informal caregivers from patients that agreed to participate in the trial. As caregivers were often involved in the patients' decision to participate, the study population is more likely to have a positive attitude towards early discharge. This may have biased the results towards lower estimates of strain, higher preference for home treatment and higher satisfaction scores. The number of carers that provided valid questionnaires was small, which may have reduced the power of this study. Finally, the questionnaire used to evaluate early discharge along usual hospital care has not been validated. However, we believe our questionnaire contained items on specific aspects of care which provided insight in informal caregivers' evaluation of both early discharge and 
hospital care. Nonetheless, more research is needed to gain more insight in caregivers opinions on hospital-at-home care, and how these opinions are constructed.

In conclusion, we found no differences in caregiver strain between early assisted discharge and usual hospital care. Patients preferred the treatment they received, which means place of treatment is of inferior importance in patients opinion. Informal caregivers are inclined to prefer early discharge when the patient also prefers early discharge. There is a risk that informal caregivers feel pressured by the preference of patients, which should be taken into account by hospital staff. Satisfaction is high, although there is room for improvement. Results of the current study support the dissemination of hospital-at-home for selected patients from the informal caregivers' point of view. In the absence of a clear difference in effectiveness between early discharge and usual hospital care, early discharge should be a treatment option for those patients and informal caregivers that prefer home treatment. When implemented, attention is needed for adequate coordination and continuity of care. 


\section{References}

1. Shepperd S, Doll H, Angus RM et al. Admission avoidance hospital at home. Cochrane Database Syst Rev 2008;CD007491.

2. Shepperd S, Doll H, Broad J et al. Early discharge hospital at home. Cochrane Database Syst Rev 2009;CD000356.

3. Montalto M. Hospital in the Home principles \& practice. Ivanhoe, Victoria, Australia: ArtWords Pty Ltd 2002.

4. Gunnell D, Coast J, Richards SH et al. How great a burden does early discharge to hospital-athome impose on carers? A randomized controlled trial. Age Ageing 2000;29:137-142.

5. Shepperd S, Harwood D, Jenkinson C et al. Randomised controlled trial comparing hospital at home care with inpatient hospital care. I: three month follow up of health outcomes. BMJ 1998;316:1786-1791.

6. Leff B, Burton L, Mader SL et al. Comparison of stress experienced by family members of patients treated in hospital at home with that of those receiving traditional acute hospital care. J Am Geriatr Soc 2008;56:117-123.

7. Skwarska E, Cohen G, Skwarski KM et al. Randomized controlled trial of supported discharge in patients with exacerbations of chronic obstructive pulmonary disease. Thorax 2000;55:907-912.

8. Ojoo JC, Moon T, McGlone S et al. Patients' and carers' preferences in two models of care for acute exacerbations of COPD: results of a randomised controlled trial. Thorax 2002;57:167-169.

9. Montalto M. Patients' and carers' satisfaction with hospital-in-the-home care. Int J Qual Health Care 1996;8:243-251.

10. Wilson A, Wynn A, Parker H. Patient and carer satisfaction with 'hospital at home': quantitative and qualitative results from a randomised controlled trial. Br J Gen Pract 2002;52:9-13.

11. Leff B, Burton L, Mader S et al. Satisfaction with hospital at home care. J Am Geriatr Soc 2006;54:1355-1363.

12. Caplan GA, Ward JA, Brennan NJ et al. Hospital in the home: a randomised controlled trial. Med J Aust 1999;170:156-160.

13. Baanders AN, Heijmans MJ. The impact of chronic diseases: the partner's perspective. Fam Community Health 2007;30:305-317.

14. Sexton DL, Munro BH. Impact of a husband's chronic illness (COPD) on the spouse's life. Res Nurs Health 1985;8:83-90.

15. Utens CM, Goossens LM, Smeenk FW et al. Effectiveness and cost-effectiveness of early assisted discharge for Chronic Obstructive Pulmonary Disease exacerbations: the design of a randomised controlled trial. BMC Public Health 2010;10:618.

16. Robinson BC. Validation of a Caregiver Strain Index. J Gerontol 1983;38:344-348.

17. Wilkinson PR, Wolfe CD, Warburton FG et al. A long-term follow-up of stroke patients. Stroke 1997;28:507-512.

18. Charlson ME, Pompei P, Ales KL et al. A new method of classifying prognostic comorbidity in longitudinal studies: development and validation. J Chronic Dis 1987;40:373-383.

19. Kocks JW, Tuinenga MG, Uil SM et al. Health status measurement in COPD: the minimal clinically important difference of the clinical COPD questionnaire. Respir Res 2006;7:62.

20. van der Molen T, Willemse BW, Schokker S et al. Development, validity and responsiveness of the Clinical COPD Questionnaire. Health Qual Life Outcomes 2003;1:13.

21. Askim T, Rohweder G, Lydersen S et al. Evaluation of an extended stroke unit service with early supported discharge for patients living in a rural community. A randomized controlled trial. Clin Rehabil 2004;18:238-248.

22. Donnelly $\mathrm{M}$, Power $\mathrm{M}$, Russell $\mathrm{M}$ et al. Randomized controlled trial of an early discharge rehabilitation service: the Belfast Community Stroke Trial. Stroke 2004;35:127-133. 
23. Rudd AG, Wolfe $C D$, Tilling $\mathrm{K}$ et al. Randomised controlled trial to evaluate early discharge scheme for patients with stroke. BMJ 1997;315:1039-1044.

24. Brouwer WB, van Exel NJ, van den Berg B et al. Process utility from providing informal care: the benefit of caring. Health Policy 2005;74:85-99.

25. Schofield I, Knussen C, Tolson D. A mixed method study to compare use and experience of hospital care and a nurse-led acute respiratory assessment service offering home care to people with an acute exacerbation of chronic obstructive pulmonary disease. Int J Nurs Stud 2006;43:465-476.

26. Lemelin J, Hogg WE, Dahrouge S et al. Patient, informal caregiver and care provider acceptance of a hospital in the home program in Ontario, Canada. BMC Health Serv Res 2007;7:130.

27. Bergs D. "The Hidden Client"--women caring for husbands with COPD: their experience of quality of life. J Clin Nurs 2002;11:613-621.

28. Cain CJ, Newsome Wicks M. Caregiver Attributes as Correlates of Burden in Family Caregivers Coping With Chronic Obstructive Pulmonary Disease. Journal of Family Nursing 2000;6:46-68.

29. Clarke A, Sohanpal R, Wilson G et al. Patients' perceptions of early supported discharge for chronic obstructive pulmonary disease: a qualitative study. Qual Saf Health Care 2010;19:95-98. 



\section{EVALUATION OF HEALTH CARE PROVIDERS' ROLE TRANSITION AND SATISFACTION IN HOSPITAL-AT-HOME FOR COPD EXACERBATIONS: A SURVEY STUDY}

Cecile MA Utens, Lucas MA Goossens, Onno CP van Schayck, Maureen PMH Ruttenvan Mölken, Maria W Braken, Loes MGA van Eijsden and Frank WJM Smeenk 


\begin{abstract}
Background: Hospital-at-home is an accepted alternative for usual hospital treatment for patients with a Chronic Obstructive Pulmonary Disease (COPD) exacerbation. The introduction of hospital-at-home may lead to changes in health care providers' roles and responsibilities. To date, the impact on providers' roles is unknown and in addition, little is known about the satisfaction and acceptance of care providers involved in hospital-at-home.
\end{abstract}

Methods: This survey study investigated the role differentiation, role transitions and satisfaction of professional care providers (i.e. pulmonologists, residents, hospital respiratory nurses, generic and specialised community nurses and general practitioners) from 3 hospitals and 2 home care organisations, involved in a community-based hospital-at-home scheme. A combined multiple-choice and openend questionnaire was administered in study participants.

Results: Response rate varied between $30 \%$ in community nurses and $75 \%$ in hospital respiratory nurses. For over $60 \%$ of respondents the role in early discharge was clear and over $50 \%$ was satisfied with their role in early discharge. For nurses the role in early discharge was different compared to their role in usual care. Sixty-seven percent of generic community nurses felt they had sufficient knowledge and skills to monitor patients at home, compared to $100 \%$ of specialised community nurses. Specialised community nurses responded that generic community nurses did not have sufficient knowledge and skills for monitoring patients and felt they should monitor patients, whereas $60 \%$ of generic community nurses responded they should monitor patients at home. Up to $80 \%$ all respondents was satisfied with early discharge in general. Community nurses and specialised hospital nurses had up to $30 \%$ unsatisfied responses on coordination and continuity of care.

Conclusion: A community-based early assisted discharge for COPD exacerbations is possible and well accepted from the perspective of health care providers' involved. Satisfaction with the different aspect is good and the transfer of patients in the community while supervised by generic community nurses is possible. Attention should be paid to coordination and continuity of care, especially information transfer between pulmonologists and general practitioners, and between hospital and community nurses. 


\section{Background}

Health care systems are being confronted with aging populations and an increasing prevalence of chronic illnesses, like Chronic Obstructive Pulmonary Disease (COPD) [1]. In COPD, exacerbations and hospitalisations are the main contributors to high health care costs and cause a continuous pressure on hospital beds [2,3]. As a reaction, alternative treatment schemes for hospital treatment are being developed. One widely accepted alternative is hospital-at-home, in which patients who would otherwise be hospitalised are being cared for at home by nurses [4-6]. Depending on their design, hospital-at-home schemes aim at reducing length of hospital stay (so-called early discharge schemes), or avoiding hospital admission [7,8]. It has been proved that hospital-at-home has no negative effects on patient outcomes $[6,9]$.

The introduction of hospital-at-home within a health care system may lead to changes in health care providers' roles, as patients are transferred to primary care while they would otherwise remain treated in secondary care. In addition, little is known about the satisfaction and acceptance of health care providers involved in hospital-at-home, which is necessary in order to reach successful implementation of the schemes. Three studies evaluated hospital-at-home from the perspective of 1 or more health care providers [10-12]. They reported positive results on the characteristics and operation of the schemes and on the satisfaction of the health care providers involved. Our hospital-at-home scheme is a community-based early assisted discharge scheme, in which care at home is delivered by community nurses and which only accepts patients with a COPD exacerbation. The impact of the transfer of patients on nurses and other health care providers' roles in a community-based hospital-at-home scheme is unclear. The experience of nurses and all other health care providers involved in a communitybased scheme is also unclear. Therefore, the current study has 2 aims:

1) To describe the role differentiation and role transition of health care providers involved in a community-based, early assisted discharge, hospitalat-home scheme for COPD exacerbations.

2) To evaluate health care provider satisfaction with a community-based, early assisted discharge, hospital-at-home scheme for COPD exacerbations.

\section{Methods}

\section{Setting and design}

The current study was part of a randomised controlled trial studying the effectiveness and cost-effectiveness of a community-based hospital-at-home scheme for COPD exacerbations. In this multi-centre trial, patients admitted with an exacerbation COPD were screened for participation to the trial according to the inclusion and exclusion criteria [13]. Eligible patients received 3 days of usual hospital care and were then randomised into further usual hospital care or early assisted discharge. The early 
discharge group was transferred home on the fourth day of admission and received care at home for the consecutive 4 days. Home care was, in principle, delivered by generic community nurses of the local home care organisation. Community nurses specialised in respiratory diseases, performed a follow-up visit that was scheduled between the $10^{\text {th }}$ and $14^{\text {th }}$ day of the overall treatment. The usual hospital care group continued to receive hospital care as usual.

Community nurses were informed about the patient's condition and care needs through a nursing discharge form including information on the treatment period in the hospital. The form was transferred home by the patient and available for examination to the visiting community nurses. Medical discharge notes were written by the responsible resident and sent by mail to the general practitioner, accompanied by a specific letter on the patient's participation to the trial. A copy of the trial participation letter was provided to patients to keep at home and bring it when visiting the general practitioners in case the letter had not been received yet. The multi-centre trial ran from November 2007 until March 2011. In order to avoid long recall periods and to be able to include as many respondents as possible we performed the current study between March and June 2010. The study was performed according to the Helsinki Declaration. Under Dutch law ethical approval or informed consent procedure is not required for studies not involving patients or studies in which people are not subjected to procedures or are required to follow rules of behaviour, and was therefore not sought and obtained for this study.

\section{Participants}

Participants of this study were the health care providers involved in the hospital-athome scheme from both primary and secondary care, i.e. pulmonologists, residents in training for pulmonology and respiratory nurses, all employed by the hospital and generic community nurses and community nurses with a speciality in respiratory diseases, employed by the home care organisation. The community nurses monitored the patients' recovery at home and provided counselling and reassurance to the patient and their primary informal caregiver. Medication compliance and inhalation techniques, adherence to breathing and coughing techniques, adherence to dietary advices and support daily life activities, were addressed as well. Pulmonologists and residents in training for pulmonology were responsible for the care during admission and performed the outpatient follow-up. Respiratory nurses in the hospital performed the outpatient follow-up. They were also in charge of the logistics of the trial activities (patient recruitment, patient data collection, etc.). General practitioners were informed about the patient's participation in the trial, but were not officially involved in the early assisted discharge scheme during the trial period. However, because this scheme has an integrated care character, we wanted to investigate general practitioners' opinions on the possibility to transfer clinical responsibility during the 
home treatment period to general practitioners. General practitioners were therefore included in this study. The nurses of the hospital ward were involved in the care during the hospital admission, but had no additional or changed role, as all study related activities were covered by the research team, and were therefore not included.

\section{Measurements and data collection}

To our knowledge, there is no validated questionnaire available to evaluate providers' opinions in hospital-at-home schemes. All previously performed studies developed their own questions or questionnaires in order to answer their research questions, which depended on the design of the hospital-at-home scheme. In order to develop a questionnaire that would provide answers to our research questions on role differentiation and transition and satisfaction, we consulted a representative of each group of professionals involved and identified themes that they felt were important within the early assisted discharge scheme. Not all themes were relevant to all providers and themes were only inserted in the questionnaire for the relevant professionals. In the decision process which theme was relevant to which professionals we assessed to which extent the group professional would be able to comment on that theme. In addition, we took into consideration the length of the questionnaire in relation to the expected response. To avoid overloading professionals with lengthy questionnaires we tried to balance between themes. Table 1 shows an overview of which themes were applicable to each group of providers involved. We identified 2 common themes: clarity of the role within hospital-at-home and general satisfaction with the hospital-at-home. Themes that were applicable to only some of the providers were: role description, satisfaction with role in hospital-at-home, to what extent the role in hospital-at-home differed from that in usual care, clinical responsibility during home treatment in hospital-at-home, responsibility for monitoring patients at home, the effect of hospital-at-home on the workload, whom to contact in case of problems or questions, knowledge and skills of generic community nurses for monitoring patients at home and satisfaction with different aspects of hospital-at-home. The identified themes resulted in 5 different questionnaires, 1 for each group of health care providers. Questions were asked with multiple-choice options that were dichotomous (yes/no or A/B) or had 5 options varying from a very negative to a very positive response. Questions on role description, changes in roles, role differences in regard to normal role, responsibilities, knowledge and the question for general remarks were (partly) open-ended questions and required a written response. Pulmonologists, residents, hospital respiratory nurses and general practitioners were invited to fill in the questionnaire by mail. Nurses of the home care organisation were invited by e-mail to fill in an electronic questionnaire. Non-responders were sent a reminder by mail or e-mail, 1 month after the first mailing during the study process. 


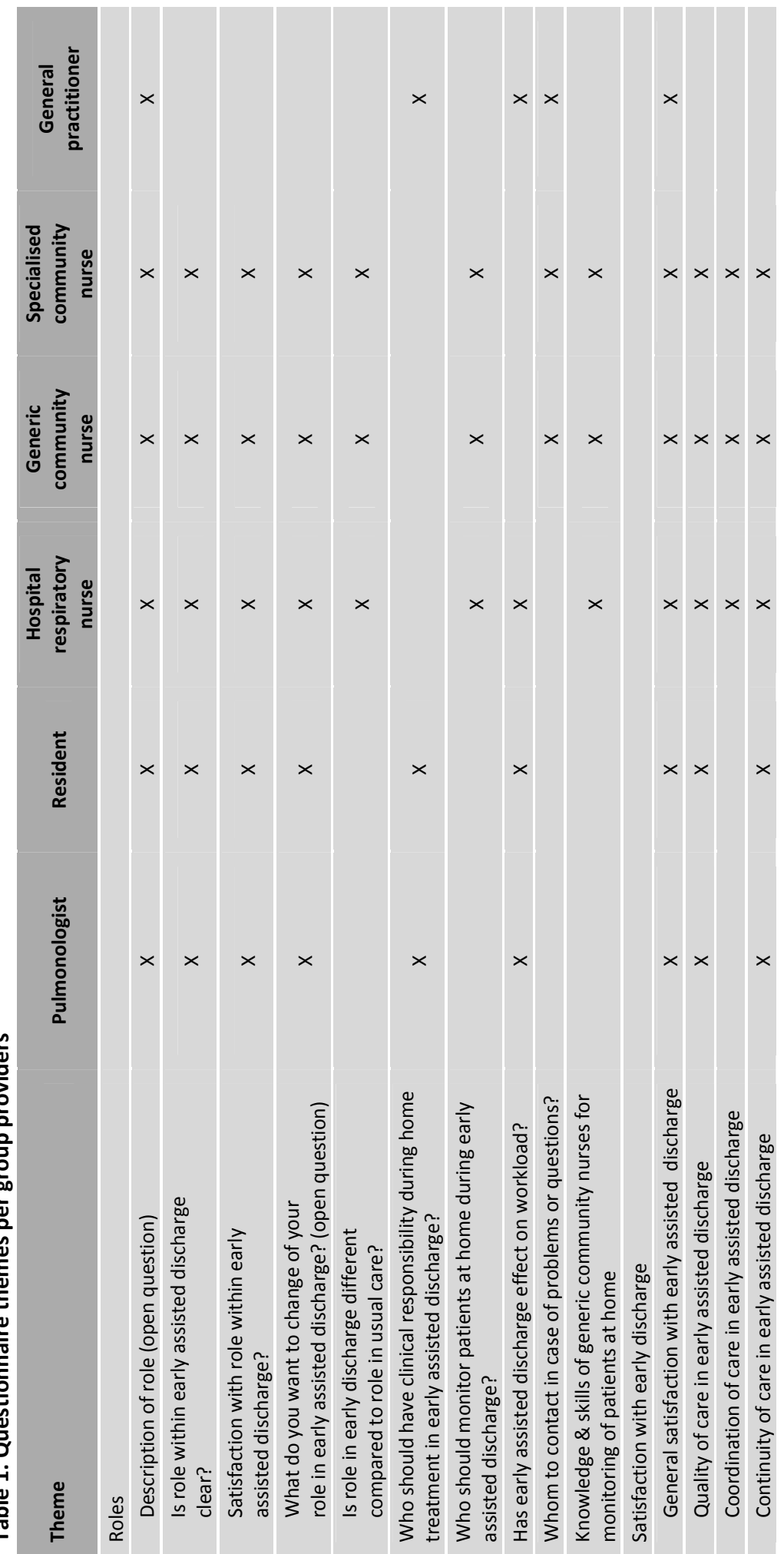




\section{Statistical analyses}

Multiple choice questions were analysed with descriptive statistics, as percentage of the total number of respondents. Open end questions were analysed with qualitative analysis. Per group of health care providers answers were categorised by 2 researchers (CU and LG). Differences were discussed until consensus was reached. Answers within and between the groups were then compared.

\section{Results}

Response rates varied between providers, and was respectively $59 \%$ in pulmonologists $(10 / 17), 43 \%$ in residents $(10 / 23), 75 \%$ in hospital respiratory nurses $(9 / 12) .25 \%$ in generic community nurses (15/60) and $60 \%$ in specialised community nurses $(6 / 10)$,

Figure 1 illustrates the role clarity among the care providers involved. For the majority of providers, except for general practitioners, their role was (very) clear. For generic community nurses their roles were the least clear (60\% responded (very) clear), whereas to all hospital respiratory nurses roles were clear.

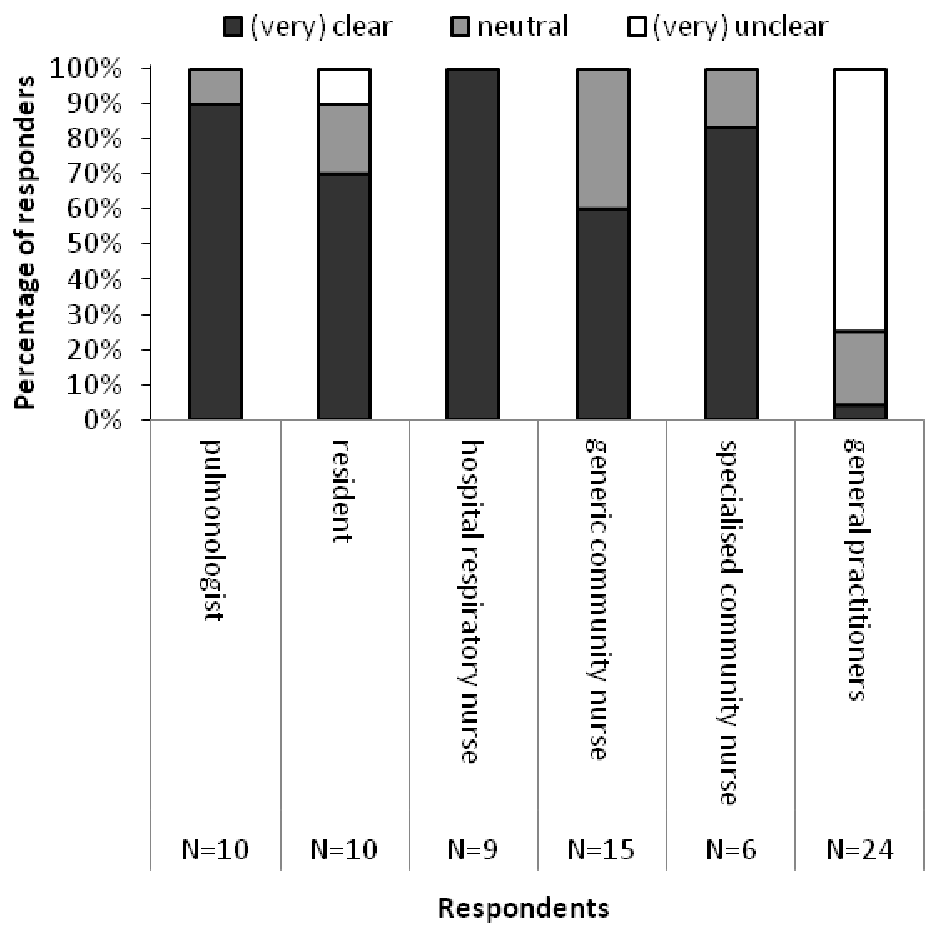

Figure 1. To what extend was it clear what your role as (profession) was within early discharge? 
Between $60 \%$ (generic community nurses) and $78 \%$ of nurses (hospital respiratory nurses) experienced their role to be different with regard to usual care. The majority of all nurses experienced their role to be different in comparison with their role in usual care. The majority ( $>50 \%$ ) of all respondents was satisfied or very satisfied with their role in the hospital-at-home scheme, as shown in figure 2 . Residents were more satisfied than pulmonologists, and specialised community nurses were more satisfied than their generic colleagues. Pulmonologists and residents did not want to change anything of their role. Hospital respiratory nurses wanted to share responsibilities, as the activities for hospital-at-home were additional to their normal activities. Most generic community nurses did not want to change anything to their role, or were unable to make suggestions.

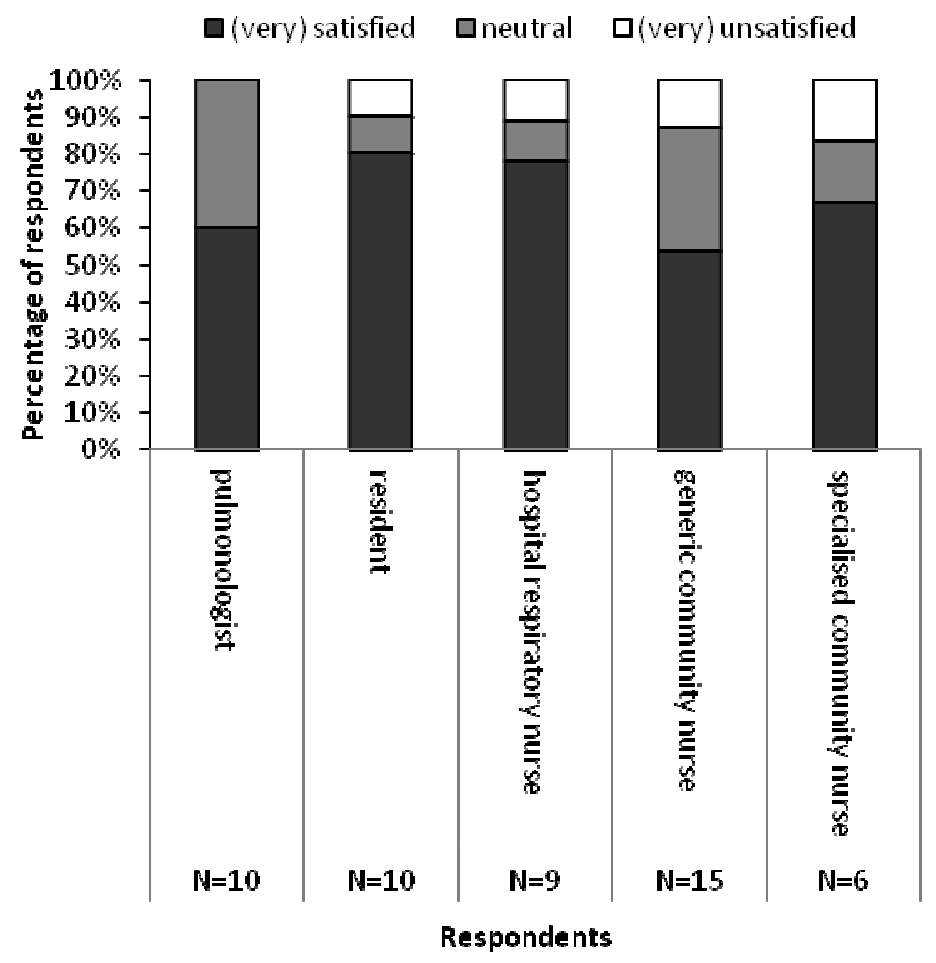

Figure 2. How satisfied are you with your role within early discharge?

For all community nurses it was clear whom to contact when they had questions. For only $32 \%$ of general practitioners is was clear whom to contact. Generic and specialised community nurses valued the possibility to contact the hospital as important or very important. 
Only $10 \%$ of pulmonologists and general practitioners and no resident experienced that early assisted discharge increased their workload. The remaining experienced it had no effect ( $60 \%$ of general practitioners and $80 \%$ of residents and pulmonologists) or had no opinion.

\section{Satisfaction}

General satisfaction with hospital-at-home and satisfaction with the different aspects are displayed in figures $3 a$ to $3 c$. Expect for generic community nurses and general practitioners, the majority of responders were (very) satisfied with early assisted discharge (figure 3a). Responses of general practitioners and generic community nurses were more neutral. Responses on quality of care were (very) satisfied or neutral, except in hospital respiratory nurses where $25 \%$ was unsatisfied and for $7 \%$ of generic community nurses. Over $50 \%$ of pulmonologists and residents was (very) satisfied with the continuity of care (figure $3 \mathrm{~b}$ ). In hospital respiratory nurses, specialised community nurses and generic community nurses this was lower, namely $25 \%, 33.3 \%$ and $40 \%$ respectively. On the coordination of care hospital respiratory nurses responded (very) satisfied or neutral (figure 3c). In generic and specialised community nurses responses were more divided with respectively $73 \%$ and $66.7 \%$ responding (very) satisfied or neutral.

All specialised community nurses and $67 \%$ of generic community nurses felt they had sufficient knowledge and skills to monitor patients at home. Some generic nurses felt they lacked knowledge on inhalation medication and COPD. Eighty-nine percent of hospital respiratory nurses and only 1 specialised community nurse thought generic community nurses had sufficient skills to monitor patients at home. They felt that generic community nurses lacked specific knowledge on COPD, COPD treatment and medication. Generic community nurses (60\%) believe they should monitor patients at home, while specialised community nurses and hospital respiratory nurses believe monitoring should be performed by specialised community nurses (56\% and $83 \%$ respectively). Thirty-three percent of hospital respiratory nurses and $17 \%$ of specialised community nurses believes generic community nurses should monitor patients.

Seventy percent of pulmonologists thought they should have clinical responsibility during the treatment period at home instead of general practitioners, while almost $50 \%$ of residents and general practitioners thought the pulmonologists should have clinical responsibility. Arguments for placing responsibility with pulmonologist are the initiation of early discharge in secondary care, presence of specific knowledge on COPD and the knowledge of course of the admission in secondary care. Arguments for 

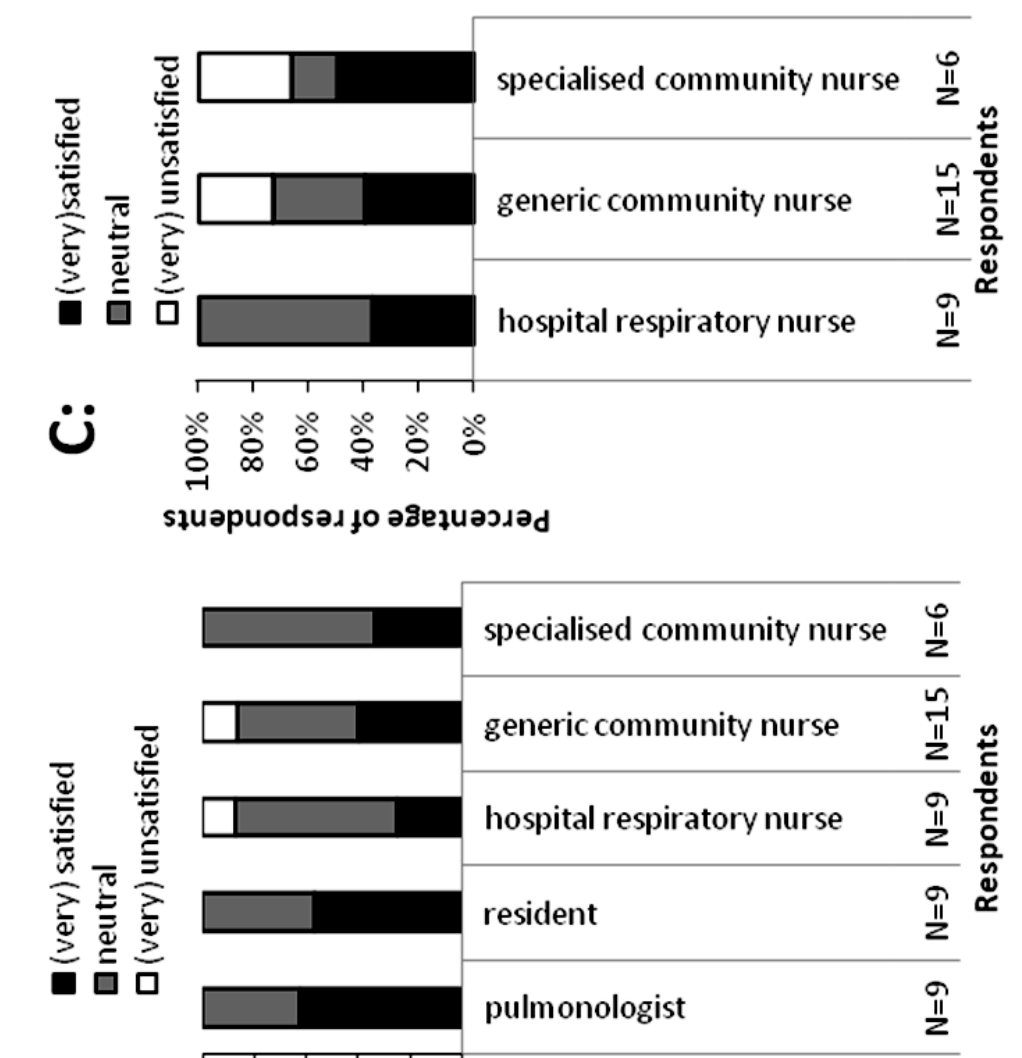

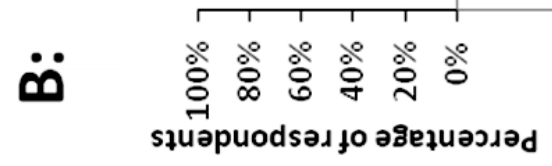

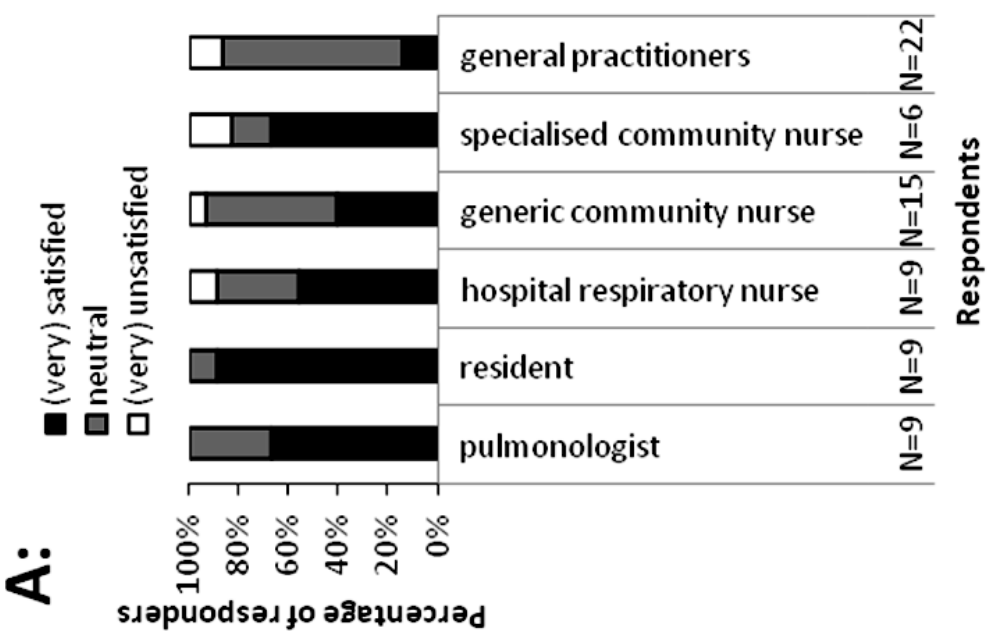


general practitioner responsibility include the existing central position in primary care, easy access for patients and better sight on the general situation at home.

\section{Discussion}

This is, to the best of our knowledge, the first study that evaluates both the impact of patient transfer on health care providers roles and satisfaction of all health care providers involved in a community-based, early discharge, hospital-at-home scheme. In general, providers are satisfied with the early assisted discharge scheme. Coordination of care and continuity of care need attention, and the possibility for primary care providers to contact the hospital and discuss patients is valued as very important. The transfer of patients from hospital to primary care does have impact on nurses roles. However, providers are satisfied with their roles and it is possible for generic community nurses to monitor patients at home.

The positive results on health care providers' satisfaction with a community-based hospital-at-home scheme are confirmative to previously published results [10-12]. However, these were results on selected professionals, where our study involved all professionals involved in the hospital-at-home scheme.

Satisfaction with quality of care in hospital-at-home was, except for hospital respiratory nurses, corresponding among the providers. Why hospital respiratory nurses were less satisfied was not clear. There were clear differences between community nurses and hospital nurses in the valuation of coordination and continuity of care. Helles $\varnothing$ and Fagermoen [14] found that cultural differences between hospital and community nurses may affect coordination and continuity of care. Cultural differences may influence the assessment of patients' care needs or affect beliefs on which information is important for the patients' transfer home.

In addition, insufficient existing information transfer systems (i.e. transfer forms) often cause insufficient coordination and continuity of care [14]. In our study, several community nurses made comments on the inadequate information transfer and the content of the information, which may explain the different responses of community nurses and hospital nurses. A convenient, mutual designed (electronic) transfer form that covering all aspects or a electronic patient file, accessible for all professionals involved could improve coordination and continuity of care.

Our study is the first to report on the effects on providers roles. Except for general practitioners, but who were also not officially involved in the scheme, roles were clear. Hospital and community nurses experienced their role to be different from usual care. 
Although hospital respiratory nurses reported an intensified contact with patients on the ward, differences in their roles were related to the activities for the randomised controlled trial, whereas reported differences by community nurses were indeed the result of the patient transfer. Community nurses state that their roles changed from mainly physical activities (washing, medication dispense etc.) to more (disease specific) guiding, counselling and controlling.

Satisfaction with the different roles was high and providers did not want to make major changes. Nonetheless, there were remarkable differences between providers in primary care, who are less satisfied, and providers in secondary care. This may partly be explained by the extremely low satisfaction scores of general practitioners, but also by the changes that are opposed on primary care (i.e. community nurses). In secondary care the population treatment did not change, whereas community nurses were confronted with a 'new' group of patients.

Generic community nurses responded that they lacked some specific knowledge on, for example, COPD or inhalation medication. Nevertheless, the majority felt they had sufficient knowledge and skills to monitor patients at home and that they should monitor patients at home. This contrasts with the responses of specialised community nurses and hospital respiratory nurses. Hospital respiratory nurses felt generic community nurses do have sufficient knowledge and skills, whereas specialised community nurses felt skills and knowledge lacked in generic community nurses. However, both state that specialised community nurses should monitor patients at home. There seems to be different opinions on what is necessary to monitor patients at home. Possibly, as a result of more training, specialised nurses know the specific needs of COPD patients better, and are better able to judge whether generic community nurses can monitor patients at home. However, previously performed studies on the effectiveness of early assisted discharge showed that the use of mainly generic community nurses had no effects on patient outcomes $[15,16]$. In addition, a study showed that in post-rehabilitation COPD patients, delivery of home care by specialised nurses showed no superior results over care delivered by generic nurses [17]. This suggests that the use of generic community nurses is feasible and safe. A possible deficit in the disease specific knowledge in generic community nurses could be solved by a special education program focussing on COPD, like was done in Davison et al. [15]. Furthermore there is the possibility for nurses and patients to contact the hospital. As the number of specialised community nurses of the home care organisation is limited and decreasing, specified and tailored education of the generic community nurses could be a good way to improve disease-specific knowledge in generic community nurses and continue the hospital-at-home scheme. 
The majority of physicians responded that early assisted discharge did not increase their workload. This confirms the results of Hood et al. [10]. However, general practitioners were clinical responsible this study, whereas in our study general practitioners were officially not involved. Physicians had to answer a hypothetical question. It can be debated, also from a legal point of view, who should have clinical responsibility for patients that are discharged early from hospital, but still receive treatment that substitutes the hospital admission within the hospital-at-home scheme. Arguments for responsibility with either general practitioner or hospital doctor were similar among general practitioners and hospital doctors, but pulmonologist were more likely to hold responsibility at the hospital. It is possible that not only medical and safety arguments are the foundation of this opinion, but that financial issues are of importance as well [18]. However, it can be concluded that in the future it is possible that general practitioners have clinical responsibility during the treatment at home, but it can be debated whether this is advisable. Patients appreciate general practitioners' involvement after hospital stay [19], However, early discharge in our scheme was possible for a limited percentage of patients $(25-30 \%)$ and it would have required large involvement of general practitioners to cover the care for these patients while being treated at home within the early discharge scheme. Most general practitioners from the region will not have had patients in the schemes and those who had patients in scheme had on average 1-2 patients during the study period. A sharedcare model, which is the most described hospital-at-home model in the United Kingdom [4], with possibilities for fast and direct consultation of pulmonologists, could be a satisfying model for both physicians and patients. The exact design of shared-care would depend on regional arrangements between general practitioners and pulmonologists and clear arrangements between general practitioners' roles and pulmonologists' roles should be made.

This study has some limitations. Firstly, despite an electronic questionnaire to facilitate easy and fast answering, the response rate among community nurses was lower than in other groups, which may have caused bias. The distribution of patients over a large working area has led to a low number of patients that were early discharged per community nurse. This may have contributed to a lower response rate among community nurses in relation to other health care providers involved that saw more patients per health professional In addition, in some cases there was a long recall period between the actual care for the early discharged patient(s) and the assessment of the questionnaire which may have community nurses decide not to fill in the questionnaire. Secondly, although we evaluated important aspects of early assisted discharge, results cannot just be transferred to other countries or schemes. Transferability depends on the design of the schemes, the providers involved and the culture in organisations and among providers. More specific research should be done 
on more detailed aspects of hospital-at-home schemes. This could help to improve the design of the hospital-at-home schemes and to ensure care activities are executed by the most suitable professional. This creates the necessary platform for implementation of community-based early assisted discharge schemes.

\section{Conclusions}

Our findings show for the first time that the transfer of patients and treating them at home within a community-based, early assisted discharge, hospital-at-home scheme is possible from the providers' perspective and well accepted by health care professionals involved. However, further implementation of community-based early assisted hospital-at-home with supervision by community nurses is justified from providers' perspective, provided that attention is being paid to the coordination and continuity of care, information transfer and further education of providers involved. 


\section{References}

1. Mannino DM, Buist AS. Global burden of COPD: risk factors, prevalence, and future trends. Lancet 2007;370:765-773.

2. Chapman KR, Mannino DM, Soriano JB et al. Epidemiology and costs of chronic obstructive pulmonary disease. Eur Respir J 2006;27:188-207.

3. Sullivan SD, Ramsey SD, Lee TA. The economic burden of COPD. Chest 2000;117:5S-9S.

4. Johnson MK, Flanigan U, Fuld J et al. Hospital at home services for acute exacerbation of chronic obstructive pulmonary disease: a survey of British practice. Health Bull (Edinb ) 2001;59:163-170.

5. Quantrill SJ, Lowe D, Hosker HS et al. Survey of early discharge schemes from the 2003 UK National COPD Audit. Respir Med 2007;101:1026-1031.

6. Ram FS, Wedzicha JA, Wright J et al. Hospital at home for acute exacerbations of chronic obstructive pulmonary disease. Cochrane Database Syst Rev 2003;CD003573.

7. Shepperd S, Doll H, Angus RM et al. Admission avoidance hospital at home. Cochrane Database Syst Rev 2008;CD007491.

8. Shepperd S, Doll H, Broad J et al. Early discharge hospital at home. Cochrane Database Syst Rev 2009; CD000356.

9. Aimonino RN, Tibaldi V, Leff B et al. Substitutive "hospital at home" versus inpatient care for elderly patients with exacerbations of chronic obstructive pulmonary disease: a prospective randomized, controlled trial. J Am Geriatr Soc 2008;56:493-500.

10. Hood S, Parsons S, Fulop NJ. Shifting care: GP opinions of hospital at home. Br J Gen Pract 1999;49:221-222.

11. Marsteller JA, Burton L, Mader SL et al. Health care provider evaluation of a substitutive model of hospital at home. Med Care 2009;47:979-985.

12. Lemelin J, Hogg WE, Dahrouge $S$ et al. Patient, informal caregiver and care provider acceptance of a hospital in the home program in Ontario, Canada. BMC Health Serv Res 2007;7:130.

13. Utens CM, Goossens LM, Smeenk FW et al. Effectiveness and cost-effectiveness of early assisted discharge for Chronic Obstructive Pulmonary Disease exacerbations: the design of a randomised controlled trial. BMC Public Health 2010;10:618.

14. Helles $\varnothing \mathrm{R}$, Fagermoen MS. Cultural diversity between hospital and community nurses: implications for continuity of care. Int J Integr Care 2010;10:e036.

15. Davison AG, Monaghan M, Brown D et al. Hospital at home for chronic obstructive pulmonary disease: an integrated hospital and community-based generic intermediate care service for prevention and early discharge. Chron Respir Dis 2006;3:181-185.

16. Nicholson C, Bowler S, Jackson C et al. Cost comparison of hospital- and home-based treatment models for acute chronic obstructive pulmonary disease. Aust Health Rev 2001; 24:181-187.

17. Ketelaars CA, Huyer Abu-Saad H, Halfens RJ et al. Effects of specialized community nursing care in patients with chronic obstructive pulmonary disease. Heart Lung 1998;27:109-120.

18. Utens CM, Maarse JA, van Schayck CP, Maesen BL, Rutten-van Mölken MP, SmeenkFW: Care delivery pathways for Chronic Obstructive Pulmonary Disease in England and the Netherlands: a comparative study. InternationalJournal of Integrated Care, 12, 18 May 2012.

19. Berendsen AJ, de Jong GM, Meyboom-de JB et al. Transition of care: experiences and preferences of patients across the primary/secondary interface - a qualitative study. BMC Health Serv Res 2009;9:62. 



\section{Chapter 9}

\section{GENERAL DISCUSSION}




\section{Discussion}

\section{Introduction}

The main goal of this thesis was to evaluate a community-based hospital-at-home scheme from different perspectives. The primary perspective included an assessment of the effectiveness and cost-effectiveness of the community-based hospital-at-home scheme. A patient evaluation assessed patient preferences for treatment place and their satisfaction with care. An informal caregiver evaluation assessed caregiver strain and caregiver preferences for treatment place and satisfaction with care. The care provider evaluation assessed the impact of early assisted discharge on professional care providers and their satisfaction with the scheme.

In this community-based hospital-at-home scheme, patients admitted to the hospital with a COPD exacerbation were early discharged on the fourth day of admission. The day of discharge and the 3 consecutive days they were visited by community nurses who monitored their recovery from the exacerbation. After a total of 7 days of treatment patients were discharged from the scheme and followed-up for 90 days. Aim of early discharge was to reduce length of hospital stay for patients admitted with a COPD exacerbation. Reducing length of stay may reduce the pressure on hospital beds and has the potential to reduce costs associated with hospitalisation.

This chapter provides an overview of the main findings of the separate evaluations. In addition, methodological issues of the described study are discussed. Finally the implications of the results for the design, organisation, implementation of hospital-athome schemes for COPD exacerbations and recommendations for future research are discussed.

\section{Summary of findings}

Hospital-at-home for COPD exacerbations is an alternative for usual hospital treatment that is widely implemented in the United Kingdom. Three explanations can be found for the presence of hospital-at-home schemes in England and the absence in the Netherlands. These 3 explanations are: 1 ) differences in funding system; 2 ) differences in urgency, and 3) differences in the substitution of tasks to nurses.

The effectiveness evaluation (chapter 4) showed that early assisted discharge is a safe alternative for usual hospital care and that patients that were early discharged did not have significantly different outcomes. There was no difference in change in health status, as measured by the Clinical COPD Questionnaire (CCQ), neither at the end of the hospital or home treatment (mean difference in change $-0.29,95 \% \mathrm{Cl}-0.61$ to 0.03 ), nor after 3-months follow-up (mean difference in change $-0.04,95 \% \mathrm{Cl}-0.48$ to 0.41). Furthermore there were no differences in the number of treatment failures, readmissions and mortality. Generic quality of life, as measured with the EQ-5D, had 
improved significantly more in the usual hospital care patients at the end of the hospital treatment (mean difference in change $0.0746,95 \% \mathrm{Cl} 0.010$ to 0.139 ), but this difference had disappeared after 3-months follow-up (mean difference in change $0.022,95 \% \mathrm{Cl}-0.116$ to 0.072 ). Thirty-seven percent of admitted patients were considered eligible for early discharge. However, one-third of eligible patients did not meet the criteria of clinical stability and was therefore not randomised.

The cost-effectiveness evaluation (chapter 5) showed that the answer to the question whether hospital-at-home is cost saving depends on the perspective. From the health care perspective, hospital-at-home was less costly at the end of the hospital or home treatment (difference $€-244,95 \% \mathrm{Cl}-315$ to -168 ) and at the end of the follow-up (difference $€-168,95 \% \mathrm{Cl}-1253$ to 922 ), although at 3 months the difference was no longer statistically significant. From a societal perspective, when direct non-health care costs and costs of productivity loss of patients and informal caregivers were added to the health care costs, hospital-at-home was found to be cost saving at the end of the hospital or home treatment (difference $€-65,95 \% \mathrm{Cl}-152$ to 25 ), but not at the end of the 3-month follow-up (difference $€ 908,95 \% \mathrm{Cl}-553$ to 2296). Both the short-term and long-term differences were not statistically significant.

Chapters 6 and 7 evaluated patient and informal caregiver preferences for treatment place. At the end of the treatment period, $86 \%$ of patients and $71 \%$ of caregivers from the early discharge group preferred early discharge over usual hospital care. Forty-two percent of patients and 33\% of caregivers from the usual hospital care group preferred early discharge. This suggests an overall preference for early discharge among patients participating in the trial. Associated factor for patient preference was CCQ mental state at randomisation (OR $0.349,95 \% \mathrm{Cl} 0.135$ to 0.904 ). Patients with better scores were more likely to prefer early discharge. The informal caregiver analysis showed that caregivers were more likely to prefer early discharge when the patient they care for preferred early discharge (OR $11.16,95 \% \mathrm{Cl} 3.32$ to 37.51 ).

In chapter 7, caregiver strain in early assisted discharge and usual hospital care was evaluated. Neither at the end of the treatment nor at the end of the follow-up period a difference was found between caregivers from usual hospital care and early discharge (mean difference at the end of the treatment period $0.47,95 \% \mathrm{Cl}-0.91$ to 1.91 ; mean difference at end of follow-up $-0.36,95 \% \mathrm{Cl}-1.85$ to 1.35 )

With $64 \%$ vs. $60 \%$ satisfaction in patients and $70 \%$ vs. $71 \%$ satisfaction in informal caregivers for usual hospital care and early discharge, respectively, there were no differences in overall patient and caregiver satisfaction between the 2 groups (chapters 6 and 7). Significant differences were found in satisfaction with duration of 
treatment (caregivers), feeling safe at night (patients) and ability to resume daily activities (patients). Informal caregivers from patients that were early discharged were less satisfied with the duration of the treatment. Patients that were early discharged felt less safe during nights and felt less able to resume daily activities at the end of the treatment.

Chapter 8 described the evaluation of early assisted discharge among professional care providers involved. In general, care providers involved in early assisted discharge were satisfied with the scheme. The transfer of patients from the hospital to the community did have an impact on community nurses' role. There were differences in opinions between specialised and generic nurses on who should perform home visits and monitor the patient. However, it is safe that community nurses perform the home visits. All care providers were satisfied with their role in early discharge but the coordination and continuity of care require attention.

\section{Methodological considerations}

\section{Internal validity}

In total 139 patients were randomised, where 165 was required to have sufficient power to detect a minimal clinical important difference (MCID) of 0.4 in CCQ scores between the treatment groups. Chapter 4 explained that it is highly unlikely that the results of the effectiveness analysis are influenced by the lower number of patients, for it seems improbable that an additional 29 patients would have resulted in an increase in the observed difference 0.29 to the MCID of 0.4 . The other outcome measures cannot be related to this sample size calculation, and there may have been insufficient power to detect differences in these outcomes. For example, the power to detect a difference of 0.074 , which is the supposed minimal clinical important difference, in EQ$5 \mathrm{D}$ scores with the actual number of patients in each groups was 0.44 .

In this trial, random assignment to the 2 treatment groups increased the internal validity [1]. Randomisation was performed with a block-size of 6 per participating hospital location to ensure equal numbers in both groups, and equal numbers of patients from the different hospital in both groups. Despite randomisation, we found a baseline difference in CCQ scores at randomisation, which was due to coincidence. As is obvious, the characteristics of the intervention did not allow blinding of patients, caregivers and health care staff.

COPD patients, especially those who suffer from frequent exacerbation and hospitalisations, are an elderly, frail population, with on average, less physical functioning and lower education. These characteristics made the population studied 
vulnerable for attrition during follow-up, which may threaten internal validity $[2,3]$. In this study the overall drop-out was $17 \%$ (10 in the early discharge group and $25 \%$ in the usual hospital care group), which is low. A division could be made between early drop-out, i.e. drop-out immediately after randomisation because the patient was not satisfied with the allocated place of treatment and late drop out, i.e. drop-out after 7days treatment. Early drop out was $4 \%$ in the early discharge group and $10 \%$ in the usual hospital care group, and late drop out was $6 \%$ and $14 \%$ respectively. Baseline CCQ scores of patients dropping out were not different from those who completed the study, but they did have more comorbidities. The selection bias due to attrition and imbalance in baseline CCQ can be reduced by choice of statistical analysis technique [4]. The repeated measures ANCOVA analysis used for the effectiveness analysis incorporates all patients, even those with missing values at some variables, and controls for differences in baseline characteristics.

\section{External validity}

There are several reasons why the results cannot be generalised to all COPD patients admitted to the hospital with an exacerbation.

Firstly, in trials patients need to provide informed consent before participation. Those with negative attitudes towards early discharge or those who wanted to stay in the hospital for 7 days at any price probably have refused participation. This may have led to selection bias and may have limited the generalisability of results.

Secondly, the number of patients was not equally distributed over the 6 participating hospitals. The number of patients randomised in the hospitals was 80 in the Catharina Hospital, 39 in the Atrium Medical Centre, 13 in the Máxima Medical Centre, 4 in the TweeSteden Hospital and 4 in the Rijnstate Hospital.

Thirdly, the trial was performed in the Dutch health care system. As was shown in chapter 2, the development, design and execution of hospital-at-home schemes codepend on a countries' health care system. The scheme described in this thesis was a community-based early discharge scheme. Results from the evaluations of this scheme cannot be translated to admission avoidance schemes as they probably include different patient categories.

Fourthly, although in this thesis hospital-at-home was compared with usual hospital care, the trial was not designed as a pragmatic trial. The inclusion and exclusion criteria were set to minimise the risk of mortality and serious adverse events. However, the application of (strict) criteria on 2 moments during the admission and the choice for treatment options at home implicated that, in the end, only $10 \%$ of admitted patients were eligible for early discharge. 
Fifthly, although the included population was heterogeneous regarding severity of COPD, due to the strict inclusion, exclusion and randomisation criteria, patients with severe exacerbations were likely to be excluded from participation. Therefore, results cannot be extrapolated to the general population of COPD patients admitted to the hospital with an exacerbation. However, as was stated in chapter 4, considering the low number of treatment failures, mortality and serious adverse events, it might be possible to relax the criteria for hospital-at-home treatment, and results can be more generalised.

\section{Implications of results for the design, organisation and implementation of hospital- at-home}

The results in this thesis show that hospital-at-home for COPD exacerbations is feasible in the Dutch health care system and that outcomes for patients, informal caregivers and care providers are not disadvantageous in comparison to usual hospital care. From this perspective, wider implementation would be justified. However, between operation of hospital-at-home as a trial and dissemination in daily practice stand several challenges that should be considered.

The target population of hospital-at-home schemes and the treatment options at home The number of patients that can be treated at home depends, among others, on the criteria that are set for participation and the treatment that is made available at home. Consequently, these factors also determine how severe the exacerbations and how complex the patient can be that still can be treated at home. Comparison of the criteria used in the different studies on hospital-at-home, and recorded in the British guideline for hospital-at-home, show that, in general, patients with severe comorbidities (pneumonia, neoplasm, respiratory failure) that require inpatient management, patients with deviant arterial blood gas measurement (if taken) and patients with acute confusion or impaired level of consciousness, should be excluded from hospital-at-home [5-13]. Furthermore, social circumstances are often a criterion for exclusion [5-13]. For example, Burge et al. [14] set living alone as an exclusion criterion for hospital-at-home, whereas in many schemes, including the 1 described in this thesis, up to $30 \%$ of patients are living alone and were successfully treated at home $[6,9,13,15,16]$. Some criteria are rather clear and strict in interpretation, but most criteria set are open for subjective interpretation and depend on the reviewing physician and the presentation of the patient.

In the current study, $10 \%$ of patients admitted to the hospital, was considered eligible for hospital-at-home. Indeed, this is a small number and it can be debated whether early discharge is a suitable intervention for this population in the Netherlands. However, based on the positive results in this trial, previous performed studies and experiences with the daily operation of hospital-at-home schemes in the United 
Kingdom, it is possible to relax the criteria for participation, as was described in chapter 4 . This will increase the number of eligible patients that can be treated in early discharge schemes

In this study, complexity of the treatment offered at home was lower than in previous studies. For example, no new oxygen supply at home was prescribed to patients, which lead to the exclusion of 28 (34\%) patients. In accordance with the BTS guideline, this suggests that oxygen treatment should be 1 of the components of the treatment at home, and extension of the treatment should be considered in community-based hospital-at-home schemes. However, adherence to treatment guidelines in inpatient COPD care is suboptimal [17]. Possibly not all patients who were excluded due to oxygen dependency were prescribed oxygen appropriately according to existing guidelines. Furthermore, the extension of treatment options at home also has implications for the expertise that is required from staff performing home visits. However, when possible, the treatment options provided at home should be extended with newly prescribed short-term oxygen supply and nebulised bronchodilators to include more patients into the schemes.

\section{The place of hospital-at-home in current practice}

The high number of hospital admissions for COPD exacerbations and the relative long length of stay of these patients have raised the question of the appropriateness of these admissions. Guidelines for admission are not strongly evidence-based and in practice these guidelines offer little support in determining the appropriateness of admission $[18,19]$. Because of the large contribution of social/psychosocial factors to admission, it is often debated whether the clinical problem is large enough to warrant hospital admission or whether a social problem is more prominent. Indeed, an evaluation of adherence to admission guidelines showed that only $42 \%$ of admitted patients required admission according to the criteria [20]. Not only the criteria for admission are ambiguous, no clear criteria are available for the discharge of patients either. The lack of clarity in the criteria often leads to (unnecessary) prolongation of hospital stay [20]. Furthermore, adherence to the guidelines available for inhospital management of COPD exacerbations is suboptimal, which may lead to recurrent exacerbations and hospitalisations [17].

The relative low number of patients that can be treated in hospital-at-home schemes, and the low-complex treatment that is offered at home raises the question whether the patients treated in hospital-at-home schemes required hospital admission in the first place, or, whether outpatient treatment would have been sufficient. However, in practice patients do get hospitalised and in absence of effective methods to standardise the admission and discharge process of patients, early assisted discharge 
allows hospitals to relieve some of the pressure on the hospital beds, without compromising patient outcomes. A method to standardise the care and discharge process of COPD patients and optimise patient outcomes after hospitalisation are the use of care pathways [in Dutch: zorgpaden], which have been developed in many Dutch hospitals [21]. However, despite the wide implementation of these pathways, there are no evaluations available on their effect on the length of hospital stay. Nonetheless, hospital-at-home schemes can be easily integrated in the existing pathways.

\section{Design and operation of hospital-at-home and logistics of the home care}

This hospital-at-home scheme was executed as a randomised controlled trial with strict criteria and preset time points for assessing eligibility and discharge. In practice it is possible to be less strict. As said, it is possible to relax the criteria, but it is also possible to discharge patients 1 day earlier or later. Furthermore, in this study it was hard to find a difference in CCQ scores between the groups. On average a larger improvement in scores was found between days 1 and 3 of admission (0.95 SD 0.98), in which the treatment was equal for both groups. The average improvement between days and 7 of the treatment was 0.15 (SD 0.91). Therefore, the inclusion criteria should not be applied to patients on their first day of admission after 48 to 72 hours of admission allowing patients to recover and become eligible for early discharge.

Disease specific questionnaires like the Clinical COPD Questionnaire, St Georges' Respiratory Questionnaire and the COPD Assessment Test showed to significant changes in scores during exacerbations and recovery [22-24]. In our study the CCQ only showed a small contrast between the groups during the last days of the treatments. To objectify the assessment of eligibility for home treatment and the recovery from the exacerbation, the use of questionnaires, either combined with physical parameters, should be investigated.

In this hospital-at-home scheme the home care was community-based, which contrasts with most previous studies in which home care visits were made outreach from hospital. Hospital-at-home schemes that are designed as early discharge schemes, reduce length of hospital stay rather than that they reduce the number of hospitalisations [5]. Admission avoidance schemes, however, might reduce the number of hospitalisations, as patients are immediately discharged from the emergency department. However, considering the high number of ineligible patients at admission, admission avoidance schemes are not feasible (yet) with the current criteria and treatment options at home. Furthermore, early discharge schemes have 1 major advantage over admission avoidance schemes, which is the larger amount of time available to plan and prepare early discharge. In cases of community-based schemes 
this is preferable because of the logistics that need to be arranged for the home visits that are planned in addition to usual care the agencies provide in their region [5]. Almost $50 \%$ of patients already received treatment for the exacerbation, started in primary care, suggesting that treatment was not successful (yet). In order to assure adequate assessment and diagnosis of the patient, and to ensure the recovery trend, it is advised that the design of hospital-at-home is early discharge and not admission avoidance.

In this hospital-at-home scheme, patients were visited daily, at least once, for 4 days. This is different from most previously described schemes in which the duration of the home treatment was variable (mean 11 days) and decided upon the discretion of the nurses performing the home visits [5-13,25-29]. Furthermore, in these schemes patients were not necessarily visited every day, but with an interval of 2 or 3 days, at the discretion of the nurse. It can be debated whether home visits beyond an overall treatment duration of 10 days are still substitutive to hospital treatment or have gradually shifted to follow-up care with disease management features. The optimal length of supervision at home and the optimal number of home visits is unknown. The results of this study show that a follow-up of 4 days, with at least 1 visit daily, is possible and sufficient, according to patients and carers. However, in current practice treatment of the exacerbation is mainly focussed at short-term recovery and little attention is paid to life after hospital admission. Patients feel they are poorly prepared for life after discharge and the future management of their COPD, lacking sufficient care and/or knowledge on who to call or what to do in certain circumstances, and experiencing fear and anxiety for future dyspnoea attacks [30,31]. Prolonged follow-up after hospital admission with specific additional care packages, like self-management, education, ongoing follow-up and pulmonary rehabilitation are associated with a decrease in primary care consultations [32], improvement of patients' knowledge and quality of life [33], treatment adherence [34] and a decrease of readmissions to hospital $[35,36]$. The close and intensified follow-up of patients during and after the exacerbation by community nurses and respiratory nurses in hospital-at-home schemes offers a great opportunity for integration with long-term follow-up chronic management programmes. This has previously been shown by Lawlor et al [36]. In practice, for specific patients, hospital-at-home schemes should be integrated with long-term follow-up. Further research is necessary to determine the feasibility and (cost-) effectiveness of such integration.

This study showed that it is possible to run a hospital-at-home scheme with community nurses of whom the majority is generally trained. The use of mainly generic trained nurses contrasted with most studies describing hospital-at-home schemes for COPD exacerbations, in which care was provided by respiratory nurses. In this study 
the content of home visit was standardised and patient were not discharged with newly prescribed oxygen treatment, newly prescribed nebulised treatment or major changes in medication use. Considering this low-complex treatment, specialisation of nurses was not necessary. The BTS guideline on hospital-at-home recommends that home visits should be performed by specialist respiratory nurses or by generic district nursing teams that meet the proposed set of skills, which includes proficiency in assessing clinical condition, familiarity with pharmacological and non-pharmacological approaches and knowledge of current guidelines on COPD management [5].

The discussion of which requirements for nursing staff are needed for the home visits relates to the discussion on criteria for patients to participate and the treatment options. Relaxation of the criteria and expansion of the treatment options possibly requires additional knowledge form nursing staff. This could be met in 2 ways. First way is to employ specialised nurses instead of generic nurses. Nurse practitioners are an upcoming and growing profession in the Netherlands and in COPD care $[37,38]$ and could be considered for hospital-at-home schemes. Considering that $75 \%$ of nurse practitioners is employed by hospitals, the design of hospital-at-home would be like the British schemes: outreach from hospitals. However, Lemelin et al [39] showed that the nurse practitioners involved in their hospital-at-home scheme were not satisfied with the role they had in the scheme because not all their skills were exploited. Furthermore, the Dutch funding system does not allow hospital staff to work outreach. The Netherlands have a unique network of home care organisations, which can be used for hospital-at-home schemes, as has been shown in this study. Both generic and specialised community nurses feel competent to monitor patients at home. They probably experience this new patient category as a challenge and opportunity to expand their roles and skills. However, specialised community nurses may experience the allocation of the home visits to generic community nurses as a threat to their position. Traditionally home care organisations employed specialised community nurses, which could be used in hospital-at-homes schemes that require more specialised supervision at home. However, the number of specialised nurses in home care organisation has reduced significantly. Therefore, a second way to meet the additional knowledge requirements, is to increase skills and knowledge of generic community nurses, by additional training and support, as was done in a similar British community based scheme that involved generic community nurses [8]. The challenge for the future is to find the right balance between treatment options, the required expertise, skills and knowledge from staff that follows from this and the job satisfaction of nurses involved. 
Implementation of hospital-at-home in the Netherlands and facilitators and barriers for implementation

In absence of a clear difference between effectiveness and cost-effectiveness of hospital-at-home in comparison with usual hospital care, hospital-at-home is a preference-sensitive treatment. This means that the answer to the question whether hospital-at-home should be implemented in the Netherlands is largely dependent on the preference and satisfaction of patients and informal caregivers. Based on the positive results from the patient and informal caregiver evaluation it is recommended to implement hospital-at-home more widely in the Netherlands and to offer this to patients who meet the criteria for participation and prefer to be treated at home.

For the implementation of a community-based hospital-at-home scheme in the Netherlands several barriers and facilitators should be considered. Hospital-at-home is a treatment option in which care is transferred from secondary care (hospital) to primary care (home). Hospital care and home care are covered by different insurance schemes. Hospital care is covered by the basic health insurance schemes, whereas home care is covered by the exceptional medical expenses act. Furthermore, for home care a co-payment is required. The institutional split between the basic health insurance scheme and the exceptional medical expenses scheme is hampering the coordinated delivery of COPD care and the development of intermediary services, like hospital-at-home.

The existing funding structure is known to be a barrier for integrated services that operate across health care levels and institutes. However, no substantial changes to the funding structure have been made yet to solve these problems. The introduction of a bundled payment system for chronic care is an attempt to facilitate the integrated delivery of care to patients in the community [40]. Unfortunately, the funding of inpatient care and outpatient care provided by the hospital is not (yet) included in this budget. Community nursing is not included in this budget either. It should be investigated whether it is possible to cover all types of care in primary care, secondary care and community care in the chain. However, currently care groups (in most cases general practitioners) are in charge of the chain budget, which causes a 'power' imbalance between providers. As shown in chapter 2, the English design of primary care trusts commissioning care from all types of providers on all levels, overcomes this issue, and allowing all care to be reimbursed. If this design would be transferred to the Dutch health care system this would implicate that insurance companies control the entire budget for primary and secondary care and that there is no institutional split for the coverage of the different types of care. However, this requires substantial changes in policy, which cannot be accomplished in the near future. Therefore, when designing, planning and implementing hospital-at-home schemes, the challenge will be to find 
long-term funding within the current system that allows the schemes to be developed in the optimal way.

\section{Unanswered questions and future research}

In this thesis a full evaluation of a community-based hospital-at-home scheme for COPD patients was described for the first time. Community-based hospital-at-home, as described in this thesis, has no different outcomes in comparison to usual hospital care as it is currently provided by Dutch hospitals. Implementation of this hospital-at-home scheme is therefore justified, especially because it is preferred by the majority of patients. However, although many aspects have been studied, more research is necessary to determine the optimal design and organisation of hospital-at-home schemes in different patient populations. Future research should focus on determining the best-practice design of hospital-at-home schemes concerning the treatment provided at home and which treatment or patients require the supervision of specialised or generic nurses. Furthermore, the optimal number of home visits (for which patients) and the duration of the home treatment should be investigated. It must be taken into account that changes to the hospital-at-home scheme as described in this thesis (e.g. different treatments at home, different number of home visits or changing the moment of discharge) will affect cost-effectiveness. Finally, as the criteria for admission to and discharge from the hospital for COPD patients are unclear, a clear set of criteria for the admission and discharge of patients would be a valuable instrument that will also help to select the patient group that is most eligible for hospital-at-home, and which criteria should be applied to them. 


\section{References}

1. Denise F.Polit, Cheryl Tatano Beck. Nursing Research: Principles and Methods. Philidelphia: Lippincott Williams \& Wilkins 2004.

2. Chatfield MD, Brayne CE, Matthews FE. A systematic literature review of attrition between waves in longitudinal studies in the elderly shows a consistent pattern of dropout between differing studies. J Clin Epidemiol 2005;58:13-19.

3. Young AF, Powers JR, Bell SL. Attrition in longitudinal studies: who do you lose? Aust N Z J Public Health 2006;30:353-361.

4. Rothman KJ. Epidemiology an introduction. New York: Oxford University Press 2002.

5. British Thoracic Society. Intermediate care--Hospital-at-Home in chronic obstructive pulmonary disease: British Thoracic Society guideline. Thorax 2007;62:200-210.

6. Cotton MM, Bucknall CE, Dagg KD et al. Early discharge for patients with exacerbations of chronic obstructive pulmonary disease: a randomized controlled trial. Thorax 2000;55:902-906.

7. Davies L, Wilkinson M, Bonner S et al. "Hospital at home" versus hospital care in patients with exacerbations of chronic obstructive pulmonary disease: prospective randomised controlled trial. BMJ 2000; 321:1265-1268.

8. Davison AG, Monaghan M, Brown D et al. Hospital at home for chronic obstructive pulmonary disease: an integrated hospital and community based generic intermediate care service for prevention and early discharge. Chron Respir Dis 2006;3:181-185.

9. Hernandez C, Casas A, Escarrabill J et al. Home hospitalisation of exacerbated chronic obstructive pulmonary disease patients. Eur Respir J 2003;21:58-67.

10. Murphy NM, Byrne CC, O'Neill SJ et al. An outreach programme for patients with an exacerbation of chronic obstructive pulmonary disease. Ir Med J 2003;96:137-140.

11. Nicholson C, Bowler S, Jackson C et al. Cost comparison of hospital- and home-based treatment models for acute chronic obstructive pulmonary disease. Aust Health Rev 2001;24:181-187.

12. Ojoo JC, Moon T, McGlone S et al. Patients' and carers' preferences in two models of care for acute exacerbations of COPD: results of a randomised controlled trial. Thorax 2002;57:167-169.

13. Skwarska E, Cohen G, Skwarski KM et al. Randomized controlled trial of supported discharge in patients with exacerbations of chronic obstructive pulmonary disease. Thorax 2000;55:907-912.

14. Burge S, Wedzicha JA. COPD exacerbations: definitions and classifications. Eur Respir J Suppl 2003;41:46s-53s.

15. Quantrill SJ, Lowe D, Hosker HS et al. Survey of early discharge schemes from the 2003 UK National COPD Audit. Respir Med 2007;101:1026-1031.

16. Utens CM, Goosens LM, Smeenk FW et al. Early assisted discharge with community nursing for Chronic Obstructive Pulmonary Disease exacerbations: results of a randomised controlled trial. Provisionally accepted for publication in BMJ open 2012.

17. Lodewijckx C, Sermeus W, Vanhaecht K et al. Inhospital management of COPD exacerbations: a systematic review of the literature with regard to adherence to international guidelines. J Eval Clin Pract 2009;15:1101-1110.

18. Quintana JM, Esteban C, Barrio I et al. The IRYSS-COPD appropriateness study: objectives, methodology, and description of the prospective cohort. BMC Health Serv Res 2011;11:322.

19. Garcia-Gutierrez S, Quintana JM, Aguirre $U$ et al. Explicit criteria for hospital admission in exacerbations of chronic obstructive pulmonary disease. Int J Tuberc Lung Dis 2011;15:680-686.

20. Kelly MG, Elborn JS. Admissions with chronic obstructive pulmonary disease after publication of national guidelines. Ir J Med Sci 2002;171:16-19.

21. Lodewijckx C, Sermeus W, Panella M et al. Impact of care pathways for in-hospital management of COPD exacerbation: a systematic review. Int J Nurs Stud 2011;48:1445-1456.

22. Kocks JW, Tuinenga MG, Uil SM et al. Health status measurement in COPD: the minimal clinically important difference of the clinical COPD questionnaire. Respir Res 2006;7:62. 
23. Mackay AJ, Donaldson GC, Patel AR et al. Utility of the COPD Assessment Test (CAT) to Evaluate Severity of COPD Exacerbations. Am J Respir Crit Care Med 2012.

24. Spencer S, Jones PW. Time course of recovery of health status following an infective exacerbation of chronic bronchitis. Thorax 2003;58:589-593.

25. Aimonino RN, Tibaldi V, Leff B et al. Substitutive "hospital at home" versus inpatient care for elderly patients with exacerbations of chronic obstructive pulmonary disease: a prospective randomized, controlled trial. J Am Geriatr Soc 2008;56:493-500.

26. Diaz LS, Gonzalez LF, Gomez Mendieta MA et al. [Evaluation of a home hospitalization program in patients with exacerbations of chronic obstructive pulmonary disease]. Arch Bronconeumol 2005;41:5-10.

27. Gravil JH, Al-Rawas OA, Cotton MM et al. Home treatment of exacerbations of chronic obstructive pulmonary disease by an acute respiratory assessment service. Lancet 1998;351:1853-1855.

28. Ansari K, Shamssain M, Farrow M et al. Hospital-at-home care for exacerbations of chronic obstructive pulmonary disease: an observational cohort study of patients managed in hospital or by nurse practitioners in the community. Chron Respir Dis 2009;6:69-74.

29. Sala E, Alegre L, Carrera M et al. Supported discharge shortens hospital stay in patients hospitalized because of an exacerbation of COPD. Eur Respir J 2001;17:1138-1142.

30. Gruffydd-Jones K, Langley-Johnson C, Dyer C et al. What are the needs of patients following discharge from hospital after an acute exacerbation of chronic obstructive pulmonary disease (COPD)? Prim Care Respir J 2007;16:363-368.

31. British Thoracic Society and British Lung Foundation: Ready for home? Improving hopspital dicharge care for people living with COPD. 2011.

32. Sridhar M, Taylor R, Dawson S et al. A nurse led intermediate care package in patients who have been hospitalised with an acute exacerbation of chronic obstructive pulmonary disease. Thorax 2008;63:194-200.

33. Hermiz O, Comino E, Marks G et al. Randomised controlled trial of home based care of patients with chronic obstructive pulmonary disease. BMJ 2002;325:938.

34. Garcia-Aymerich J, Serra P, I, Mannino DM et al. Lung function impairment, COPD hospitalisations and subsequent mortality. Thorax 2011;66:585-590.

35. Casas A, Troosters T, Garcia-Aymerich J et al. Integrated care prevents hospitalisations for exacerbations in COPD patients. Eur Respir J 2006;28:123-130.

36. Lawlor M, Kealy S, Agnew $\mathrm{M}$ et al. Early discharge care with ongoing follow-up support may reduce hospital readmissions in COPD. Int J Chron Obstruct Pulmon Dis 2009;4:55-60.

37. Zwijnenberg NC, Bours GJ. Nurse practitioners and physician assistants in Dutch hospitals: their role, extent of substitution and facilitators and barriers experienced in the reallocation of tasks. J Adv Nurs 2011.

38. Donato AS. Nurse practitioners in Holland: Definition, preparation, and prescriptive authority. J Am Acad Nurse Pract 2009;21:585-587.

39. Lemelin J, Hogg WE, Dahrouge S et al. Patient, informal caregiver and care provider acceptance of a hospital in the home program in Ontario, Canada. BMC Health Serv Res 2007;7:130.

40. Struijs JN, Baan CA. Integrating care through bundled payments--lessons from The Netherlands. N Engl J Med 2011;364:990-991. 


\section{SUMMARY}

SAMENVATTING

CO-AUTHORS AND AFFILIATIONS

DANKWOORD

ABOUT THE AUTHOR 


\section{Summary}

Chronic Obstructive Pulmonary Disease (COPD) is a chronic lung disease that is characterised by exacerbations, especially in the more severe stages of the disease. Exacerbations are the main cause for hospitalisations in COPD patients, with approximately $20 \%$ of exacerbations resulting in hospitalisation. In 2007 , the number of hospitalisations for COPD in the Netherlands was 11.6 per 10,000 population and the average length of hospital say was 11 days. As a result, exacerbations and hospitalisations have not only serious impact on patients, they are also responsible for high health care costs. Hospital-at-home for COPD exacerbations is proved to be an alternative for usual hospital treatment. It aims to reduce the length of hospital stay and reduce the pressure on hospital beds without compromising patient outcomes. The studies in this thesis evaluate the effectiveness and cost-effectiveness of hospitalat-home in comparison to usual hospital care. Furthermore, the value of patients and informal caregivers, and informal caregivers strain is investigated. Finally the impact of early assisted discharge on professional caregivers is evaluated.

Forty-four percent of British hospitals have a hospital-at-home service for COPD exacerbations, whereas this service is not available in the Netherlands for COPD exacerbations. In chapter 2 we investigated why the development of hospital-at-home did take place in England and why not in the Netherlands. We found 3 possible explanations for this difference. First, there is a difference in urgency for alternatives for hospital treatment in England in comparison with the Netherlands. The number of hospitalisations in England is higher than in the Netherlands, while the number of available hospital beds is lower. Secondly, the single source funding in England and the central role of primary care trusts is beneficial for the development of hospital-athome. The existence of distinct financial flows in the Netherlands obstructs the integration of care that is necessary for hospital-at-home. Final explanation is the difference in substitution of tasks to nurses. Supervision of patients at home is performed by (specialised) nurses. Substitution to the nursing profession in general has started earlier in England than in the Netherlands, and on a larger scale. In England the incentive for this has been much stronger, because of a lower number of hospital doctors.

Chapter 3 described the rationale and design of the GO AHEAD study. All patients admitted with an exacerbation of their COPD to 1 of the 5 participating hospitals, were screened for eligibility for early assisted discharge. Patients who were willing to participate to the trial and met the criteria for clinical stability on the third day of admission were randomised to usual hospital care or the early assisted discharge. Patients assigned to the early discharge group were discharged home on the fourth 
day and continued treatment at home. They were visited by community nurses of the local home care organisation on the day of discharge and the following 3 days. At day 7 of the treatment they were discharged from the scheme. Patients assigned to usual hospital care continued hospital treatment and were discharged home on the $7^{\text {th }}$ day. All patients are followed until 90 days after admission. Effectiveness was measured by change in scores on the Clinical COPD Questionnaire. Data on outcomes and costs were collected at admission ( $\mathrm{T}-2$ days), at randomisations (TO), at the end of the treatment ( $T+4$ days) and at the end of the follow-up period ( $T+90$ days).

In chapter 4 the effects of early assisted discharge on the CCQ, treatment failures, readmissions, mortality and generic health-related quality of life are presented. In total, 139 patient were randomised, 70 to early assisted discharge and 69 to usual hospital care. There was no short-term or long-term significant or clinical relevant difference in CCQ scores between the early assisted discharge group and the usual hospital care group. There was also no difference in treatment failures, readmissions and mortality. There was a significant difference in generic health-related quality of life at the end of the treatment ( $T+4$ days). This difference had disappeared at the end of the 3-month follow-up.

In chapter 5 the cost-effectiveness of hospital-at-home is outlines. From the health care perspective, early assisted discharge is less costly in comparison with usual hospital care, although at 3 months the difference was no longer statistically significant. From a societal perspective, when direct non-health care costs and costs of productivity loss of patients and informal caregivers were added to the health care costs, early assisted discharge was found to be cost saving at the end of the hospital or home treatment, but not at the end of the 3-month follow-up. Both the short-term and long-term differences are not statistically significant.

In chapter 6 an evaluation of early assisted discharge from the patient perspective is presented. Overall satisfaction was similar in both treatment groups. At the of the treatment $(T+4$ days), patients in the early assisted discharge group were less satisfied with care at night and were less able to resume normal daily activities. Eighty percent of patients that were early discharged and $42 \%$ patients that were treated in the hospital prefers home treatment. Patients' mental state is associated with preference. Patients with worse mental state scores were less likely to prefer early discharge. The satisfaction and preference results support the wider implementation of early assisted discharge for COPD exacerbations and this treatment option should be offered to selected patients who prefer home treatment. 
Chapter 7 presents the results of the evaluation of early assisted discharge from the perspective of informal caregivers. Early assisted discharge had no negative effect on informal caregiver strain. Seventy-one percent of informal carers of patients that experienced early discharge and one-third of informal caregivers of patients that experienced usual hospital care preferred home treatment. Informal caregivers were satisfied with home treatment. Results from this evaluation complement those of the evaluation from the patient perspective and support the dissemination of early assisted discharge.

In chapter 8 the impact of early assisted discharge on health care providers' roles and their satisfaction is presented. Pulmonologists, residents, hospital respiratory nurses, generic and specialised community nurses, involved in the early discharge scheme, were surveyed on this topic. Half of the respondents was satisfied with their role in the hospital-at-home, but for community nurses their role was different in comparison to their usual role. Generic community nurses feel they have sufficient knowledge and skills to supervise patients at home, but specialised community nurses feel generic community nurses have not sufficient skills and knowledge. Nonetheless, early discharge with supervision by generic community nurses is feasible and health care professionals involved are satisfied. Attention should be paid to coordination and continuity of care.

The main conclusion and recommendations, as described in chapter 9, are that community-based hospital-at-home for selected patients with a COPD exacerbation should be implemented and that this is justified, because a) there are no different outcomes in comparison to usual hospital care; b) home treatment is preferred by a substantial part of the patient and informal caregivers; c) patients and informal caregivers are satisfied with hospital-at-home; d) hospital-at-home has no negative effect on informal caregivers' strain; and e) it is feasible from the perspective of professional health care professionals. Chapter 9 also describes the implications of these findings for practice and several aspects that need to be considered prior to implementation. 


\section{Samenvatting}

Chronic Obstructive Pulmonary Disease (COPD) is een chronische longziekte, die gekenmerkt wordt door exacerbaties. Deze komen het vaakst voor bij ernstige vormen van de aandoening. Exacerbaties zijn de meest voorkomende oorzaak van ziekenhuisopnames van COPD patiënten. Ongeveer $20 \%$ van de exacerbaties leidt tot een ziekenhuisopname. Het aantal ziekenhuisopnames voor COPD in Nederland in 2007 was 11.6 per 10,000 inwoners, de gemiddelde duur van een ziekenhuisopname was 11 dagen. Ziekenhuisopnames hebben niet alleen een grote invloed op patiënten, zij brengen ook hoge gezondheidszorgkosten met zich mee. Hospital-at-home (ziekenhuiszorg in de thuissituatie) voor COPD exacerbaties is een bewezen alternatief voor reguliere ziekenhuiszorg. Doel van hospital-at-home is om de opnameduur in het ziekenhuis te verkorten en de druk op de beschikbare ziekenhuisbedden te verminderen, zonder negatieve uitkomsten voor de patiënt. In de studies in dit proefschrift, is de effectiviteit en de kosteneffectiviteit van hospital-at-home, in vergelijking met reguliere ziekenhuiszorg, onderzocht. Daarnaast is de tevredenheid en voorkeuren van patiënten en mantelzorgers onderzocht, samen met de impact die hospital-at-home heeft op mantelzorgers. Tenslotte is ook bekeken wat de invloed van hospital-at-home op professionele zorgverleners is.

In $44 \%$ van de Britse ziekenhuizen is een hospital-at-home service beschikbaar. In Nederland is hospital-at-home voor COPD exacerbaties nog niet beschikbaar. In hoofdstuk 2 is onderzocht hoe dit verschil in ontwikkeling tussen Engeland en Nederland kan worden verklaard. We vonden 3 mogelijke verklaringen. Ten eerste is er een verschil in noodzaak om alternatieven voor reguliere ziekenhuiszorg te ontwikkelen tussen Engeland en Nederland. Het aantal opnames voor COPD is elk jaar groter in Engeland dan in Nederland, terwijl het aantal beschikbare ziekenhuisbedden kleiner is. Ten tweede is de aanwezigheid van 1 financieringsstroom in Engeland, en de centrale rol van de zogenaamde primary care trusts in Engeland gunstig voor de ontwikkeling van hospital-at-home. De aanwezigheid van verschillende financieringsstromen voor verschillende vormen van zorg in Nederland is een barrière voor de integratie van zorg, wat noodzakelijk is voor hospital-at-home. Derde verklaring is het verschil in substitutie van taken naar verpleegkundigen. In hospital-at-home wordt de patiënt thuis gemonitord door (gespecialiseerde) verpleegkundigen. In het algemeen is de substitutie van taken naar verpleegkundigen in Engeland eerder gestart, en vindt op grotere schaal plaats. In Engeland is de stimulans om taken te substitueren ook sterker gezien het kleinere aantal artsen in ziekenhuizen.

Hoofdstuk 3 beschrijft de rationale en studie opzet van de GO AHEAD studie. Alle patiënten die in één van de 5 deelnemende ziekenhuizen werden opgenomen met een 
exacerbatie van hun COPD zijn gescreend op geschiktheid voor begeleid vervroegd ontslag. De patiënten die deel wilden nemen aan het onderzoek en tevens op de derde dag van de opname voldeden aan de criteria van klinische stabiliteit, werden gerandomiseerd in de reguliere ziekenhuisgroep of de begeleid vervroegd ontslaggroep. Patiënten in de begeleid vervroegd ontslag groep gingen op de vierde dag met vervroegd ontslag en vervolgden de behandeling thuis. Thuis werden deze patiënten bezocht door een verpleegkundige van de lokale thuiszorgorganisatie. De bezoeken vonden plaats op de dag van ontslag en de 3 dagen die volgden. Daarna werden ze ontslagen uit de thuisbehandeling. Patiënten die toegewezen werden aan de reguliere ziekenhuisgroep, continueerden de behandeling in het ziekenhuis en gingen op de zevende dag met ontslag. Alle patiënten werden tot 90 dagen na opname gevolgd. Effectiviteit van begeleid vervroegd ontslag in vergelijking met reguliere ziekenhuiszorg wordt gemeten door middel van verschil in scores van de Clinical COPD Questionnaire. Alle data voor de uitkomstmaten worden verzameld bij opname (T-2 dagen), bij randomisatie (TO), aan het einde van de behandeling ( $T+4$ dagen) en aan het einde van de follow up periode ( $T+90$ dagen).

In hoofdstuk 4 zijn de effecten van begeleid vervroegd ontslag op de CCQ scores, gefaalde behandelingen, aantal heropnames, mortaliteit en generieke kwaliteit van leven beschreven. In totaal zijn er 139 patiënten gerandomiseerd, 70 in de begeleid vervroegd ontslag groep en 69 in de reguliere ziekenhuisgroep. Er was geen verschil in CCQ scores op de korte en lange termijn. Er was ook geen verschil in gefaalde behandelingen, heropnames en mortaliteit. Er was wel een significant verschil in generieke kwaliteit van leven aan het einde van de behandeling ( $T+4$ dagen). Echter, dit verschil was verdwenen aan het einde van de 3 maanden follow up.

In hoofdstuk 5 wordt de kosteneffectiviteit van begeleid vervroegd ontslag getoond. Vanuit gezondheidszorgperspectief gezien is begeleid vervroegd ontslag goedkoper, hoewel het verschil aan het einde van de 3 maanden follow up niet meer significant is. Vanuit maatschappelijk perspectief gezien, (wanneer directe niet-gezondheid gerelateerde kosten en kosten van productiviteitsverlies van patiënt en mantelzorger worden ook werden meegenomen), is begeleid vervroegd ontslag kostenbesparend aan het einde van de behandeling. Aan het einde van de follow up was dit niet zo. Zowel het korte termijn als het lange termijn verschil zijn vanuit maatschappelijk perspectief niet significant.

Hoofdstuk 6 beschrijft de evaluatie van begeleid vervroegd ontslag vanuit patiënt perspectief. De algehele tevredenheid met de ontvangen behandeling was vergelijkbaar in beide groepen. Aan het einde van de behandeling ( $T+4$ dagen) waren patiënten in de begeleid vervroegd ontslag groep minder tevreden met de zorg 's 
nachts en voelden zich minder in staat om de normale dagelijkse activiteiten te hervatten. Tachtig procent van de patiënten die met vervroegd ontslag zijn gegaan en $42 \%$ van de patiënten die reguliere ziekenhuiszorg hebben ontvangen gaven aan een voorkeur te hebben voor thuisbehandeling. De voorkeur voor plaats van behandeling van patiënten is geassocieerd met de mentale toestand van de patiënt. Patiënten met slechtere scores voor de mentale toestand hebben minder snel een voorkeur voor thuisbehandeling. De tevredenheid en voorkeuren van patiënten rechtvaardigen een verdere implementatie van hospital-at-home voor COPD exacerbaties. Deze behandeloptie zou moeten worden aangeboden aan geselecteerde patiënten die de voorkeur geven aan thuisbehandeling.

In hoofdstuk 7 stond de evaluatie van begeleid vervroegd ontslag vanuit mantelzorger perspectief centraal. Hospital-at-home had geen negatief effect op de belasting van de mantelzorger. Eenenzeventig procent van de mantelzorgers van patiënten die begeleid vervroegd ontslag hebben ervaren, had een voorkeur voor thuisbehandeling. Bij de mantelzorgers van patiënten die reguliere ziekenhuisbehandeling hadden ondergaan was dit 33\%. Mantelzorgers waren tevreden met de thuisbehandeling. Resultaten van de evaluatie vanuit mantelzorgperspectief vullen die van de patiëntevaluatie aan en ondersteunen de verdere implementatie van begeleid vervroegd ontslag.

In hoofdstuk 8 zijn de effecten van begeleid vervroegd ontslag voor professionele zorgverleners beschreven, samen met hun tevredenheid. Longartsen, assistenten in opleiding tot longarts, longverpleegkundigen in het ziekenhuis en generieke en gespecialiseerde thuiszorgverpleegkundigen die betrokken waren bij hospital-at-home zijn bevraagd over deze onderwerpen. De helft van de respondenten was tevreden met de rol die zij hadden in hospital-at-home, maar voor de thuiszorgverpleegkundigen is deze rol anders dan hun normale rol. Generieke thuiszorgverpleegkundigen waren van mening dat zij over voldoende kennis en vaardigheden beschikken om patiënten thuis te monitoren. Echter, de gespecialiseerde thuiszorgverpleegkundigen vonden dat generieke verpleegkundigen hiervoor over onvoldoende kennis en vaardigheden beschikken. Desalniettemin is begeleid vervroegd ontslag met monitoring door generieke thuiszorgverpleegkundigen haalbaar en zijn de betrokken professionele zorgverleners tevreden. Aandacht moet worden besteed aan de coördinatie en continuïteit van zorg.

De algehele conclusie en aanbeveling, zoals beschreven in hoofdstuk 9, is dat hospitalat-home voor geselecteerde patiënten met een COPD exacerbatie geïmplementeerd zou moeten worden en dat dit gerechtvaardigd is omdat a) er geen verschil in uitkomsten is ten opzichte van reguliere ziekenhuiszorg; b) aan thuisbehandeling door een substantieel deel van de patiënten de voorkeur wordt gegeven; c) patiënten en 
168 | Chapter 10

mantelzorgers tevreden zijn met hospital-at-home; d) hospital-at-home geen negatieve invloed heeft op de belasting van mantelzorgers; en e) omdat het vanuit het perspectief van de professionele zorgverlening mogelijk is om patiënten vervroegd te ontslaan. In hoofdstuk 9 worden ook de implicaties van de gevonden resultaten voor de praktijk beschreven en welke aspecten in beschouwing moeten worden genomen vóór implementatie. 


\section{Co-authors and affiliations}

M (Maria) W Braken

Department of Staff Nurses Nursing and Care, Zuidzorg, Veldhoven, the Netherlands

P (Peter) J de Bruijn, MD

Department of Respiratory Medicine, Rijnstate Hospital, Arnhem, the Netherlands

D (Dirk) RAJ DeMunck, MD

Department of Respiratory Medicine, Máxima Medical Centre, Veldhoven, the Netherlands

\section{L (Loes) MGA van Eijsden}

Department of Health Policy, Meander Group Zuid-Limburg, Heerlen, the Netherlands

R (Riet) Eijsermans

Department of Transmural Care, Thebe, Tilburg, the Netherlands

L (Lucas) MA Goossens

Institute for Medical Technology Assessment, Erasmus University, Rotterdam, the Netherlands

\section{A (Annet) Janssen}

Department of Respiratory Medicine, Catharina Hospital, Eindhoven, the Netherlands

P (Petra) de Laat-Bierings

Department of Respiratory Medicine, TweeSteden Hospital, Tilburg, the Netherlands

W (Walter) van Litsenburg

Department of Respiratory Medicine, Catharina Hospital, Eindhoven, the Netherlands

J (Hans) AM Maarse, PhD

Department of Health Organisation Policy and Economics CAPHRI School for Public Health and Primary Care, Maastricht University, Maastricht, the Netherlands

B (Boudewijn) Maessen, MD, PhD

Department of Respiratory Medicine, Orbis Medical Centre, Sittard, the Netherlands 
170 | Chapter 10

B (Brigitte) van der Pas

Department of Respiratory Medicine, Máxima Medical Centre, Veldhoven, the Netherlands

A (Anouschka) van der Pouw

Department of Respiratory Medicine, Rijnstate Hospital, Arnhem, the Netherlands

J (Jeroen) MAM Retera, MD

Department of Respiratory Medicine, TweeSteden Hospital, Tilburg, the Netherlands

M (Maureen) PMH Rutten-van Mölken, PhD

Institute for Medical Technology Assessment, Erasmus University, Rotterdam, the Netherlands

C (Onno) P van Schayck, PhD

Department of General Practice, CAPHRI School for Public Health and Primary Care, Maastricht University, Maastricht, the Netherlands

W (Wiel) Seezink

Department of Respiratory Medicine, Atrium Medical Centre, Heerlen, the Netherlands

F (Frank) WJM Smeenk, MD, PhD

Department of Respiratory Medicine, Catharina Hospital, Eindhoven, the Netherlands

$\mathrm{M}$ (Monique) van Vliet, MD

Department of Respiratory Medicine, Atrium Medical Centre, Heerlen, the Netherlands 


\section{Dankwoord}

Datgene wat maar steeds ver weg leek is dan toch echt gebeurd: het proefschrift en mijn promotie zijn volbracht. Een periode van 5 jaar met ups en downs, maar met een resultaat waar ik ontzettend trots op ben. Nu het einde er is, is de tijd gekomen om een woord te richten aan die mensen die belangrijk zijn geweest voor het project en/of voor mij persoonlijk.

Allereerst al die patiënten die af wilden stappen van de 'normale' manier van behandelen en deel hebben genomen aan het GO AHEAD onderzoek. Zonder hen zouden er geen data zijn en zou ik geen proefschrift over hospital-at-home hebben kunnen schrijven.

Mijn onderzoekswerk heb ik uitgevoerd in het Catharina Ziekenhuis Eindhoven. Toen ik daar in 2007, als verpleegkundige van 13-west, aan longarts Frank Smeenk vertelde dat ik mijn Masters studie had afgerond en vroeg "of er niets met onderzoek mogelijk was bij de longziekten" was het antwoord: "Gefeliciteerd" en "misschien wel ja". Niet veel later was ik promovendus bij de longziekten en rolde ik het GO AHEAD project binnen. Ik wil de maatschap longziekten van het Catharina Ziekenhuis Eindhoven danken voor de mogelijkheid dit promotieonderzoek bij hen te doen.

Diezelfde longarts dr. F.W.J.M. Smeenk werd mijn dagelijks begeleider. Frank, jij bent de goedheid zelve. Promovendi begeleiden is niet je hoofdtaak, maar altijd was jij de eerste die reageerde op mijn mails met vragen en stukken waardoor ik altijd snel verder kon. Het voor mijn memorabele gebaar van het memoblaadje met je thuisnummers zorgde ervoor dat ik op een gegeven moment meer met je ben gaan bespreken. Gek genoeg kwam dat niet alleen mijn persoonlijke ontwikkeling ten goede, ook de wetenschappelijke. Het heeft namelijk leuke discussies opgeleverd waarin ik je wilde overtuigen van mijn standpunt (getuige hoofdstuk 2 is dat soms aardig gelukt). Tenslotte was jouw praktische invalshoek de waardevolle brug tussen de dagelijkse praktijk waar we mee te maken hadden en 'wetenschappelijk onderzoek doen'. Mijn promotor is prof. dr. C.P. van Schayck van de Universiteit Maastricht. Onno, ook al zagen we elkaar niet veel, door je snelle reacties via mail en goede telefonische bereikbaarheid was de samenwerking heel goed. Ik heb van je geleerd hoe om te gaan met al die verschillende bestaande belangen in personen en organisaties. Dank daarvoor! Mijn andere promotor was prof. dr. M.P.M.H. Rutten-van Mölken. Maureen, jij bent echt ontzettend goed in onderzoek doen. Een correctieronde door jou maakte artikelen altijd nog beter. Op het gebied van onderzoeksmethodologie, analyses en vooral rapportage heb ik ontzettend veel van je geleerd! Tenslotte Lucas, mede promovendus. Wij zijn twee onderzoekers met 
verschillende achtergronden, verschillende persoonlijkheden en verschillende focus van onderzoek. Samen hebben we onze krachten ingezet om uit GO AHEAD te halen wat erin. Met succes vind ik. Je enorme kennis en ervaring van statistische analyses en powerberekeningen waren voor mij onmisbaar om, als ik de weg kwijt was op dat gebied, weer on track te komen. Zeker toen het project vorderde heb ik heel fijn met je samengewerkt en het contact gewaardeerd, dank daarvoor. Ik wens je ook heel veel succes met je eigen promotie straks!

Diverse mensen hebben ervoor gezorgd dat dit onderzoek kon draaien in de verschillende ziekenhuizen en thuiszorgorganisaties. Het is onmogelijk iedereen apart te noemen, maar ik heb in de diverse organisaties contactpersonen gehad die ik persoonlijk wil noemen en bedanken. In het Atrium Medisch Centrum: Monique van Vliet, longarts en Wiel Seezink, longverpleegkundige. Na een bezoek in Heerlen ging ik er vaak met frisse moed weer tegenaan om die patiënten bij elkaar te sprokkelen. Jullie enthousiasme was aanstekelijk en hartelijk dank daarvoor. In het Maxima Medisch Centrum: Brigitte van de Pas. Ondanks het moeizame verloop van het onderzoek in jullie ziekenhuis bleef je je met je collega longverpleegkundigen inzetten om het tot een goed einde te brengen. Loes van Eijsden en Maria Braken van de thuiszorgorganisaties in de regio's Heerlen en Eindhoven/Veldhoven. Jullie hebben veel werk verzet om de logistieke operatie van alle thuisbezoeken mogelijk te maken. Jullie hebben dit perfect gedaan. In het Rijnstate ziekenhuis: Anouschka van der Pouw. Je was heel enthousiast om deel te gaan nemen, maar tot je eigen teleurstelling bleef het bij een paar patiënten. Toch was ook jouw enthousiasme een stimulans om door te gaan. Tenslotte de mensen in de regio Tilburg: de patiënten die jullie wierven waren zeer welkom, dank daarvoor.

Aan de Universiteit Maastricht heeft 1 iemand met regelmaat (ik was goed in spullen opsparen) hard gewerkt om alle verzamelde gegevens in te voeren, zodat ik ermee kon gaan werken. Kitty van der Meer, ontzettend bedankt voor al je werk voor het GO AHEAD project. Niet alleen de data invoer heb je perfect gedaan, je hebt er ook voor gezorgd dat de dataverzameling voor de zorgverlener evaluatie (hoofdstuk 8) perfect georganiseerd werd. We waren een heel goed team samen. Als ik naar Maastricht kwam was het altijd fijn om bij te kletsen en ik denk dat we elkaar op verschillende gebieden hebben kunnen ondersteunen. Dank je wel daarvoor!

Op mijn thuisbasis, het Catharina Ziekenhuis heb ik toch bijna 5 jaar gewerkt aan het GO AHEAD project. Oud-collega's van de research longziekten, bedankt dat ik bij jullie een plekje had met welkome afleiding. Lisette, kamergenoot: samen was minder alleen. Veel succes met je eigen promotie! Lidwien, met een lach en een traan (en soms die twee tegelijk) hebben we 2 jaar een kamer en daarmee heel wat 
(promotie)perikelen gedeeld. Je zei het al: promoveren kan echt! Walter en Annet, door jullie werk viel er een zware last van mijn schouders en kon ik me meer focussen op wat onderzoekers (althans ik) het liefst doen: analyseren en schrijven. Jullie weten hoe groot mijn dank daarvoor is.

Sinds enige tijd werk ik bij het KEMTA in het academisch ziekenhuis Maastricht, waar een nieuwe onderzoekswereld is opengegaan, waar ik me helemaal op mijn plek voel en waar ik ook kan onderzoeken wat ik nu verder wil met mijn onderzoekscarrière. Prof. dr. C. Dirksen, Carmen, bedankt dat je me hebt aangenomen en dat je in de beoordelingscommissie wilde plaatsnemen. Ik ben heel erg blij met onze samenwerking. De overige leden van de beoordelingscommissie, prof. dr. G. Wesseling en prof. dr. T. van der Molen wil ik ook hartelijk danken voor het plaatsnemen in de commissie.

Dan lieve vrienden: mede dankzij jullie is mijn leven in goede en slechte tijden naast werk ook gevuld met vriendschap, heel veel plezier, muziek, theeleuten, etentjes, feestjes, yoga, TP-avondjes, weekendjesweg, lachen en huilen en nog veel meer. Dank jullie wel allemaal, het betekent heel veel voor me. Jullie hebben me vaak (terecht) voor gek verklaard als ik na een feestje, bruiloft of gewoon het weekend, naar het ziekenhuis ging, maar gelukkig, het gaat in elk geval al een hele tijd niet meer over hoeveel patiënten er nog te gaan zijn en heb ik vooral leuke verhalen! Marieke, heel erg bedankt voor het ontwerpen van de omslag van mijn proefschrift. Ik word er nog elke keer blij van als ik er naar kijk.

Isabelle, samen hebben we verpleegkunde gestudeerd en de master gezondheidswetenschappen behaald. $\mathrm{Nu}$ is er nog steeds een fijne vriendschap. Ik ben blij dat je dit stukje Maastricht als paranimf met mij wilt afsluiten.

Carlijn, al meer dan 25 jaar kennen wij elkaar en of we nu $10.000 \mathrm{~km}$ of $10 \mathrm{~km}$ bij elkaar vandaan wonen: jij bent er altijd. Ik ben heel blij dat je alweer een tijd gewoon in Nederland woont en mijn paranimf wilt zijn.

Naast vrienden heb ik ook nog een lieve familie.

In-laws, Roland en Marianne, Lia en Toon, Jan. Het is fijn als je goed kunt opschieten met je schoonfamilie! Dank voor jullie interesse de afgelopen jaren.

Lieve opa en oma. Voor jullie was het misschien een beetje een raadsel wat ik nu deed al die jaren, maar 'school' is nu eindelijk klaar. Ik vind het fantastisch dat jullie bij de afsluitende verdediging zijn! 
Lieve zusjes, Dianne en Veronique met aanhang. Heel verschillend, maar ook zo het hetzelfde. Jullie zijn mijn roots en bij jullie ben ik gewoon Cecile, jullie zus. De zuster die nu doctor is geworden.

Pap en Mam. Zonder jullie zou ik niet zijn wie ik nu ben en waar ik nu sta. Jullie opvoeding, alle mogelijkheden die jullie mij geboden hebben en vooral de onvoorwaardelijke liefde en steun, hebben me mede gebracht tot waar ik nu sta. Ik hou van jullie.

Last but not least, mijn lief Mark. Je hebt je vast afgevraagd wat ik hier voor jou zou schrijven. Door de jaren heen heb je veel regels verdiend, maar alle woorden doen gewoon tekort aan wat jij voor mij betekend hebt de afgelopen jaren en nog steeds elke dag doet. Bij en door jou ben ik geworden wie ik ben en kan ik helemaal mezelf zijn. Wat wij samen hebben is uniek en ik wil het echt nooit meer missen.

Dank je wel, jij weet waarvoor.

\section{Cecile}




\section{About the Author}

Cecile Utens was born on February the 13th, 1982 in Geleen, the Netherlands. After finishing her secondary education in 2000 at SG Sint Ursula in Horn she started studying Nursing at Fontys Hogescholen Eindhoven. After graduating in 2004, she started working as a registered nurse at the respiratory ward of the Catharina Hospital Eindhoven. As a nurse, she experienced limited opportunities to work on a scientific level which encouraged her to start her Master Public Health at Maastricht University. She obtained her Master's degree in 2006. During her internship, which was a study on the influence of socioeconomic status and severity of the disease on experienced physical functioning of COPD patients, she got caught by the research virus. From March 2007 until December 2011, she worked as a PhD student at the department of respiratory medicine of the Catharina Hospital Eindhoven and performed the GO AHEAD study, which is the foundation of the work described in this thesis. She performed her work under the supervision of dr. FWJM Smeenk (Catharina Hospital Eindhoven), prof. dr. MPMH Rutten-van Mölken (institute for Medical Technology Assessment, Erasmus University Rotterdam) and prof. dr. CP van Schayck (CAPHRI, Maastricht University). After working 8 years in the Catharina Hospital and the field of respiratory diseases she continued her career in the Maastricht University Medical Centre as a postdoctoral researcher at the KEMTA, performing a study on the integration of evidence on patient preferences in health care policy decisions. 